
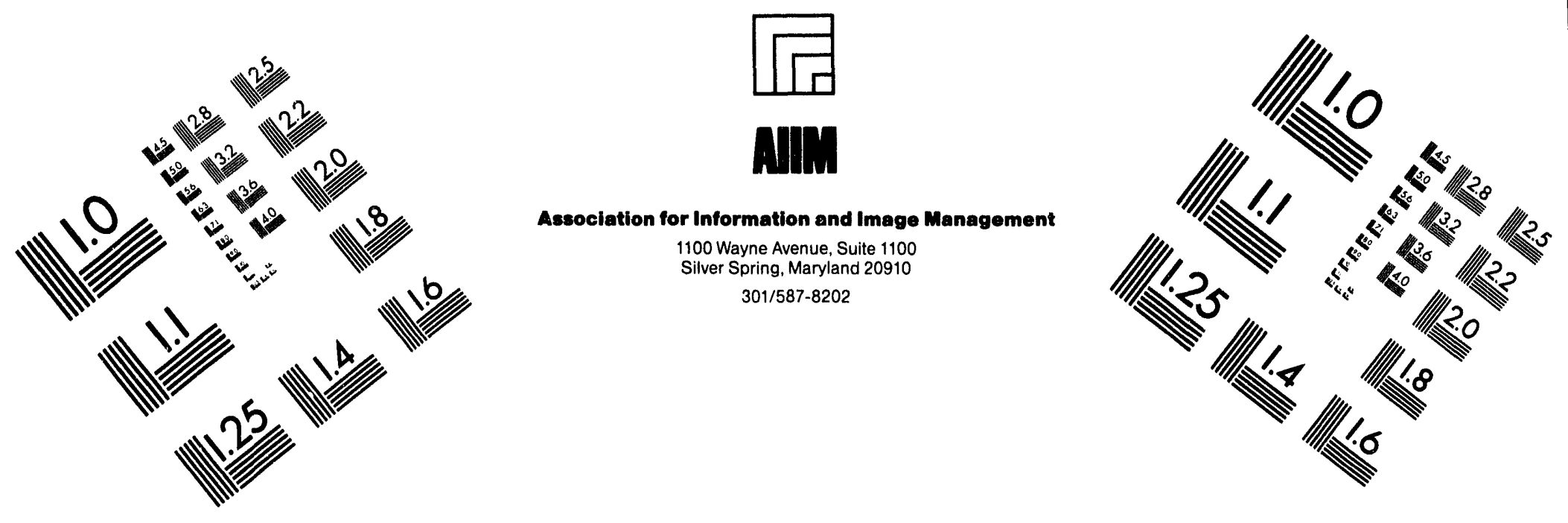

\title{
Centimeter
}

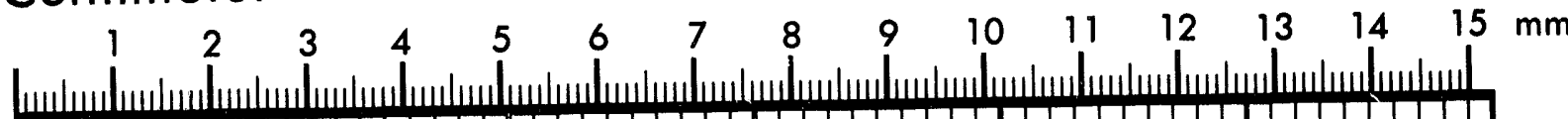

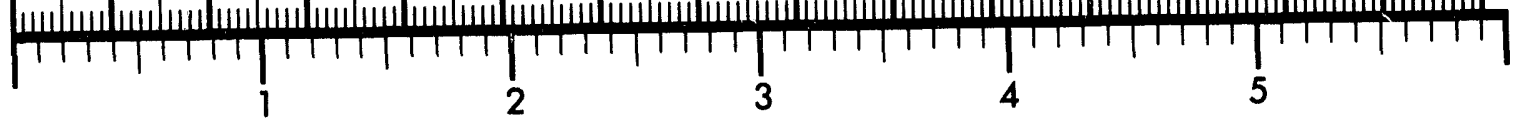
Inches
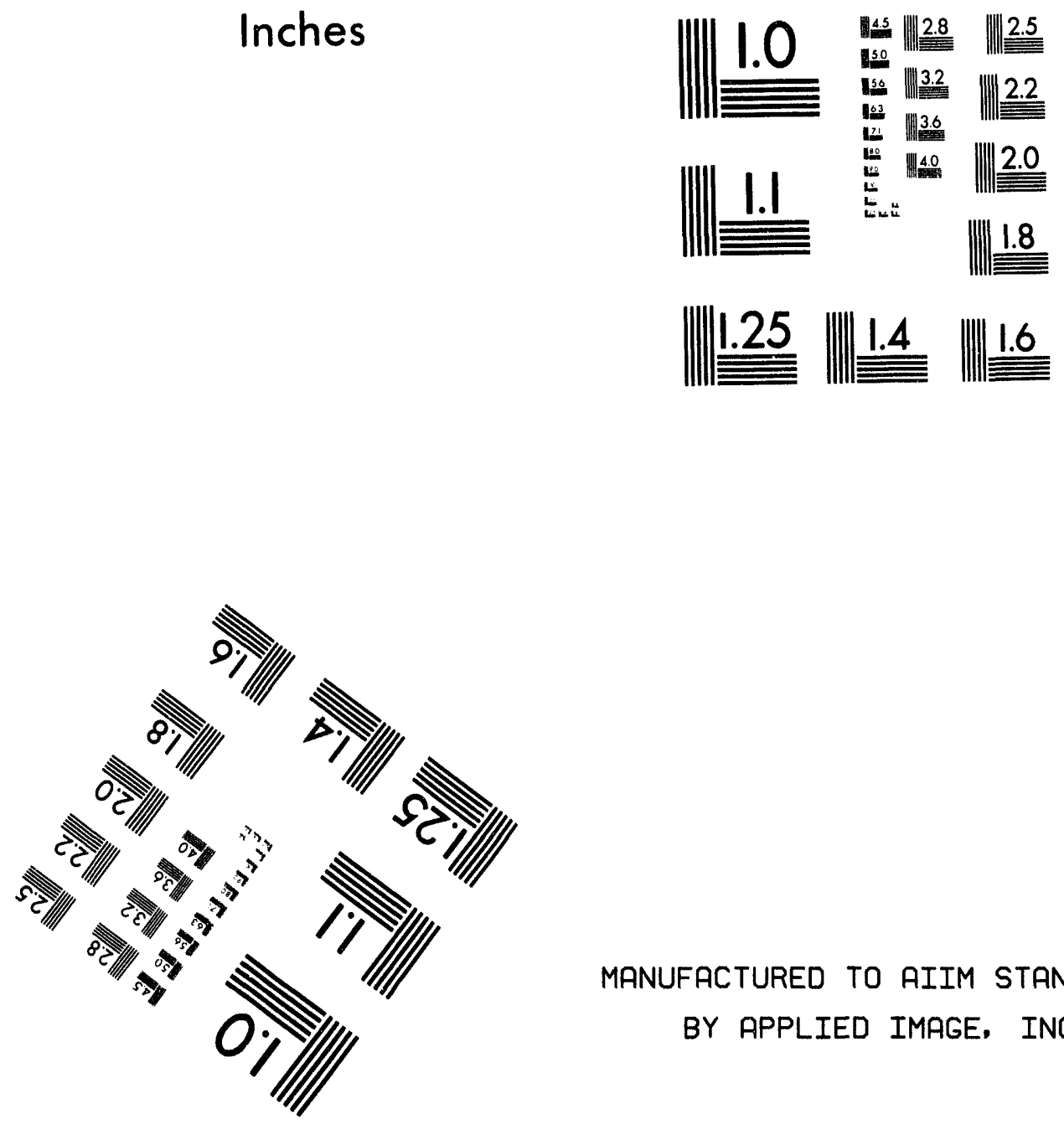

MANUFACTURED TO AIIM STANDARDS BY APPLIED IMAGE, INC.

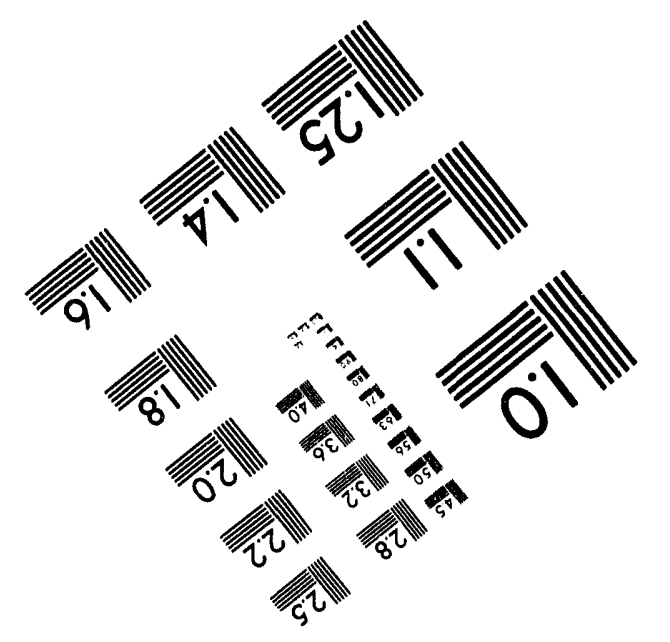



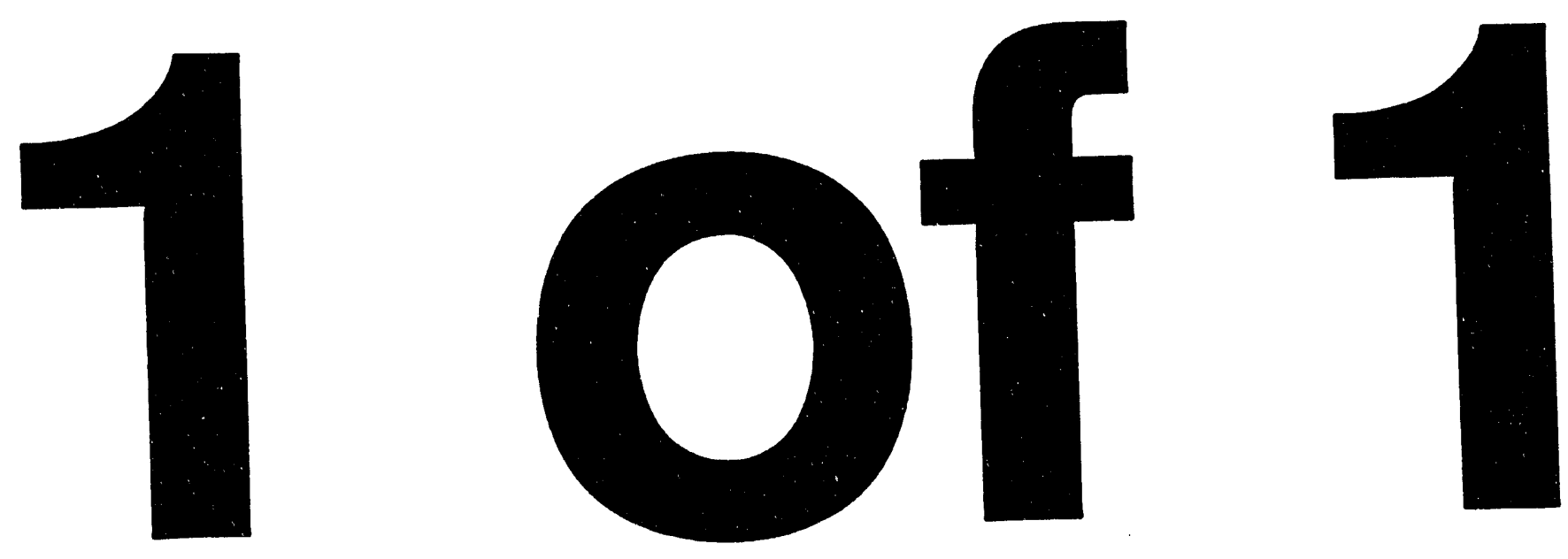


\section{YEAR-END REPORT FOR UST: CESIUM EXTRACTION TESTING PROJECT DOE/DT\&E TTP NO. SR1-03-20-01 (U)}

by

J. P. Bibler

Westinghouse Savannah River Company

Savannah River Site

Aiken, South Carolina 29808

N. E. Bibler

C. L. Crawtord

This paper was prepared in connection with work done under the above contract number with the U.S.

Department of Energy. By acceptance of this paper, the publisher and/or recipient acknowledges the U. S.

Government's right to retain a nonexclusive, royalty-free license in and to any copyright covering this paper, along with the right to reproduce and to authorize others to reproduce all or part of the copyrighted paper. 
WSRC-RP-94-146

\title{
Year-End Report for UST:Cesium Extraction Testing Project DOE/DT\&E TTP No. SR1-03-20-01 (U)
}

\author{
February 1, 1994
}

Revision 0

Jane P. Bibler

INCLUDING

WSRC-RP-94-148

\section{An Investigation of the Radiolytic Stability of a Resorcinol-Formaldehyde Ion Exchange Resin}

January 31, 1994

Revision 0

Ned E. Bibler

Charles L. Crawford

Westinghouse Savannah River Company

Savannah River Technology Center

Aiken, South Carolina 29808

Prepared for the U.S. Department of Energy under Contract No. DEAC09-8\$SR18035 


\section{DISCLAIMER}

This report was prepared as an account of work sponsored by an agency of the United States Government. Neither the United States Government nor any agency thereof, nor any of their employees, makes any warranty, express or implied, or assumes any legal liability or responsibility for the accuracy, completeness, or usefulness of any information, apparatus, product, or process disclosed, or represents that its use would not infringe privately owned rights. Reference herein to any specific commercial product, process, or service by trade name, trademark, manufacturer, or otherwise does not necessarily constitute or imply its endorsement, recommendation, or favoring by the United States Government or any agency thereof. The views and opinions of authors expressed herein do not necessarily state or reflect those of the United States Government or any agency thereof.

This report has been reproduced directly from the best available copy.

Available to DOE and DOE contractors from the Office of Scientific and Technical Information, $P$. O. Box 62, Oak Ridge, TN 37831; prices available from (615) $576-8401$.

Available to the public from the National Technical Information Service, U. S. Department of Commerce, 5285 Port Royal Rd., Springfield, VA 22161 


\section{TABLE OF CONTENTS}

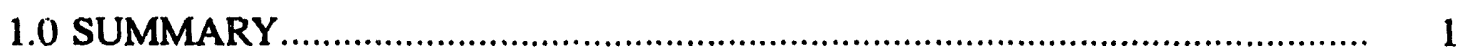

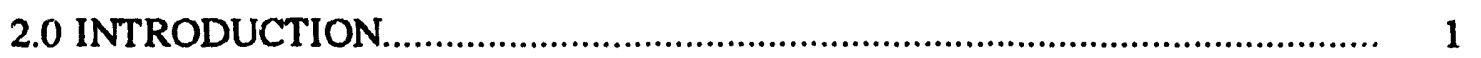

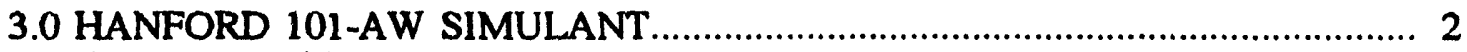

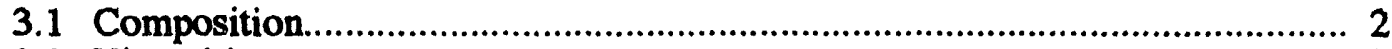

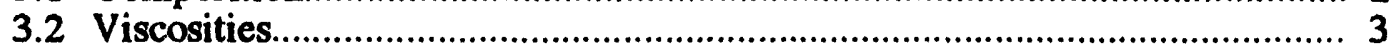

4.0 SMALL COLUMN FLOW STUDIES............................................................ 4

4.1 The Effect of Increasin Flow Rate on Breakthrough.................................... 5

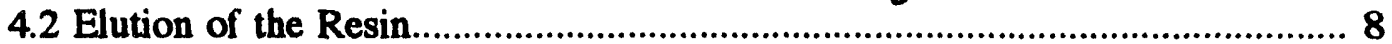

4.2.1 Effect of Increasin Elutriant Acid Concentration.................................. 8

4.2.2 Elution of Ten-Milliliter Columns........................................................... 9

4.2.3 Total Alkali Metal Ion in Eluate......................................................... 12

4.3 Effect of Temperature on Resin Loading and Elution.................................. 15

5.0 RESIN QUALITY STUDIES............................................................ 20

$5.1 \mathrm{Kd}$ Studies on Stored Resin...................................................................... $\quad 20$

5.2 Tests to Determine Possible Cause of Resin
Degradation........................................................................................ 21

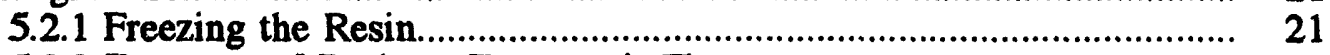

5.2.2 Exposure of Resin to Excess Air Flow............................................. 22

5.2.3 Procurement of New Resin from Boulder
Scientific Co................................................................................ 24

5.2.4 Thermal Analysis of Resorcinol-Formaldehyde
Resin

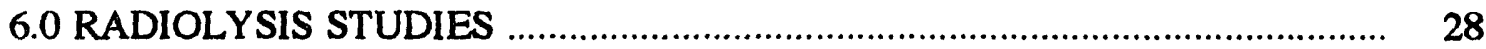

(Report found in Attachment 3, p 31.)

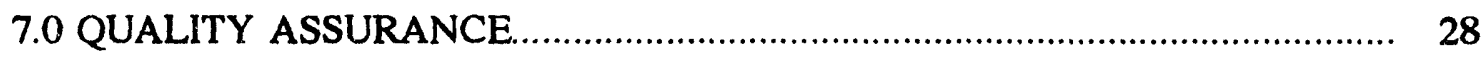

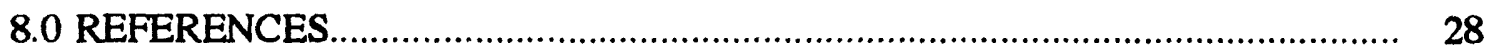

\section{ATTACHMENTS}

1. Procedure IWT-OP-067, "Measuring the Viscosity of Transparent Liquids"...... 29

2. Scope of Work for Resin Degradation Studies at Clark Atlanta University.......... 30

3. WSRC-RP-94-148, "An Investigation of the Radiolytic Stability of a Resorcinol-Formaldehyde Ion Exchange Resin"... 


\section{LIST OF TABLES}

\section{TABLE}

PAGE

Table 1. The Composition of Hanford 101-AW Simulant

Table 2. Densities, Kinematic Viscosities, and Dynamic Viscosities of 101-AW Simulant at Six Temperatures

Table 3. Effluent Cs-137 Concentrations at Four Flow Rates · 6

Table 4. Effluent Cesium Concentration From 10-mL Columns 7

Table 5. Cesium Ion Elution in Three Nitric Acid Concentrations 9

Table 6 Cesium Ion Concentration in Eluate from Ten-Milliliter Columns 11

Table 7. Alkali Metal Ion Concentrations in Eluate Fractions 14

Table 8. Total Alkali Metal Ion Concentration in Elution From the Second $10 \mathrm{~mL}$ Column

Table 9. Breakthrough Data at Elevated Temperatures

Table 10. Alkali Metal Ion Elution from 5-mL Columns at Elevated Temperatures

Table 11. Acceptance Tests on Boulder Scientific Co. Resin 


\section{LIST OF FIGURES}

$\begin{array}{ll}\text { FIGURE } & \text { PAGE }\end{array}$

Figure 1. The Effect of Increasing Temperature on Dynamic Viscosity 3

Figure 2. The Effect of Increasing Temperature on Kinematic Viscosity 4

Figure 3 Breakthrough Curves From Four Flow Rates at $25^{\circ} \mathrm{C}$. 5

$\begin{array}{lr}\text { Figure 4. Breakthrough Curves for Two Ten-Milliliter Column Runs } & 8\end{array}$

Figure 5. Elution of 2-mL Columns with Three Nitric Acid Concentrations $\quad 10$

Figure 6. Cesium Elution from Two Ten-Milliliter Columns 11

Figure 7. Elution Profile for Cs-137 From Two Runs on the Same TwoMilliliter Column

Figure 8. Elution Profile for $\mathrm{Na}^{+}$From Two Runs on the Same TwoMilliliter Column

Figure 9. Elution Profile for $\mathrm{K}^{+}$From Two Runs on the Same TwoMilliliter Column

Figure 10. Breakthrough Curves for a Five-Milliliter Column at Three Temperatures Greater Than $25^{\circ} \mathrm{C}$

Figure 11. Cs-137 Elution Curves at Three Elevated Temperatures 19

Figure 12. $\mathrm{Na}^{+}$Elution Curves at Three Elevated Temperatures $\quad 19$

Figure 13. $\mathrm{K}^{+}$Elution Curves at Three Elevated Temperatures 20

Figure 14. Loss in Cs Kd with Time in Drum 21

Flgure 15. Effect of Freezing on Kd 22

Figure 16. Cs Kd's Before and After One-Week Air Flush 23

Figure 17. TGA Calibration Curve for Calcium Oxalate 25

Figure 18. TGA for K-form of Resorcinol-Formaldehyde Resin 26

Figure 19. TGA for H-form of Resorcinol-Formaldehyde Resin 26

Figure 20. DSC Calibration Curve for Indium Metal 27

Figure 21. DSC for K-form of Resorcinol-Formaldehyde Resin 27

Figure 22. DSC for H-form of Resorcinol-Formaldehyde Resin 28 
SAVANNAH RIVER TECHNOLOGY CENTER

WESTINGHOUSE SAVANNAH RIVER COMPANY
WSRC-RP-94-146

KEY WORDS: ion

exchange, high-level waste, cesium decontamination

February 1, 1994

TO: S.D. FINK, 773-A

FROM: J.P. BIBLER, 773-A

YEAR-END REPORT ON WORK PERFORMED FOR TECHNICAL TASK

PLAN \# SR1-03-20-01, Cs EXTRACTION STUDIES (U)

\subsection{SUMMARY}

This document contains results of a variety of studies on the SRS (Savannah River Site) resorcinol-formaldehyde ion exchange resin with a simulant of the high-level liquid waste found in the Hanford 101-AW tank. Small column studies indicate that flow rates of 2.5 column volumes or less per hour give well-defined breakthrough curves. More rapid flow rates of three to twenty column volumes per hour produce leakage of cesium ion before $50 \%$ breakthrough has been reached after processing about 100 column volumes of feed. Upflow elution of the small columns with three concentrations of nitric acid $(0.1,0.3$, and 0.5 molar) show that about $85 \%$ of the cesium, sodium, and potassium ions on the resin can be removed simultaneously with $0.5 \mathrm{M} \mathrm{HNO} 3$, the most efficient of the three. Radiolysis studies at doses as high as $1 \mathrm{E}+09$ rads have shown that the resin is more stable to radiation in water than in the 101-AW simulant. Radiation doses up to 1 E+08 rads did not alter the performance of the resin for cesium removal. Exposure to radiation or storage did not affect the thermal stability of the resin. Gas production rates for several resin slurries in the order of resin with 101-AW, resin with ASTM (American Society of Testing Materials) water, and resin with $0.5 \mathrm{M} \mathrm{HNO}_{3}$. Hydrogen gas is produced from radiolysis of resin in 101-AW simulant with a $G$ value of $\mathrm{G}\left(\mathrm{H}_{2}\right)$ of $0.11 \pm 0.02$ molecules $/ 100 \mathrm{eV}$ and in $0.5 \mathrm{M} \mathrm{HNO} 3$ with a $\mathrm{G}$ value of $\mathrm{G}\left(\mathrm{H}_{2}\right)$ of $0.27 \pm 0.02$ molecules $/ 100 \mathrm{eV}$. Other gases that were measured were $\mathrm{N}_{2}, \mathrm{O}_{2}, \mathrm{CO}_{2}, \mathrm{~N}_{2} \mathrm{O}, \mathrm{CO}$, and $\mathrm{CH}_{4}$. Densities and kinetic and dynamic viscosities were determined for the 101-AW simulant at six temperatures ranging between $25^{\circ} \mathrm{C}$ and $80^{\circ} \mathrm{C}$. The behavior of small columns of the resin at $25^{\circ} \mathrm{C}, 40^{\circ} \mathrm{C}, 50^{\circ} \mathrm{C}$, and $67^{\circ} \mathrm{C}$ was studied. Preliminary results indicated that the performance of the resin was only slightly diminished with increase in temperature although elution efficiency appeared to be enhanced. Data is presented to show that samples of resin purchased five years ago had degraded with time relative to its ability to remove cesium ion from simulated supernate. Analyses of new resin samples, supplied in bulk by a vendor, indicate a product of very uniform particle size and good Cs-selectivity in a simulant of Savannah River supernate.

\subsection{INTRODUCTION}

The initial pury ise of this study was to test the SRS resorcinol-formaldehyde resin with a simulant of Hanford's 101-AW waste to develop design information for the compact processing units (CPU's) proposed for Hanford pretreatment processing. To that end, 
S.D. FINK

February 1, 1994
WSRC-RP-94-146

Revision 0

Page 2 of 31

flow rate and elution studies on small columns were undertaken. Radiolysis studies on the resin in the presence of the simulant, ASTM water, and $0.5 \mathrm{M} \mathrm{HNO}$, were performed to investigate the radiolytic stability of the resin and to determine whether gaseous or organic products were produced in the presence of ionizing radiation. As the work progressed, a problem with the quality of resin purchased and stored in drums for five years. The scope of work was expanded to test the available resin for its cesium selectivity and to perform preliminary tests to determine the cause of the apparent degradation of the resin. A new batch of resin was purchased from a commercial vendor and that resin was subjected to chemical and particle size analyses before acceptance. A contract was placed with Clark Atlanta University for formal spectral studies to define the cause of resin degradation on storage and to characterize the structure of the resin.

Because of the diversity of the studies that were ultimately performed, this report will devote a section to each study in order to more clearly report tests and results. All results reported here reflect studies on the newly-purchased resin, except those from some early radiolysis studies.

\subsection{HANFORD 101-AW SIMULANT}

\subsection{Composition}

The composition of the Hanford 101.AW simulant used throughout these studies is shown in Table 1 . The table compares expected composition of the simulant and the composition as determined by chemical analyses.

Table 1. The Composition of Hanford 101-AW Simulant

Molarity

\begin{tabular}{|c|c|c|c|c|}
\hline Chemical & $\mathrm{g} / \mathrm{L}$ & Species Analyzed & Calculated & Analyzed \\
\hline $\begin{array}{l}\mathrm{NaOH} \\
\mathrm{KOH}\end{array}$ & $\begin{array}{l}203 \\
114\end{array}$ & $\begin{array}{l}\mathrm{Na} \\
\mathbf{K}\end{array}$ & $\begin{array}{c}10.1^{*} \\
1.1\end{array}$ & $\begin{array}{l}10.3^{*} \\
0.83\end{array}$ \\
\hline $\begin{array}{l}\mathrm{Al}\left(\mathrm{NO}_{3}\right)_{3} \cdot 9 \mathrm{H}_{2} \mathrm{O} \\
\mathrm{NaNO}_{3}\end{array}$ & $\begin{array}{l}188 \\
204\end{array}$ & $\begin{array}{l}\mathrm{Al} \\
\mathrm{Na}\end{array}$ & $\begin{array}{l}0.50 \\
2.4\end{array}$ & 0.49 \\
\hline $\begin{array}{l}\mathrm{Na}_{2} \mathrm{CO}_{3} \cdot \mathrm{H}_{2} \mathrm{O} \\
\mathrm{NaNO}_{2} \\
\mathrm{Na}_{2} \mathrm{SO}_{4} \\
\mathrm{CsNO}_{3} \\
\text { Free OH }\end{array}$ & $\begin{array}{l}26 \\
152 \\
1.5 \\
2.76 \mathrm{E}-3\end{array}$ & $\begin{array}{l}\mathrm{Na} \\
\mathrm{Na} \\
\mathrm{Na} \\
\mathrm{Cs}\end{array}$ & $\begin{array}{c}0.21 \\
2.2 \\
0.01 \\
1.4 \mathrm{E}-4 \\
9.2\end{array}$ & $\begin{array}{l}1.4 \mathrm{E}-4 \\
5.4\end{array}$ \\
\hline
\end{tabular}

The salts did not entirely dissolve in the preparation of the simulant. The greatest loss to the solution appears to be reflected in the potassium ion concentration. The mixture was filtered before use in these studies. For radioactive studies, trace amounts ( 50 microliters of a $1.43 \mathrm{E}-5 \mathrm{Ci} / \mathrm{mL} \mathrm{CsNO} 3$ solution) of $\mathrm{Cs}-137$ stock solution was added. 
S.D. FINK

February 1, 1994
WSRC-RP-94-146

Revision 0

Page 3 of 31

\subsection{Viscosities}

Since temperature studies using the Hanford 101-AW simulant were planned for small column tests, it was of interest to determine what effect elevated temperatures would have on the feed material. The kinematic and dynamic viscosities were determined following Savannah River Technology Center Procedure IWT-OP-067, found in Attachment 1. Cannon-Fenske routine viscometers were used in controlled temperature water baths. Temperatures were measured using calibrated thermometer WP-560, weighings were made using calibrated balances IW-0004 and IW-003, and calibrated stopwatch WP-822 was used to record flow times. Temperatures used for the tests were $25^{\circ} \mathrm{C}, 40^{\circ} \mathrm{C}, 50^{\circ} \mathrm{C}$, $60^{\circ} \mathrm{C}, 70^{\circ} \mathrm{C}$ and $80^{\circ} \mathrm{C}$. Results of the study are found in Table 2 .

Table 2. Densities, Kinematic Viscosities, and Dynamic Viscosities of 101-AW Simulant at Six Temperatures

$\begin{array}{cccc}\text { Temperature. }{ }^{\circ} \mathrm{C} & \text { Densityeg/mL } & \begin{array}{c}\text { Dynamic Viscosity } \\ \text { centipoise }\end{array} & \begin{array}{c}\text { Kinematic Viscosity } \\ \text { centiStokes }\end{array} \\ 25 & 1.431 & 9.53 & 6.66 \\ 40 & 1.420 & 5.58 & 3.93 \\ 50 & 1.415 & 3.91 & 2.76 \\ 60 & 1.408 & 2.98 & 2.12 \\ 70 & 1.402 & 2.30 & 1.64 \\ 80 & 1.392 & 1.86 & 1.34\end{array}$

The relationships between dynamic and kinematic viscosities and temperature for the simulant are shown in Figures 1 and 2.

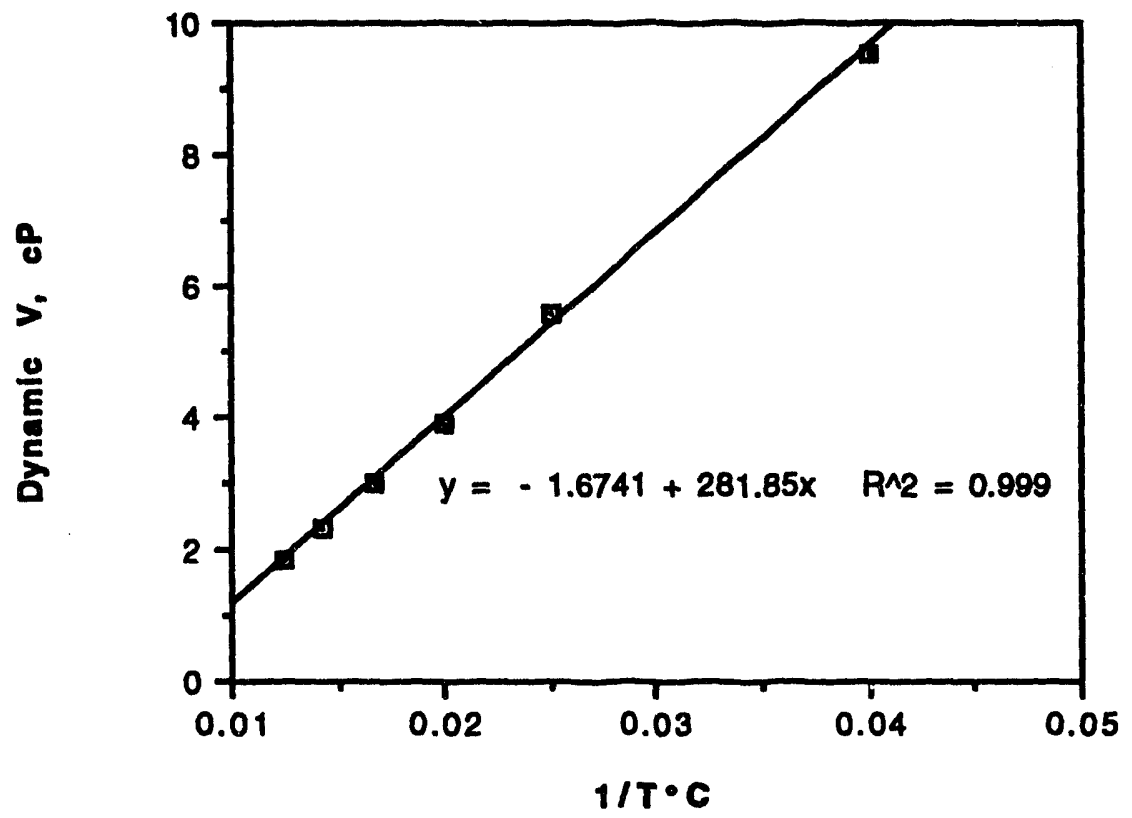

Figure 1. The Effect of Increasing Temperature on Dynamic Viscosity 
S.D. FINK

February 1, 1994

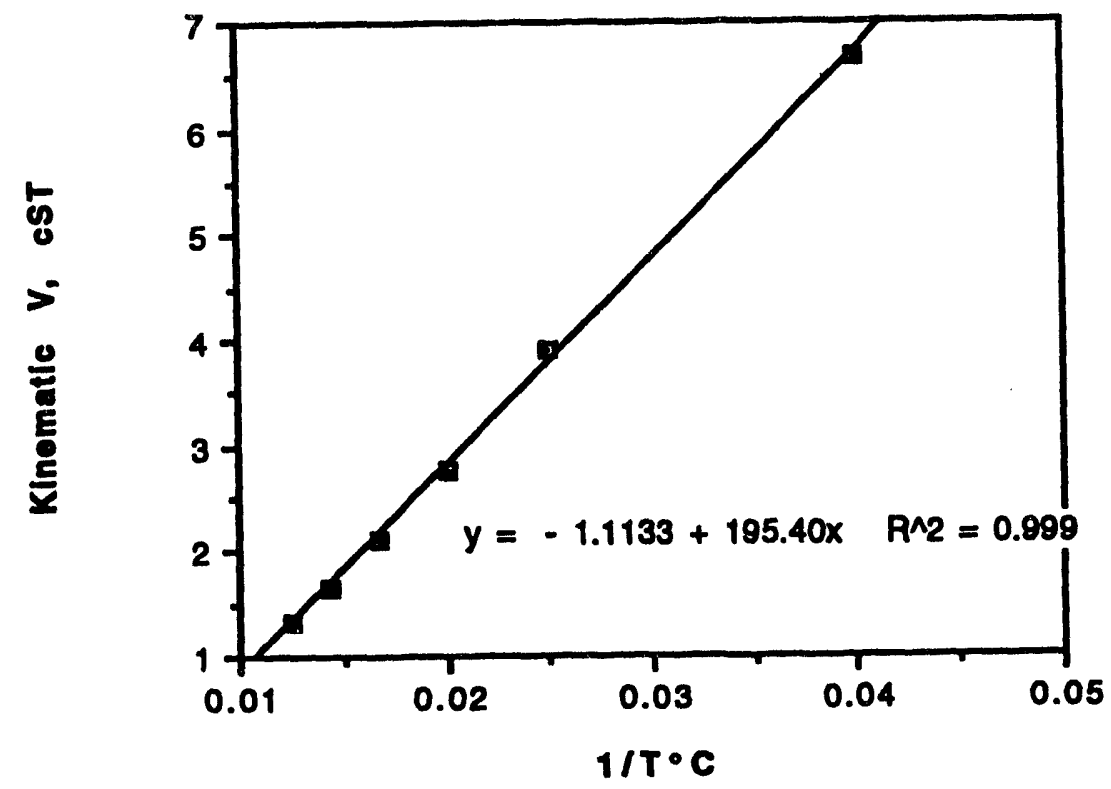

Figure 2. The Effect of Increasing Temperature on Kinematic Viscosity

\subsection{SMALL COLUMN FLOW STUDIES}

Two sizes of small columns, consisting of two and ten milliliter resin beds, were used. Radioactive studies were performed on two milliliter columns to minimize exposure from the dose at the face of the radioactive hood. All columns used resorcinol-formaldehyde resin that had been first washed with $2 \mathrm{M} \mathrm{NaOH}$ and deionized water and then air-dried. This so-called Na-form of the resin was placed in a graduated cylincisr, covered with $6 \mathrm{M}$ $\mathrm{NaOH}$, and allowed to swell. When swelling had ceased, resin was removed until the level of the resin in the cylinder was even with either the $2-\mathrm{mL}$ or the $10 \mathrm{~mL}$ mark. The resin was transferred to a column using a dropper. Both columns had an inner diameter of $9 \mathrm{~mm}$. A 2-mL column had a bed depth of 3 centimeters. The $10 \mathrm{~mL}$ column had a bed depth of approximately 16 centimeters.

The column bed was prepared in $6 \mathrm{M} \mathrm{NaOH}$, which was drained from the column until the liquid level was even with the resin level at the top of the bed. Feed was introduced in downflow mode until the desired number of column volumes had been treated. Fractions of the treated effluent were collected and analyzed for cesium content. Radioactive samples were analyzed by gamma counting. Non-radioactive samples were analyzed by atomic absorption (AA) spectroscopy.

Following the feed step, three column volumes of $6 \mathrm{M} \mathrm{NaOH}$ were used to push residual interstitial feed off the column without causing precipitation of aluminum in the process. Another three column volumes of deionized water were passed through the resin to prepare it for elution. The process flow was then changed to an upflow mode and fifty column volumes of nitric acid elutriant were processed through the resin. Eluate fractions were collected and analyzed for $\mathrm{Cs}^{+}, \mathrm{Na}^{+}$, and $\mathrm{K}^{+}$content. Sodium ion was analyzed by Inductively Coupled Plasma Emission Spectroscopy (ICPES), potassium ion was analyzed by AA, and cesium ion concentrations were determined either by gamma 
S.D. FINK

February 1, 1994
WSRC-RP-94-146

Revision 0

Page 5 of 31

counting or by AA. In some cases, eluted resin that had been contacted with radioactive feed was collected and sent for gamma counting to determine the amount of Cs-137 still on the resin.

If the resin was to be reused, the direction of flow was reversed and the bed was washed with water and reconditioned with $6 \mathrm{M} \mathrm{NaOH}$ before the next feed cycle was begun.

\subsection{The Effect of Increasing Flow Rate on Breakthrough}

Four representative flow rates were used to process the Hanford 101-AW simulant in a downflow mode on a $2 \mathrm{~mL}$ resin bed. The results of those tests are shown graphically in Figure 3. The value $\mathrm{C} / \mathrm{Co}$ represents the ratio of the cesium concentration in the effluent from the column relative to the concentration in the feed. Data for gamma analysis of Cs137 in the feeds and in the fractions collected as treated effluent exited the column are listed in Table 3. A 50\% breakthrough occurs after about 100 column volumes of feed have been treated. The sharpness of the breakthrough curve improved as the flow rate decreased. At flow rates above 3 column volumes per hour there was leakage of cesium from the column before $50 \%$ breakthrough, although above that flow rate the sharpness of the breakthrough curve was not significantly reduced by more rapid flows. It is possible that column performance is affected by the similarity between the resin and the feed. The density of the resin is about $1.5 \mathrm{~g} / \mathrm{mL}^{1}$ and that for the Hanford 101-AW is about $1.4 \mathrm{~g} / \mathrm{mL}$ (Table 2). This similarity in densities could cause loose packing of the resin bed and subsequent leakage of the column, a phenomenon that would be exacerbated as the flow rate was increased. Dilution of the feed would widen the difference in densities between resin and feed and might give better early performance.

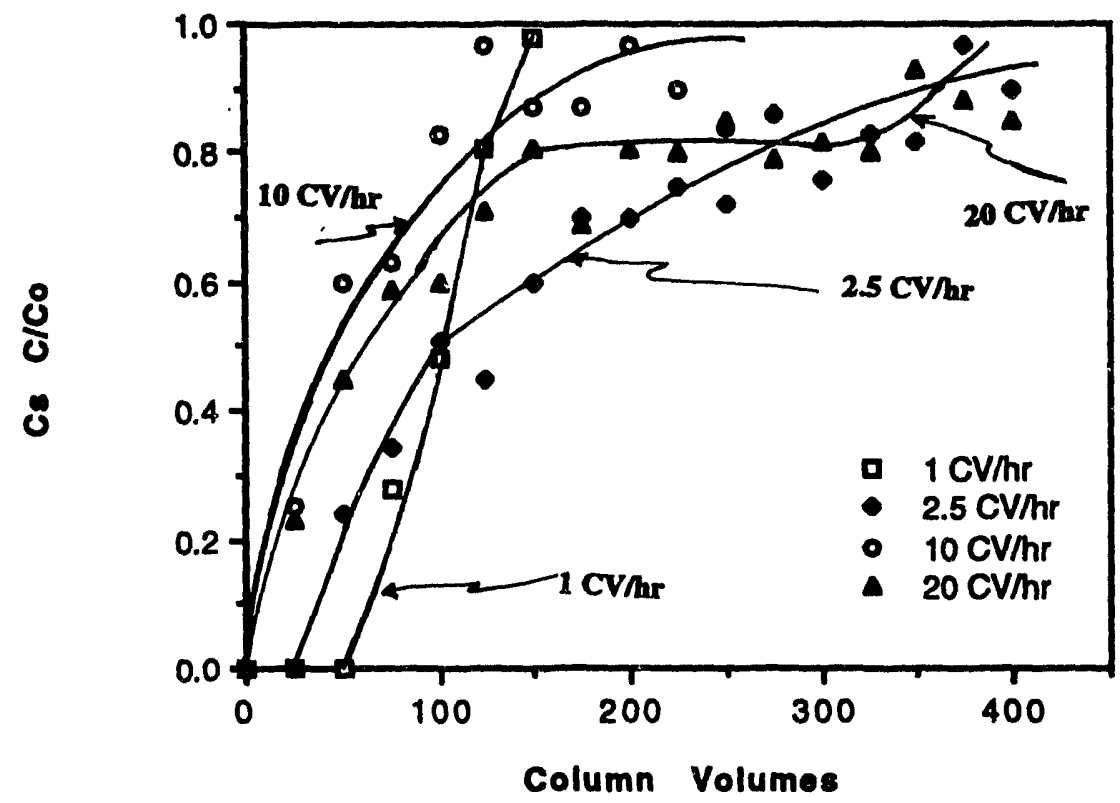

Figure 3. Breakthrough Curves From Four Flow Rates at $25^{\circ} \mathrm{C}$ 
S.D. FINK

WSRC-RP-94-146

February 1, 1994

Revision 0

Page 6 of 31

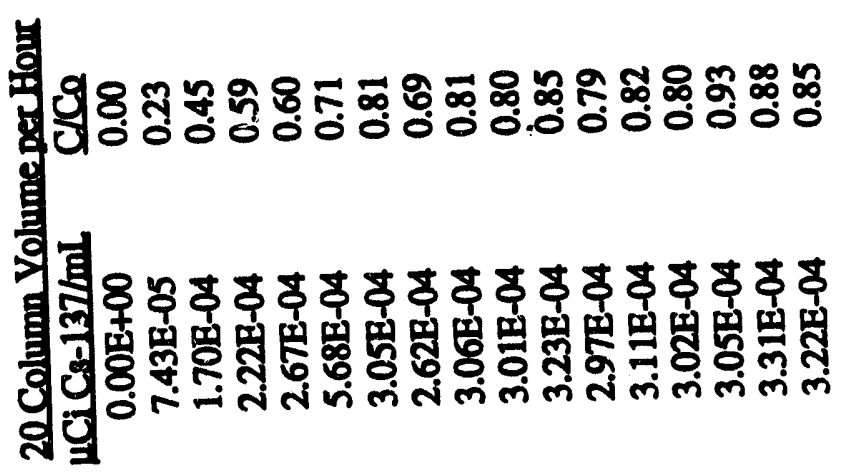

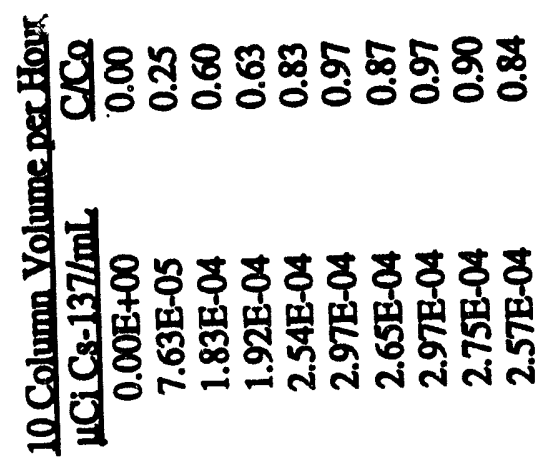

费

首

๕్

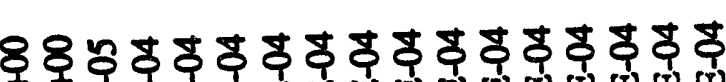

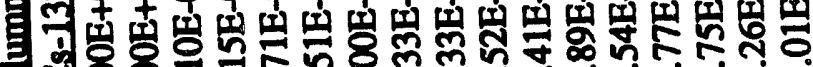

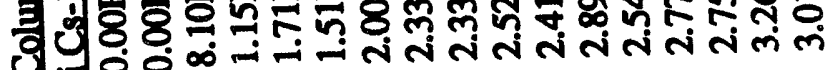

옳

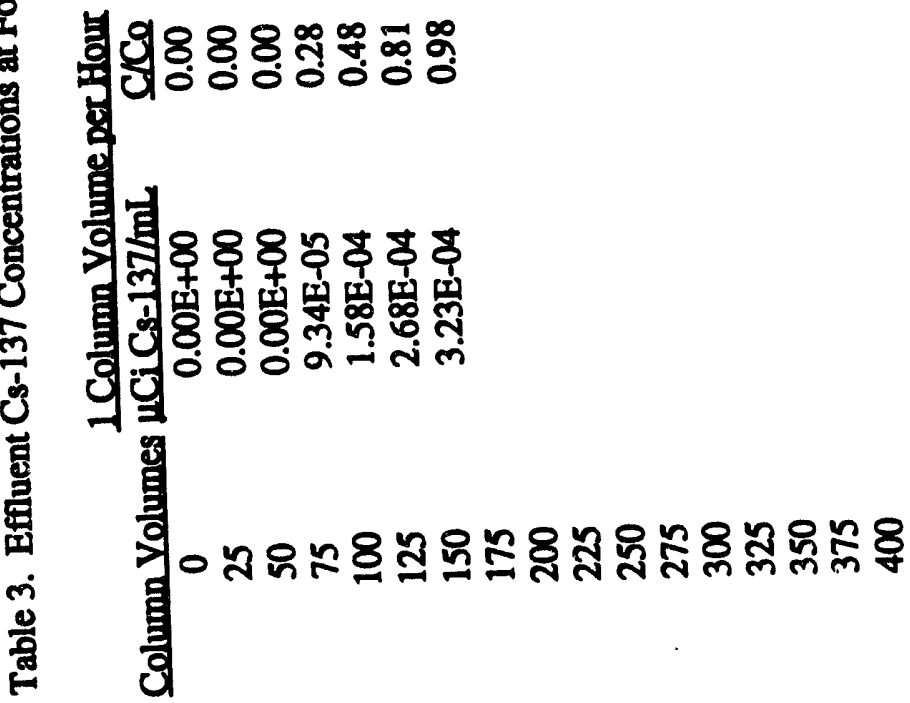

లె

苑

ह

. 
A larger, $10 \mathrm{~mL}$, bed size was used with non-radioactive feed. Two feed and elution cycles were performed on the same resin bed at a flow rate of 10 column volumes per hour. Effluent from the column was collected in $100 \mathrm{~mL}$ fractions followed by one 800 $\mathrm{mL}$ fraction, collected while running overnight, and five more $100 \mathrm{~mL}$ fractions. Run 1 , as noted in Table 4, was completed by collecting a $400 \mathrm{~mL}$ fraction. These fractions were analyzed for Cs content by atomic absorption spectroscopy. The resin was eluted with $0.5 \mathrm{M} \mathrm{HNO}_{3}$ between runs. It will be shown in Section 4.2.2 that only the first ten column volumes of eluate were analyzed for $\mathrm{Cs}$ content. The column was treated with an additional $500 \mathrm{~mL}$ of the acid to assure complete elution before the next run was begun. A more complete analysis of the eluate was made for the second run.

Breakthrough curves are shown graphically in Figure 4. It should be noted that $\mathrm{K}^{+}$and $\mathrm{Na}+$ concentrations in some effluent fractions were monitored. There was no apparent change in the concentration of either ion in the column effluent when the $\mathrm{Na-form}$ of the resin was being used. For resin that had been eluted, treated with $6 \mathrm{M} \mathrm{NaOH}$, and then reused, resin uptake of $\mathrm{K}^{+}$was evident at the start of the feed cycle. After about 10 column volumes had been processed, the potassium ion concentration in the effluent reached equality with that of the feed.

Table 4. Effluent Cesium Concentrations From 10-mL Columns

\begin{tabular}{|c|c|c|c|c|c|}
\hline & & & & & Run \\
\hline ColumnVolumes & Cs.opm & $\mathrm{Cs} \mathrm{C} / \mathrm{Co}_{0}$ & Column Yolumes & Cs. opm & $\mathrm{Cs} C / \mathrm{Co}_{0}$ \\
\hline 0 & $0.00 \mathrm{E}+00$ & $0.00 \mathrm{E}+00$ & 0 & $0.00 \mathrm{E}+00$ & $0.00 \mathrm{E}+00$ \\
\hline 10 & $2.13 E+00$ & $9.96 \mathrm{E}-02$ & 10 & $9.88 \mathrm{E}-01$ & $4.63 \mathrm{E}-02$ \\
\hline 20 & $3.55 \mathrm{E}+00$ & $3.14 \mathrm{E}-01$ & 20 & $3.81 E+00$ & $1.79 \mathrm{E}-01$ \\
\hline 40 & $6.44 E+00$ & $3.01 \mathrm{E}-01$ & 30 & $5.02 E+00$ & $2.35 \mathrm{E}-01$ \\
\hline 120 & $9.56 \mathrm{E}+00$ & 4.47E-01 & 40 & $6.33 E+00$ & $2.96 \mathrm{E}-01$ \\
\hline 130 & $1.19 E+01$ & $5.54 \mathrm{E}-01$ & 120 & $1.02 E+01$ & $4.77 \mathrm{E}-01$ \\
\hline 140 & $1.24 E+01$ & $5.79 \mathrm{E}-01$ & 130 & $1.27 E+01$ & $5.97 \mathrm{E}-01$ \\
\hline 150 & $1.30 E+01$ & $6.08 \mathrm{E}-01$ & 140 & $1.32 E+01$ & $6.16 \mathrm{E}-01$ \\
\hline 160 & $1.30 \mathrm{E}+01$ & $6.08 \mathrm{E}-01$ & 150 & $1.33 E+01$ & $6.23 \mathrm{E}-01$ \\
\hline 200 & $1.40 E+01$ & $6.56 \mathrm{E}-01$ & 160 & $1.35 E+01$ & $6.32 \mathrm{E}-01$ \\
\hline & & & 170 & $1.27 \mathrm{E}+01$ & $5.95 \mathrm{E}-01$ \\
\hline Total Cs fed & & & & & \\
\hline to column & $42.64 \mathrm{mg}$ & & & $36.31 \mathrm{mg}$ & \\
\hline Total Cs in & & & & & \\
\hline Effluent & $16.25 \mathrm{mg}$ & & & $16.27 \mathrm{mg}$ & \\
\hline Total Cs on & & & & & \\
\hline Column & $26.39 \mathrm{mg}$ & & & $20.04 \mathrm{mg}$ & \\
\hline
\end{tabular}


S.D. FINK

February 1, 1994

WSRC-RP-94-146

Revision 0

Page 8 of 31

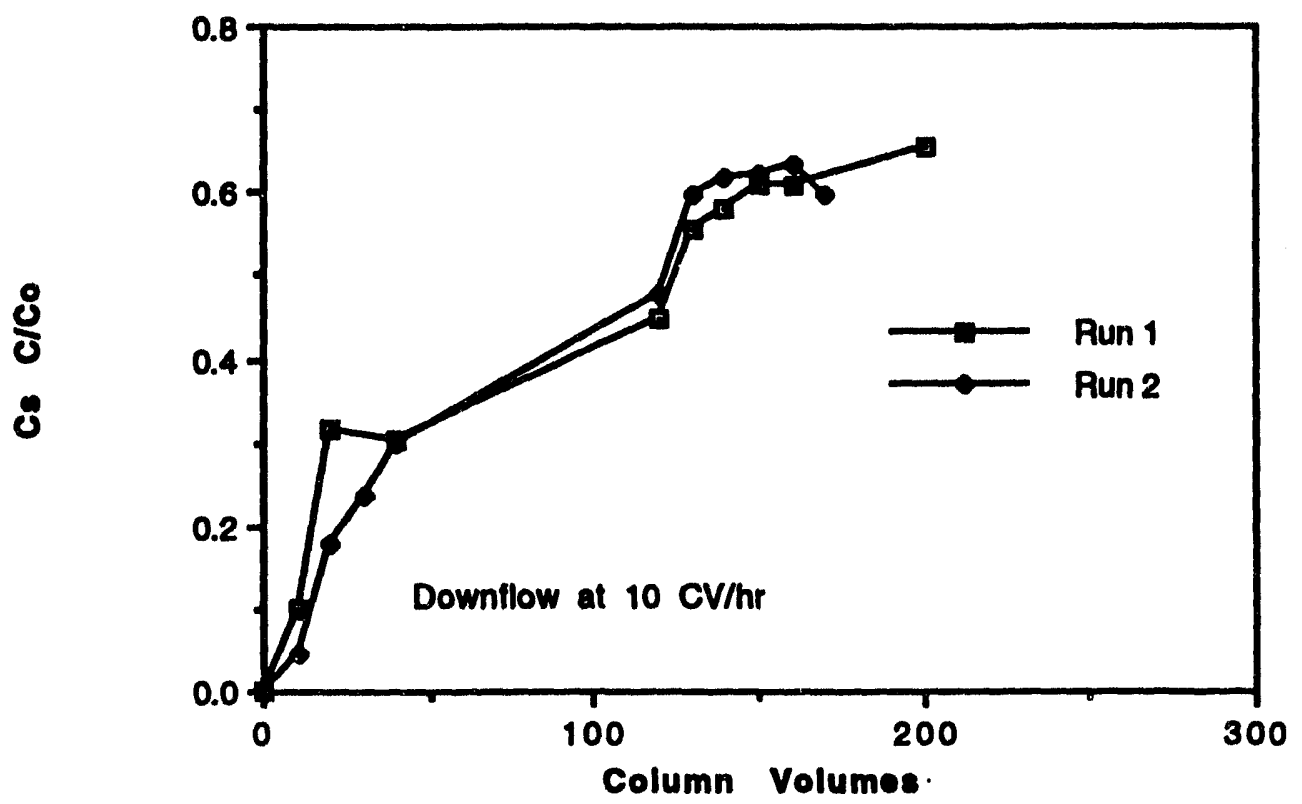

Figure 4. Breakthrough Curves for Two Ten-Milliliter Column Runs

The $10-\mathrm{mL}$ columns indicate a $50 \%$ breakthrough at approximately 120 column volumes, similar to the value found for the smaller, 2-mL columns. Although the larger column removes cesium ion somewhat better than the smaller column, in part because of the reduced importance of wall effects in the larger column, the early breakthrough or leakage is still evident.

\subsection{Elution of the Resin}

Resin beds were saturated with $\mathrm{Cs}^{+}$by processing Hanford 101-AW simulant through the column until the cesium ion concentration in the effluent was essentially equal to that of the feed (i.e., $\mathrm{C} / \mathrm{Co}=1$ ). Three column volumes of deionized water were processed through the column to remove as much interstitial feed solution as possible. Elutions reported here were performed with $0.1 \mathrm{M}, 0.3 \mathrm{M}$, and $0.5 \mathrm{M} \mathrm{HNO} 3$ in upflow modes at flow rates from 2.5 to 10 column volumes per hour.

\subsubsection{Effect of Increasing Elutriant Acid Concentration}

The results of elutions of two milliliter columns with three nitric acid concentrations are shown graphically in Figure 5. The concentration of Cs-137 in each eluate fraction and the total Cs-137 removed in the eluate are listed in Table 5. 
S.D. FINK

February 1, 1994

WSRC-RP-94-146

Revision 0

Page 9 of 31

Table 5. Cesium Ion Elution in Three Nitric Acid Concentrations

Total $4 \mathrm{Ci} \mathrm{Cs}-137$ in Eluate

\begin{tabular}{|c|c|c|c|}
\hline \multicolumn{4}{|r|}{ 2.5 M HNO3 } \\
\hline 0.0 & $0.00 \mathrm{E}+00$ & $0.00 \mathrm{E}+00$ & $0.00 \mathrm{E}+00$ \\
\hline 5.0 & $0.00 \mathrm{E}+\infty 0$ & $0.00 \mathrm{E}+00$ & $2.21 \mathrm{E}-02$ \\
\hline 7.5 & $0.00 \mathrm{E}+00$ & $0.00 \mathrm{E}+00$ & $1.38 \mathrm{E}-02$ \\
\hline 10.0 & $0.00 \mathrm{E}+00$ & $1.54 \mathrm{E}-02$ & $7.86 \mathrm{E}-03$ \\
\hline 12.5 & $0.00 \mathrm{E}+00$ & $2.60 \mathrm{E}-02$ & 4.82E-03 \\
\hline 15.0 & $0.00 \mathrm{E} \cdot 00$ & $2.16 \mathrm{E}-02$ & 3.10E-03 \\
\hline 17.5 & 8.17E-04 & $2.06 \mathrm{E}-02$ & $1.34 \mathrm{E}-03$ \\
\hline 20.0 & 1.11E-02 & $1.88 \mathrm{E}-02$ & $9.00 \mathrm{E}-04$ \\
\hline 22.5 & $1.29 \mathrm{E}-02$ & $1.36 \mathrm{E}-02$ & 4.64E-04 \\
\hline 25.0 & $1.07 \mathrm{E}-02$ & 8.37E- -03 & $3.49 \mathrm{E}-04$ \\
\hline 27.5 & $7.99 \mathrm{E}-03$ & 4.95E-03 & 2.95E-04 \\
\hline 30.0 & $7.96 \mathrm{E}-03$ & $3.40 \mathrm{E}-03$ & $0.00 \mathrm{E}+00$ \\
\hline 32.5 & $7.53 \mathrm{E}-03$ & $2.30 \mathrm{E}-03$ & $0.00 \mathrm{E}+00$ \\
\hline 35.0 & $7.26 \mathrm{E}-03$ & $1.51 \mathrm{E}-03$ & $0.00 \mathrm{E}+00$ \\
\hline 37.5 & $6.49 \mathrm{E}-03$ & $9.64 \mathrm{E}-04$ & $0.00 \mathrm{E}+00$ \\
\hline 40.0 & $5.54 \mathrm{E}-03$ & $6.96 \mathrm{E}-04$ & $0.00 \mathrm{E}+00$ \\
\hline 42.5 & $3.91 E-03$ & $3.79 \mathrm{E}-04$ & $0.00 \mathrm{E}+00$ \\
\hline 45.0 & $1.78 \mathrm{E}-03$ & 2.65E-04 & $0.00 E+00$ \\
\hline 47.5 & 2.63E-04 & 2.02E-04 & $0.00 \mathrm{E}+00$ \\
\hline 50.0 & $1.53 \mathrm{E}-04$ & 2.21E-04 & $0.00 \mathrm{E}+00$ \\
\hline 52.5 & $9.84 \mathrm{E}-05$ & & \\
\hline 55.0 & $7.78 \mathrm{E}-05$ & & \\
\hline & $8.46 \mathrm{E}-02$ & $1.39 \mathrm{E}-01$ & $1.39 \mathrm{E}-01$ \\
\hline
\end{tabular}


S.D. FINK

February 1, 1994

WSRC-RP-94-146

Revision 0

Page 10 of 31

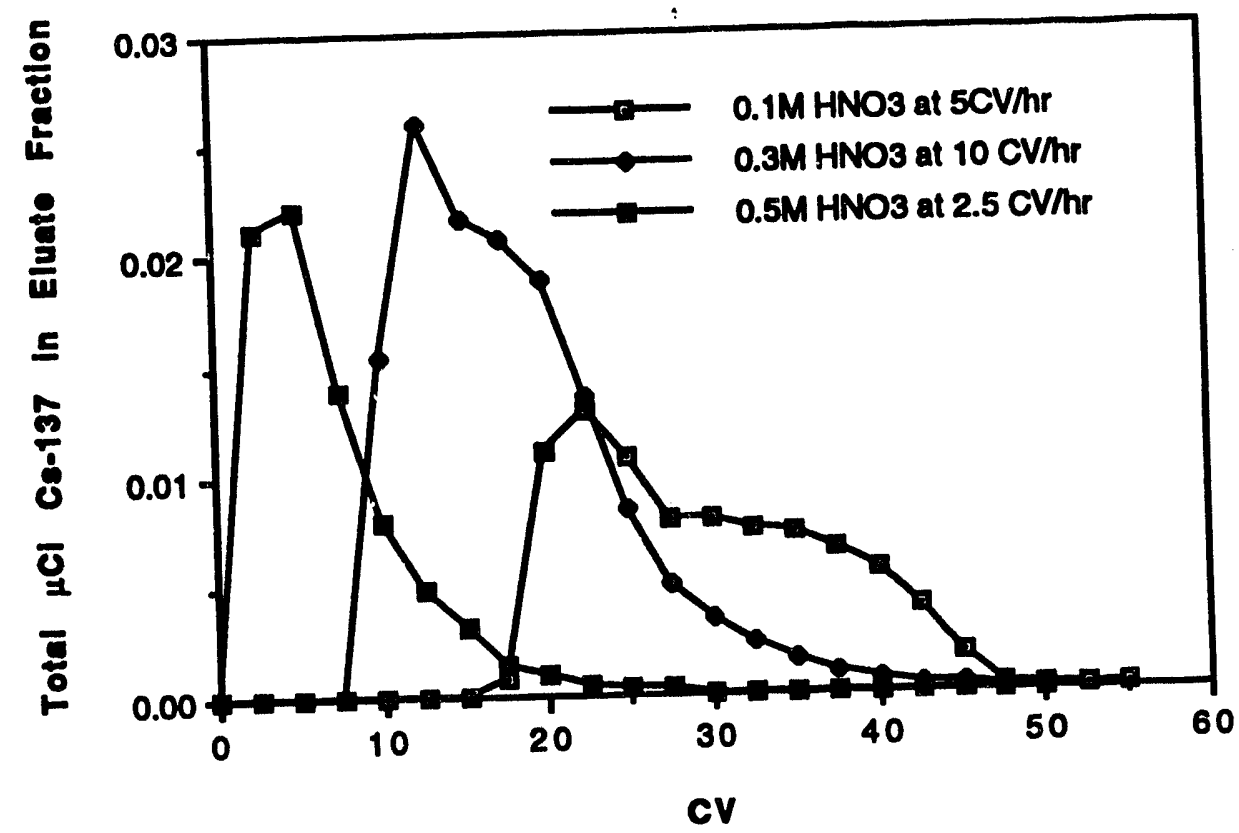

Figure 5. Elution of 2-mL Columns with Three Nitric Acid Concentrations

The most efficient removal of cesium ion from the resin was accomplished in $0.5 \mathrm{M}$ HNO3. Elution required about 20 column volumes in the $0.5 \mathrm{M}$ acid and 40 column volumes in $0.1 \mathrm{M}$ acid. Additionally, total acid needed was reduced because the stronger acid neutralized residual caustic on the resin more quickly than the weaker acids and the initial lag period of no elution evident in Figure 5 was thereby reduced. The resin from the column that was eluted with $0.5 \mathrm{HNO} 3$ was sent for gamma counting to determine whether all the Cs-137 had been removed. The results of that analysis showed no detectable Cs-137 on the resin. The detection limit of the gamma counter is $1 \mathrm{E}-5$ $\mu \mathrm{Ci} /$ sample. In general, flow rates between 2.5 and 10 column volumes per hour gave similar results for elution, removing the sorbed Cst in the same number of column volumes of elutriant.

\subsubsection{Elution of Ten-Milliliter Columns}

The elution of the 10-mL columns was accomplished with $0.5 \mathrm{M} \mathrm{HNO}_{3}$ (Figure 6). Data for the elution of the first column run was not sought past ten column volumes of elutriant. However, an additional 50 column volumes of $0.5 \mathrm{M} \mathrm{HNO} 3$ was passed through the resin before the second run to insure that all cesium ion had been removed. 
S.D. FINK

February 1, 1994

WSRC-RP-94-146

Revision 0

Page 11 of 31

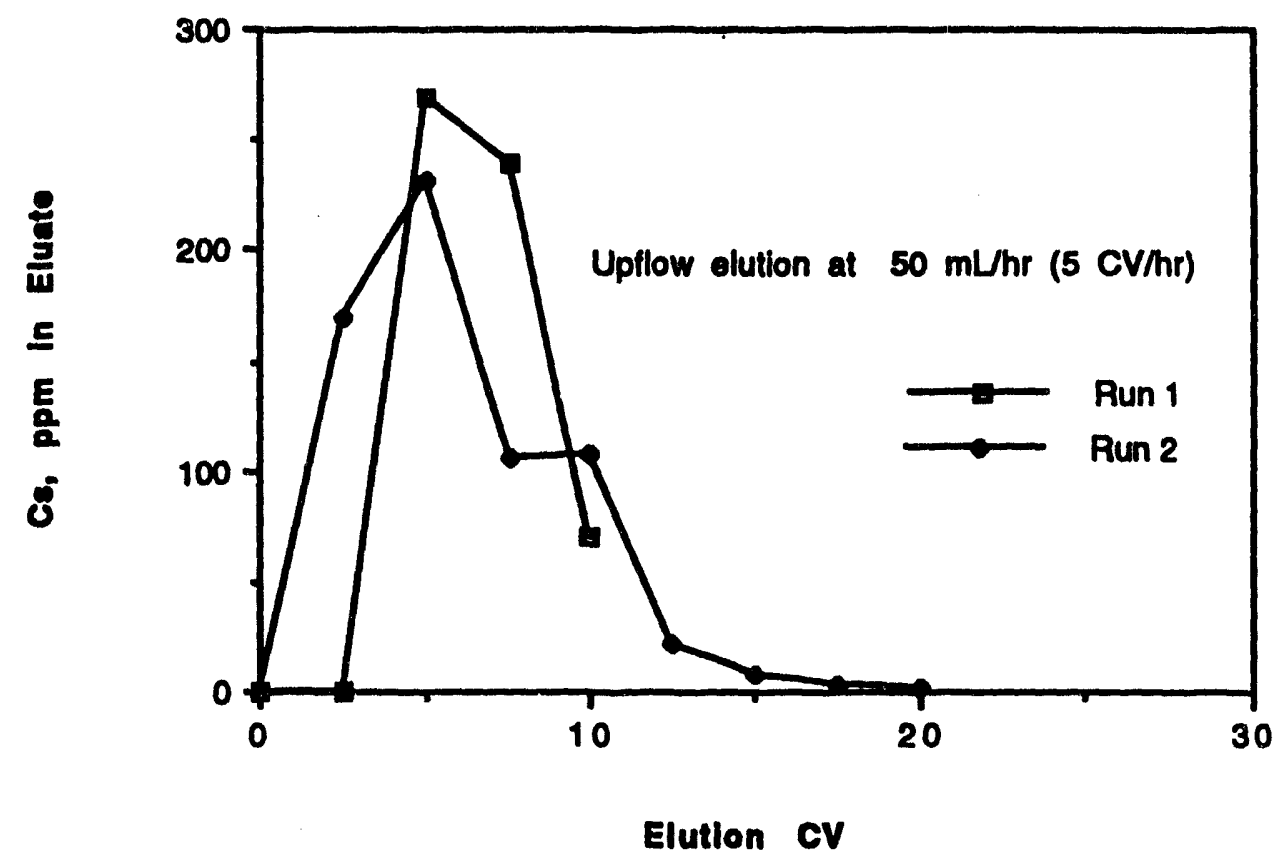

Figure 6. Cesium Elution from Two Ten-Milliliter Columns

The amount of $\mathrm{Cs}^{+}$fed to the resin and the amount found in the eluate for each run are given in Table 4. The difference is the amount of $\mathrm{Cs}^{+}$captured on the resin bed. Using those numbers and the concentration of $\mathrm{Cs}^{+}$in the eluate (Table 6), it can be shown that $55 \%$ of the $\mathrm{Cs}^{+}$was removed in 10-column volumes of acid for Run 1 and $81 \%$ was removed in $\mathbf{2 0}$ column volumes in Run 2.

Table 6. Cesium Ion Concentration in Eluate from Ten-Milliliter Columns Cs. ppm in Eluate

Column Volumes

0

2.5

5.0

7.5

10

12.5

15

17.5

20

Total $\mathrm{Cs}^{+}$in eluate
Run 1

0

0.008

269.53

239.34

69.77

-

$\cdots$

$-\cdots$

$14.47 \mathrm{mg}$
Bun 2

0

169.37

232.14

106.03

107.37

21.43

8.38

3.76

1.71

$16.25 \mathrm{mg}$ 
S.D. FINK

February 1, 1994
WSRC-RP-94-146

Revision 0

Page 12 of 31

\subsubsection{Total Alkali Metal Ion in Eluate}

Because, in a process, the eluate may be sent to the melter for vitrification, it is of interest to know the fate of $\mathrm{K}^{+}$and $\mathrm{Na}^{+}$on elution. These ions have been tracked for some of the small column runs. Two 2-mL column runs, made on the same resin bed to determine if there would be a difference between the concentration of alkali metal ions in the effluent of a column that had not been eluted relative to one that had, are displayed here (Figures 7,8 , and 9).

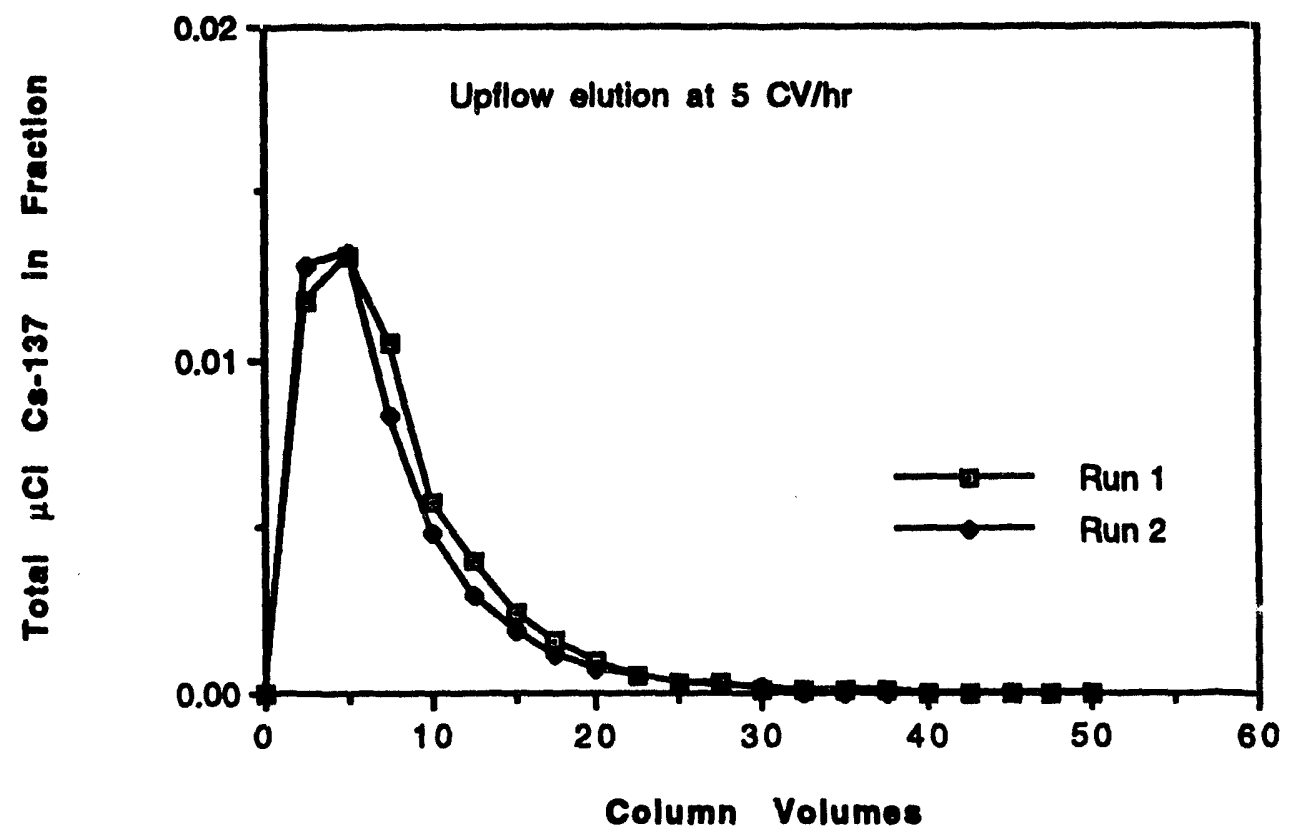

Figure 7. Elution Profile for Cs-137 From Two Runs on the Same Two-Milliliter Column 
S.D. FINK

February 1, 1994
WSRC-RP-94-146

Revision 0

Page 13 of 31

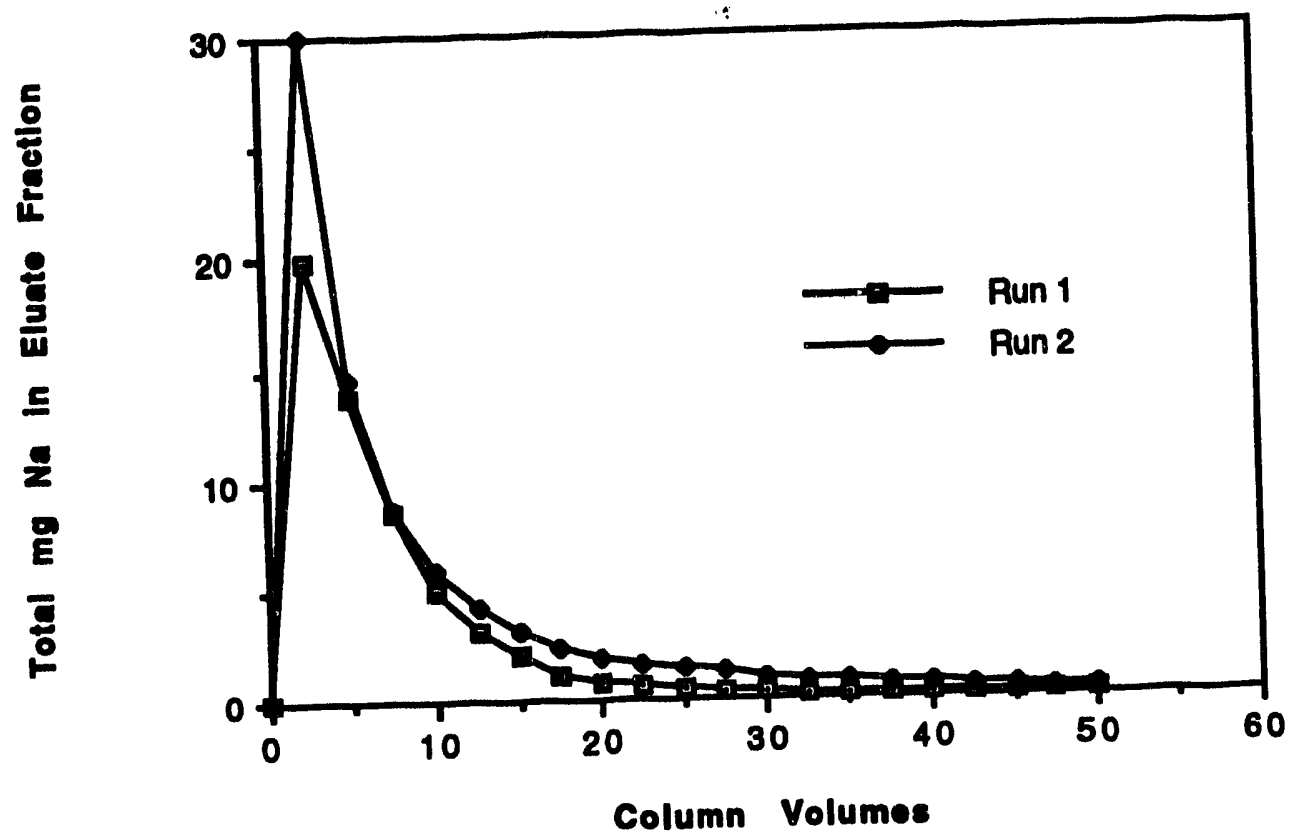

Figure 8. Elution Profile for $\mathrm{Na}^{+}$From Two Runs on the Same 2-mLColumn

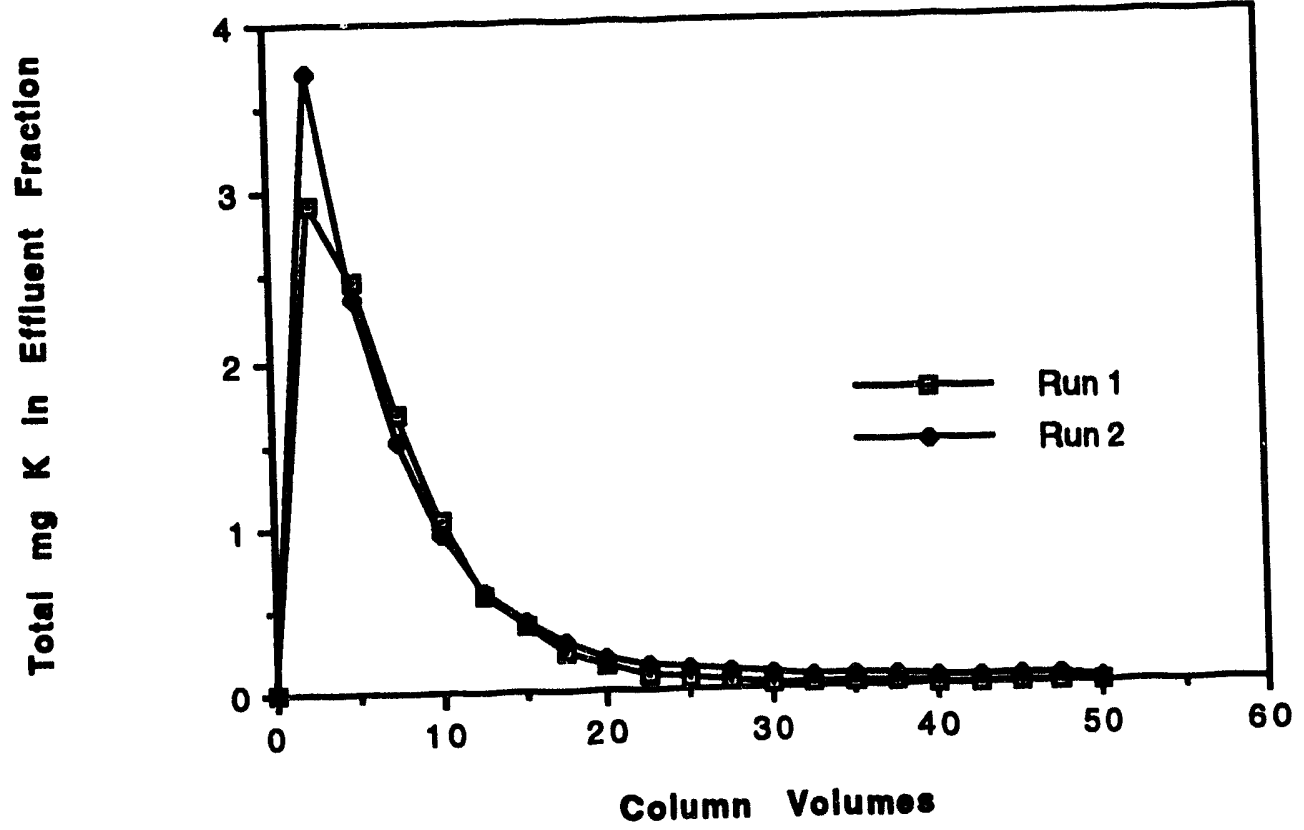

Figure 9. Elution Profile for $\mathrm{K}^{+}$From Two Runs on the Same 2-mL Column 
S.D. FINK

February 1, 1994
WSRC-RP-94-146

Revision 0

Page 14 of 31

Table 7. Alkali Metal Ion Concentrations in Eluate

Fractions

\begin{tabular}{|c|c|c|c|c|c|c|}
\hline Milliliters & meNa & $\frac{\operatorname{Run} 1}{\operatorname{meK}}$ & mgCs & meja & $\frac{\operatorname{Run} 2}{\operatorname{mgK}}$ & mgCs \\
\hline 5.0 & 19.85 & 2.93 & 0.66 & 29.98 & 3.71 & 0.72 \\
\hline 10.0 & 13.85 & 2.47 & 0.74 & 14.57 & 2.36 & 0.75 \\
\hline 15.0 & 8.60 & 1.68 & 0.59 & 8.66 & 1.51 & 0.47 \\
\hline 20.0 & 4.97 & 1.04 & 0.32 & 5.98 & 0.95 & 0.27 \\
\hline 25.0 & 3.09 & 0.58 & 0.22 & 4.24 & 0.61 & 0.16 \\
\hline 30.0 & 1.95 & 0.39 & 0.13 & 3.05 & 0.41 & 0.11 \\
\hline 35.0 & 1.13 & 0.24 & 0.09 & 2.40 & 0.28 & 0.06 \\
\hline 40.0 & 0.81 & 0.15 & 0.05 & 1.84 & 0.19 & 0.04 \\
\hline 45.0 & 0.56 & 0.09 & 0.03 & 1.58 & 0.15 & 0.03 \\
\hline 50.0 & 0.41 & 0.06 & 0.02 & 1.38 & 0.12 & 0.02 \\
\hline 55.0 & 0.32 & 0.04 & 0.02 & 1.20 & 0.10 & 0.01 \\
\hline 60.0 & 0.27 & 0.03 & 0.01 & 0.97 & 0.08 & 0.01 \\
\hline 65.0 & 0.23 & 0.02 & 0.01 & 0.83 & 0.07 & 0.00 \\
\hline 70.0 & 0.20 & 0.02 & 0.00 & 0.74 & 0.06 & 0.00 \\
\hline 75.0 & 0.18 & 0.01 & 0.00 & 0.68 & 0.05 & 0.00 \\
\hline 80.0 & 0.17 & 0.01 & 0.00 & 0.55 & 0.05 & 0.00 \\
\hline 85.0 & 0.15 & 0.01 & 0.00 & 0.50 & 0.04 & 0.00 \\
\hline 90.0 & 0.15 & 0.01 & 0.00 & 0.49 & 0.04 & 0.00 \\
\hline 95.0 & 0.15 & 0.01 & 0.00 & 0.39 & 0.04 & 0.00 \\
\hline 100.0 & 0.14 & 0.01 & 0.00 & 0.37 & 0.03 & 0.00 \\
\hline Total mg & 57.17 & 9.76 & 2.90 & 80.38 & 10.84 & 2.65 \\
\hline Molarity & $2.49 \mathrm{E}-02$ & $1.47 \mathrm{E}-02$ & 2.15E-04 & 3.49E-02 & $2.78 \mathrm{E}-03$ & $1.96 \mathrm{E}-04$ \\
\hline $\begin{array}{c}\text { Total alkali } \\
\text { M }\end{array}$ & & 3.97E-02 & & & $3.79 \mathrm{E}-02$ & \\
\hline mmoles $\mathbf{M}+$ & esin & 6.02 & & & 5.75 & \\
\hline
\end{tabular}


S.D. FINK

February 1, 1994
WSRC-RP-94-146

Revision 0

Page 15 of 31

Table 7 shows that the distribution of $\mathrm{Cs}^{+}, \mathrm{K}^{+}$, and $\mathrm{Na}^{+}$on the resin in each run was nearly identical, even though the resin had been cluted before the second run. Total alkali metal ion concentration in each effluent was about $3.9 \mathrm{E}-2 \mathrm{M}$, representing 6.0 mmoles of alkali metal ion generated per gram of resin. The eluate should be uniform for the same feed.

Table 8 presents the concentrations of the same three alkali metal ions in the eluate from the second $10 \mathrm{~mL}$ column elution. It must be remembered that column elution was only $81 \%$ complete, based on the percent $\mathrm{Cs}^{+}$removed. The value of 4.2 mmoles of alkali metal ion eluted per gram of resin calculated for the $10 \mathrm{~mL}$ column is probably low since elution was incomplete.

Table 8. Total Alkali Metal Ion Concentration In Elution From The Second $10 \mathrm{~mL}$ Column

\begin{tabular}{|c|c|c|c|}
\hline Alkali Metal Ion & $\begin{array}{l}\text { mg M+Elute } \\
\text { in } 200 \mathrm{~mL}\end{array}$ & $\begin{array}{l}\text { mg M+ Eluted } \\
\text { in } 1000 \mathrm{~mL}\end{array}$ & $\begin{array}{l}\text { Molarity of } \\
\text { Eluted Mt }\end{array}$ \\
\hline Cst & 16.26 & 81.3 & $6.02 E-04$ \\
\hline $\mathrm{Nat}$ & 293.5851 & 1467.9255 & $6.38 \mathrm{E}-02$ \\
\hline $\mathbf{K}+$ & 38.1726 & 190.863 & $4.89 \mathrm{E}-03$ \\
\hline
\end{tabular}

Total mmoles of $\mathrm{M}+$ in $200 \mathrm{~mL}$

1.39E+01

Millimoles $\mathbf{M}+$ per gram resin

Future tests on larger columns will help characterize the eluate more closely. These data, however, suggest that the total millimoles of alkali metal generated in $0.5 \mathrm{M} \mathrm{HNO} 3$ per gram of resin eluted at $25^{\circ} \mathrm{C}$ is between 5 and 6 millimoles when the feed is the Hanford 101-AW.

\subsection{Effect of Temperature on Resin Loading and Elution}

Columns having five milliliter resin beds $(0.9 \mathrm{~cm}$ diameter $\times 7.9 \mathrm{~cm})$ were tested at three elevated temperatures. The exterior of the column was wrapped with heating tape that was connected to a Variac. Prior to the experiments, resin was slurried into the column in non-radioactive Hanford 101-AW simulant. A calibrated thermometer (WP-560) was submerged in the slurry to record the temperature inside the column. The current to the heating tape was adjusted until the temperature reached $40^{\circ} \mathrm{C}$ and remained there for 30 minutes. The setting on the Variac was recorded. A similar procedure was used to determine the Variac setting required to maintain the temperature of the resin and simulant in the column at $50^{\circ} \mathrm{C}$ and $67^{\circ} \mathrm{C}$. It was not possible to sustain a $70^{\circ} \mathrm{C}$ environment for any length of time, but $67^{\circ} \mathrm{C}$ was achievable. The settings on a hot plate needed to heat the column feed to those three temperatures were also determined. The 
S.D. FINK

February 1, 1994

WSRC-RP-94-146

Revision 0

Page 16 of 31

column was then refilled with $5 \mathrm{~mL}$ of resin that had been allowed to swell in $6 \mathrm{M} \mathrm{NaOH}$ and the column was used to treat Hanford 101-AW simulant containing Cs-137 at the three different temperatures. Treated effluent was collected and analyzed for Cs-137 by gamma counting.

When the column had been saturated, as evidenced by a ratio of cesium ion concentration in the effluent relative to that in the feed $(\mathrm{C} / \mathrm{Co})$ of approximately 1 , the column was washed with three column volumes of $6 \mathrm{M} \mathrm{NaOH}$, followed by three column volumes of deionized water, both maintained at the temperature of the experiment. Then 60 column volumes of $0.5 \mathrm{HNO}_{3}$ were processed by the resin at the temperature of the experiment. The fractions of eluate were analyzed for $\mathrm{Cs}^{+}, \mathrm{Na}^{+}$, and $\mathrm{K}^{+}$, concentrations by gamma counting (for $\mathrm{Cs}^{+}$), ICPES (for $\mathrm{Na}^{+}$), and AA (for $\mathrm{K}^{+}$). All treatments and elutions were performed at $15 \mathrm{~mL} / \mathrm{hr}(3 \mathrm{CV} / \mathrm{hr})$ flow rates. Simulant was processed in downflow mode; elution was accomplished in upflow mode.

The results of the feed cycles are shown in Figure 10. The data are found in Table 9.

Table 9. Breakthrough Data at Elevated Temperatures

\begin{tabular}{|c|c|c|c|c|c|c|}
\hline Column & & ${ }^{\circ} \mathrm{C}$ & & & & ${ }^{\circ} \mathrm{C}$ \\
\hline Volumes & MCiCs-137/m & $\mathrm{c} / \mathrm{C}_{0}$ & & $\mathrm{C} / \mathrm{Co}_{0}$ & $\mu C_{i}$ ss-137/mI & $\mathbf{C d}$ \\
\hline 0 & $0.00 \mathrm{E}+00$ & 0.00 & $0.00 \mathrm{E}+00$ & 0.00 & $0.00 \mathrm{E}+00$ & 0.0 \\
\hline 10 & $0.00 \mathrm{E}+00$ & 0.00 & $0.00 \mathrm{E}+00$ & 0.00 & 1.34E-04 & 0.4 \\
\hline 20 & 1.37E-04 & 0.41 & $5.65 E-05$ & 0.17 & 1.49 & 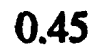 \\
\hline 30 & 6.47E-05 & 0.19 & 5.84E-05 & 0.17 & $2.85 \mathrm{E}-04$ & \\
\hline 40 & $1.03 \mathrm{E}-04$ & 0.31 & 9.35E-05 & 0.28 & $3.55 \mathrm{E}-04$ & \\
\hline 50 & 1.37E-04 & 0.41 & $E-04$ & 0.31 & 04 & \\
\hline 60 & -04 & 0.51 & $1.52 E-04$ & 0.45 & 04 & \\
\hline 70 & $2.11 \mathrm{E}-04$ & 0.63 & $1.36 \mathrm{E}-04$ & 0.41 & 04 & \\
\hline 80 & $2.16 \mathrm{E}-04$ & 0.64 & 2.75E-04 & 0.82 & 04 & \\
\hline 90 & $1.74 \mathrm{E}-04$ & 0.52 & $3.29 \mathrm{E}-04$ & 0.98 & 2.9 & 0 \\
\hline 100 & 2.21E-04 & 0.66 & $3.21 \mathrm{E}-04$ & 0.96 & 04 & 1 \\
\hline 110 & $2.46 \mathrm{E}-04$ & 0.73 & $3.02 \mathrm{E}-04$ & 0.90 & 04 & 0 \\
\hline 120 & 2.72E-04 & 0.81 & $3.12 E-04$ & 0.93 & 04 & \\
\hline 130 & $E-04$ & 0.94 & $4.11 \mathrm{E}-04$ & 1.23 & 04 & \\
\hline 14 & $8-04$ & 0.74 & $3.06 \mathrm{E}-04$ & 0.91 & $3.11 E-04$ & \\
\hline 15 & $3-04$ & 0.9 & $3.84 \mathrm{E}-04$ & 1. & 3.7 & \\
\hline 160 & 3.50E-04 & 1.04 & $2.98 \mathrm{E}-04$ & 0.8 & 3.57E-04 & \\
\hline
\end{tabular}


S.D. FINK

February 1, 1994

WSRC-RP-94-146

Revision 0

Page 17 of 31

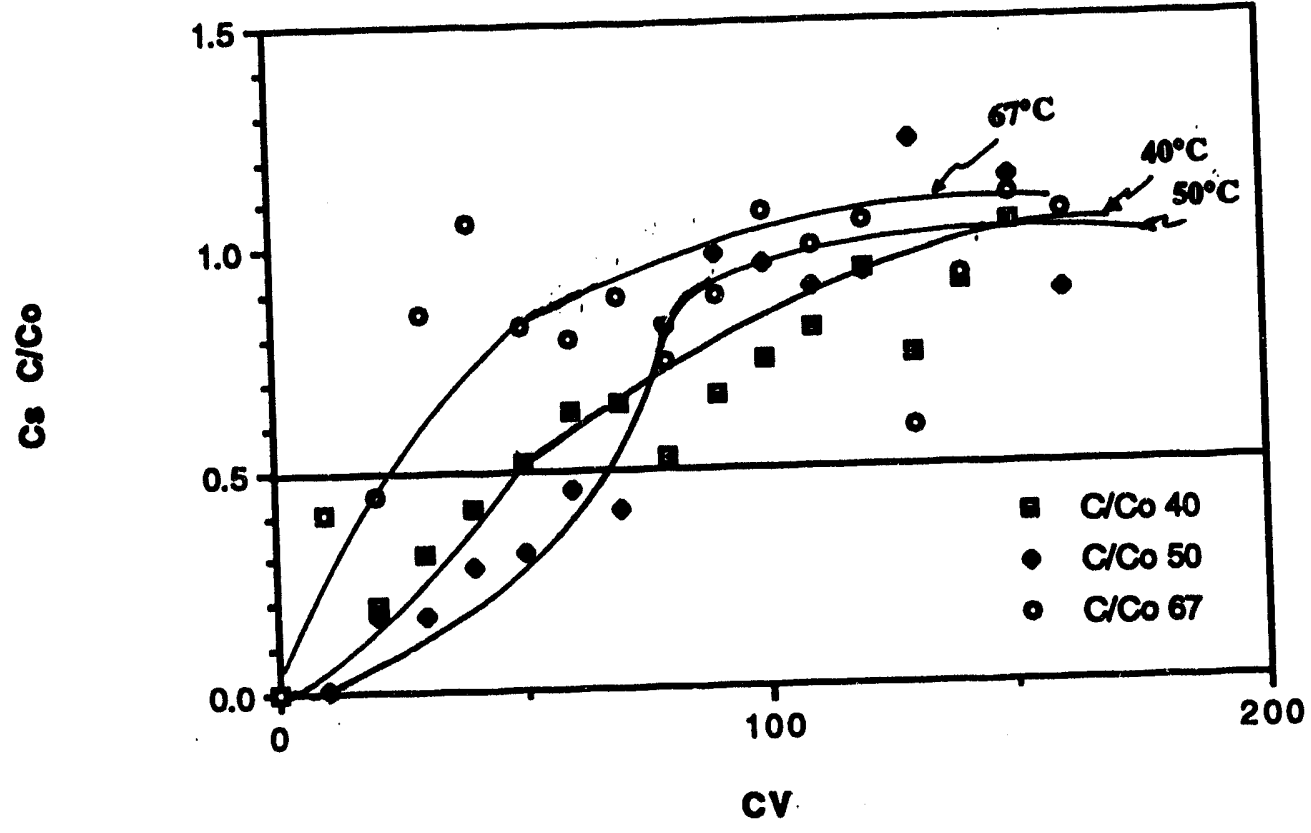

Figure 10. Breakthrough Curves for a Five-Milliliter
Column at Three Temperatures Greater Than $25^{\circ} \mathrm{C}$.

It is apparent that the performance of the column became erratic as the temperature was increased. This could have been, in part, due to disruption of the integrity of the resin bed at the higher temperatures. The efficiency of the resin at $40^{\circ} \mathrm{C}$ and $50^{\circ} \mathrm{C}$ was similar to that at room temperature, though $50 \%$ breakthrough at the higher temperatures occurred after processing 70-80 column volumes of simulant rather than the 100 column volumes recorded earlier at room temperature. Because of the scatter in the data, it is not clear if the apparent lowered capacity of the resin is actually a function of temperature or a manifestation of possible channeling in the resin bed caused by swelling of the resin with temperature increase, or both. Difficulty in maintaining control of the temperature between the feed vessel and the column in the experimental apparatus could also explain some of the scatter in data. Higher temperatures were very difficult to maintain for this simulant, particularly at $67^{\circ} \mathrm{C}$. Crystallization in the lines occurred frequently, presumably at localized cool spots, and interruption of fata from the experiment at $67^{\circ} \mathrm{C}$ are apparatus was frequent at that temperature.
considered to have wide margins of error.

Elution of the columns showed that the run at $50^{\circ} \mathrm{C}$ did not remove as much Cs ${ }^{+}$from the simulant compared to the runs at $40^{\circ} \mathrm{C}$ and $67^{\circ} \mathrm{C}$ (Figure 11). There is no apparent reason for that result since no operating difficulties were encountered in the operation of the $50^{\circ} \mathrm{C}$ run. Total cesium ion on the resin bed was less at $50^{\circ} \mathrm{C}$ and $67^{\circ} \mathrm{C}$ relative to $40^{\circ} \mathrm{C}$. In general, the efficiency of elution appears to be enhanced at the higher temperatures. The total number of column volumes needed to remove most of the Cs-137 was reduced from 20-30 column volumes of $0.5 \mathrm{M} \mathrm{HNO} 3$ at $25^{\circ} \mathrm{C}$ to about 12 column volumes at $40^{\circ} \mathrm{C}$. Elution data are found in Table 10 and are shown graphically in Figures 11-13. 
S.D. FINK

February 1, 1994

WSRC-RP-94-146

Revision 0

Page 18 of 31

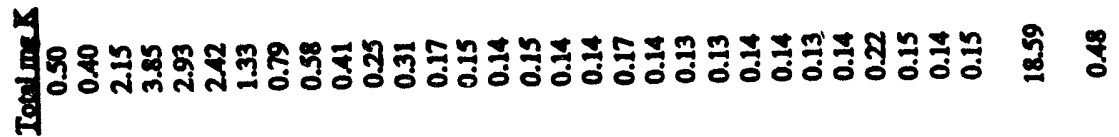

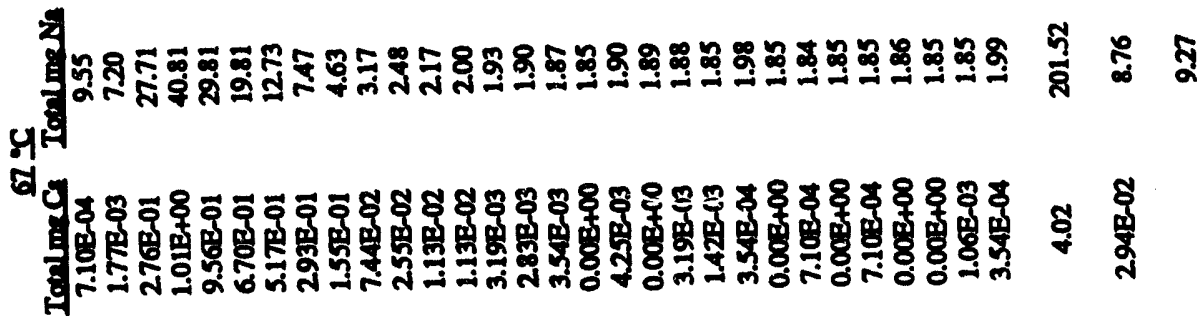

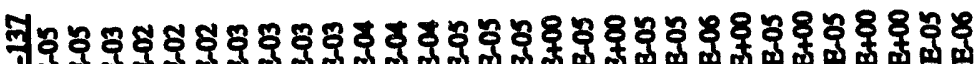
존

ได้

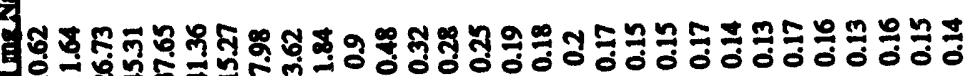
पyํำ

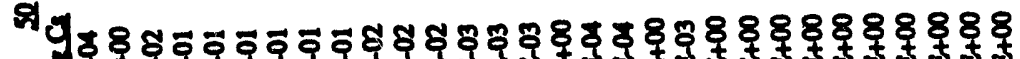

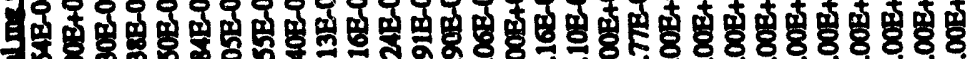

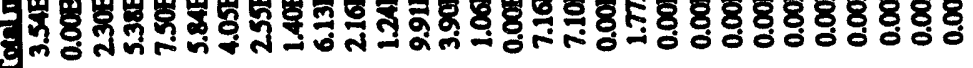

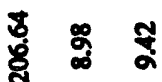

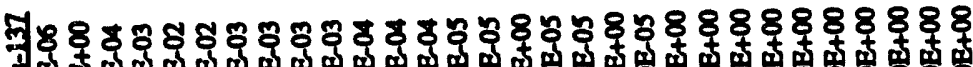

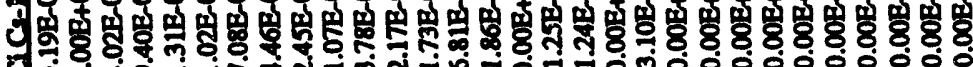

ส

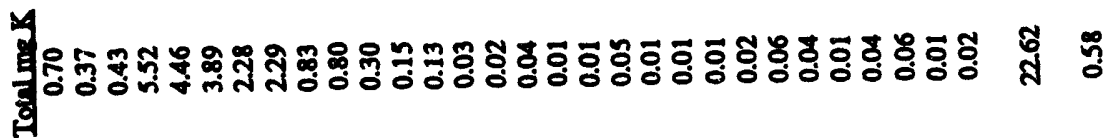

3 प्रें

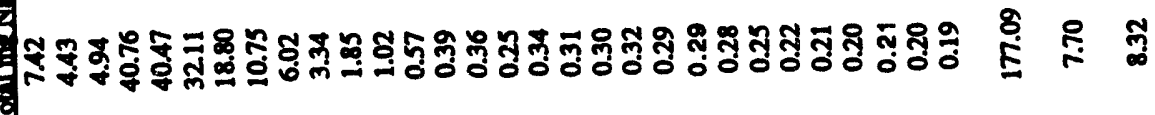

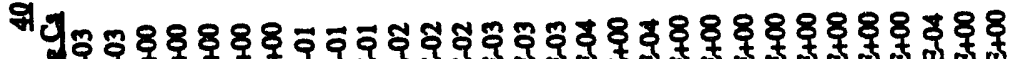

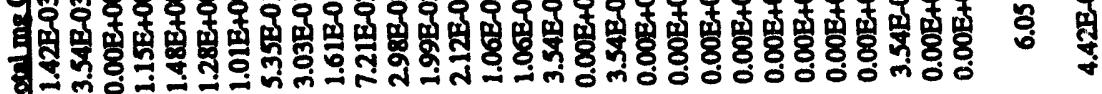

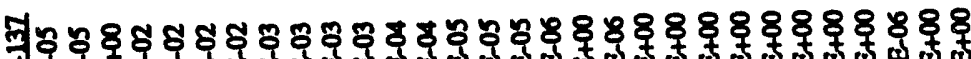

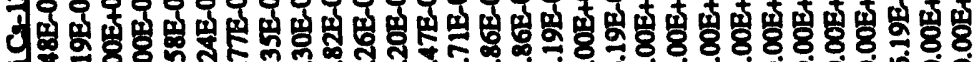

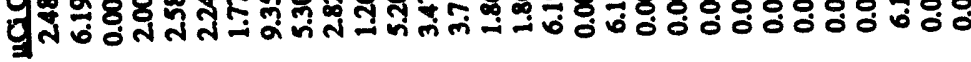

尊 
S.D. FINK

February 1, 1994
WSRC-RP-94-146

Revision 0

Page 19 of 31

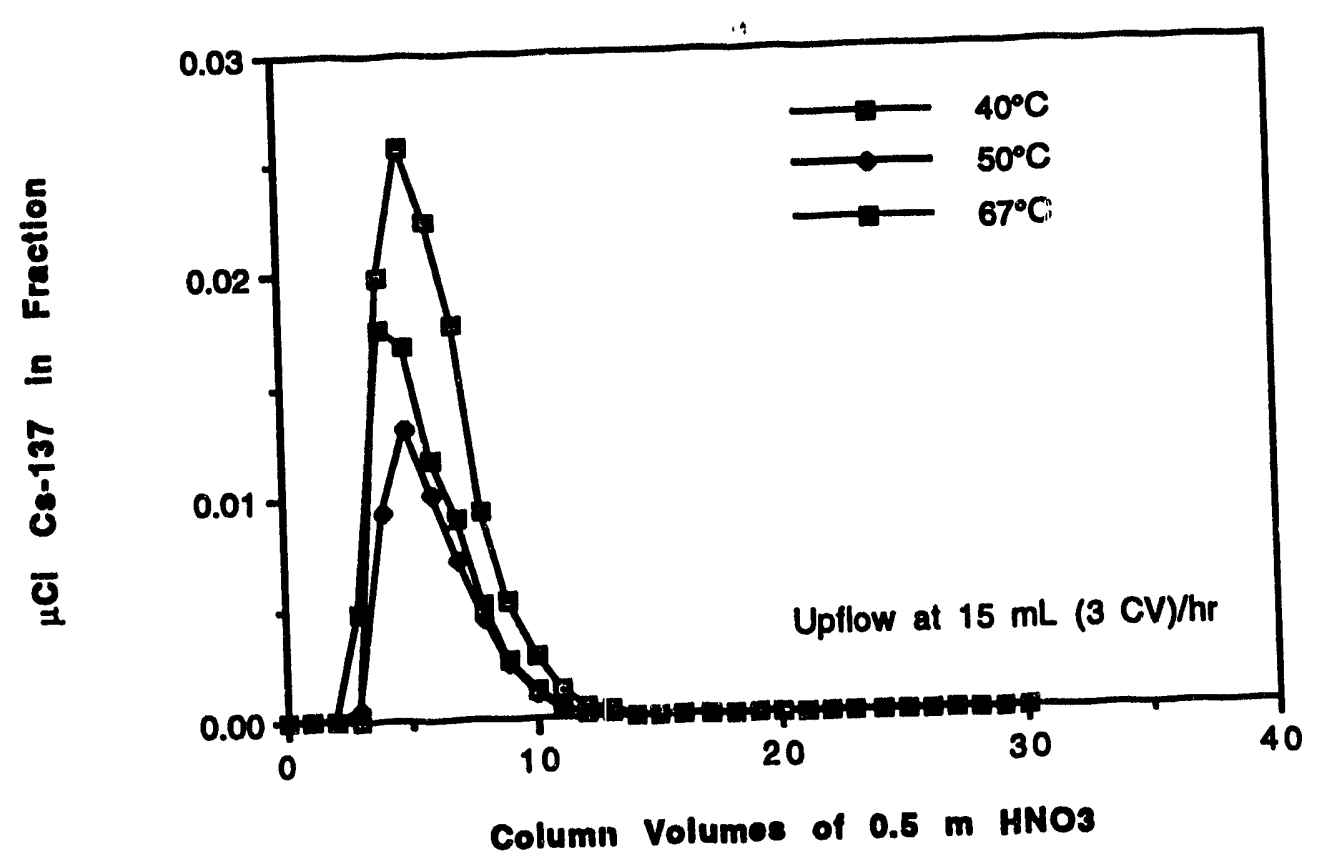

Figure 11. Cs-137 Elution Curves at Three Elevated Temperatures

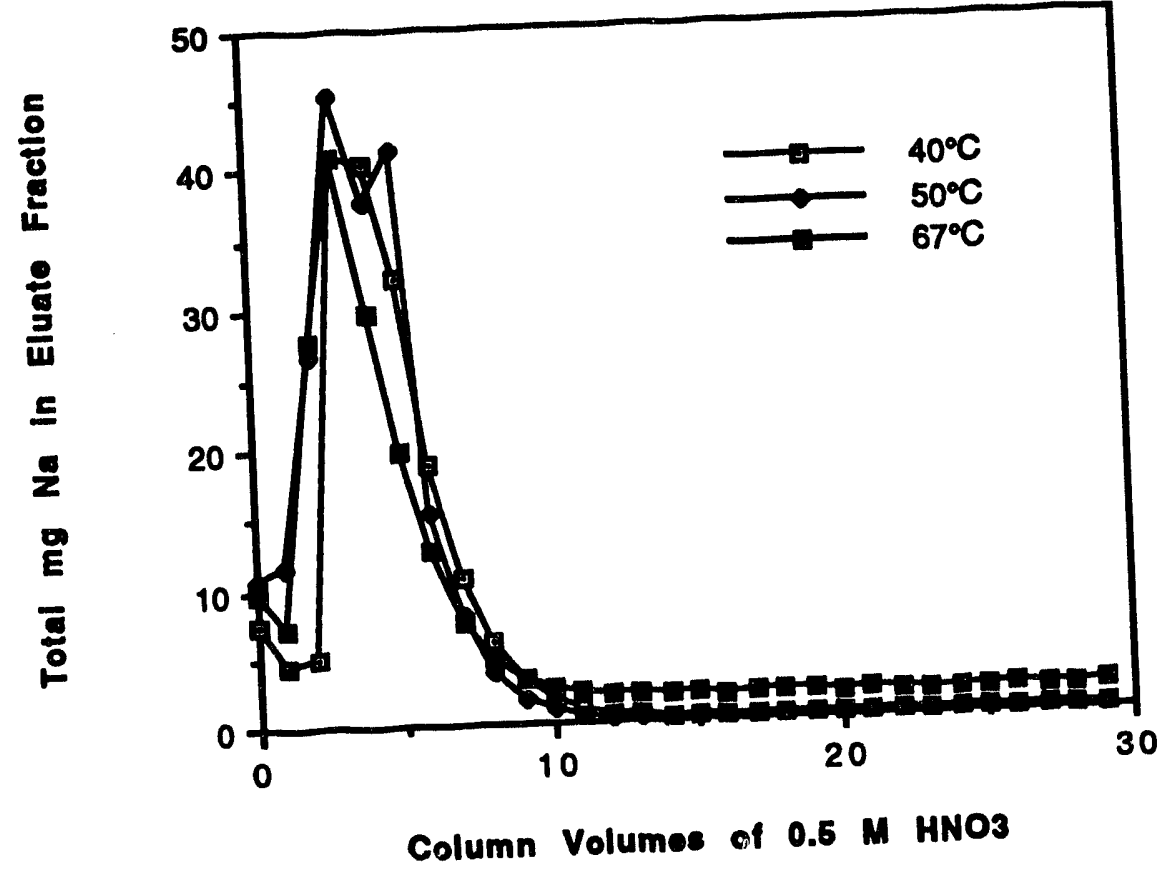

Figure 12. $\mathrm{Na}+$ Elution Curves at Three Elevated Temperatures 
S.D. FINK

February 1, 1994

WSRC-RP-94-146

Revision 0

Page 20 of 31

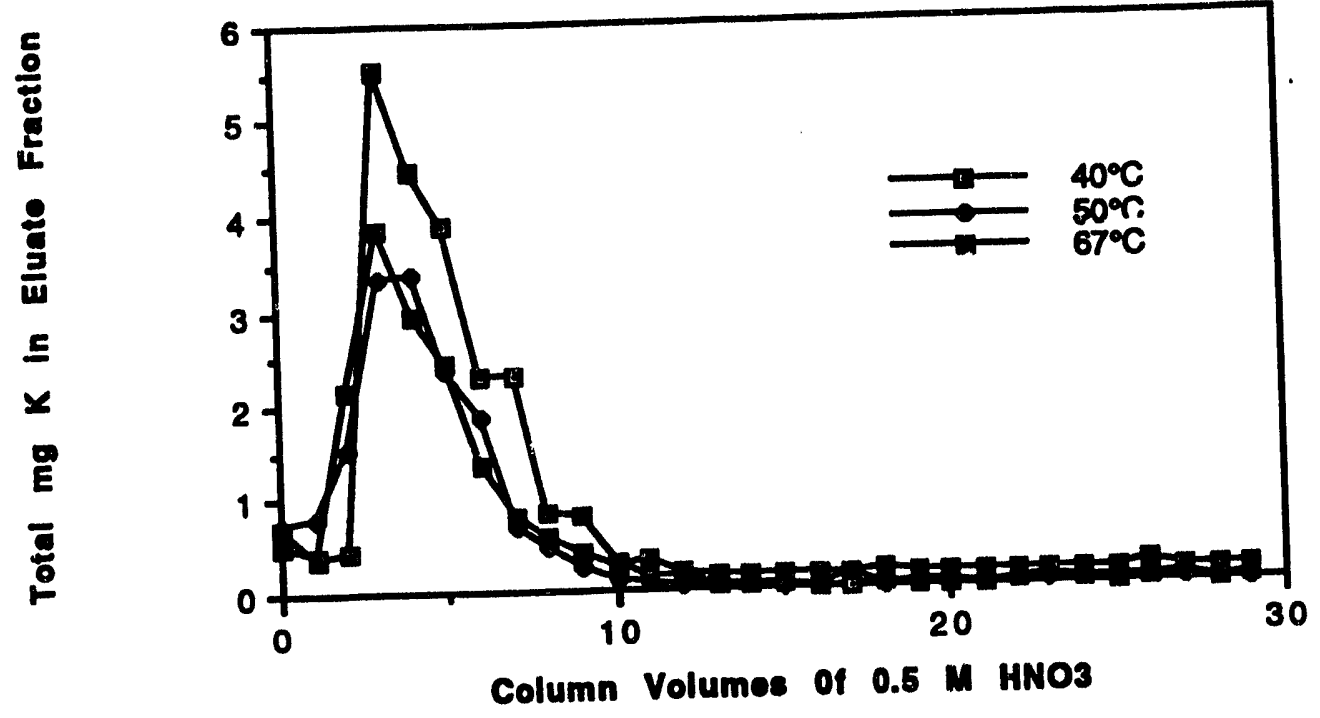

Figure 13. $\mathrm{K}^{+}$Elution Curves at Three Elevated Temperatures

In summary, loading of the resin appeared to be slightly lowered with increasing temperature. At $40^{\circ} \mathrm{C}, 2.68 \mathrm{E}-2$ mmoles of $\mathrm{Cs}^{+}$were sorbed per gram of resin in the column whereas $3.21 \mathrm{E}-2$ mmoles of Cs ${ }^{+}$were sorbed per gram of resin at $25^{\circ} \mathrm{C}$. The efficiency of elution, however, was increased as the temperature was increased from $25^{\circ} \mathrm{C}$ to $40^{\circ} \mathrm{C}$. Above $40^{\circ} \mathrm{C}$, elution efficiency was not affected by further increases in temperature to $67^{\circ} \mathrm{C}$. More carefully controlled temperature experiments on larger columns should be conducted to confirm this preliminary data since these experiments have not definitively separated effects of temperature completely from possible effects due to the disruption of the integrity of the resin bed at the higher temperatures.

\subsection{RESIN QUALITY STUDIES}

Shortiy after these studies were initiated, it became apparent to all researchers working with the resorcinol-formaldehyde resin that the resin was not as effective in 1993 as it had been when purchased in 1988. Samples were taken from drums that had been delivered to SRS in 1988 and stored at the TNX facility. The resin samples were taken at random from Drums 1171, 1995, 1931, and 1932. Resin from those drums had been tested in 1988 by performing Kd equilibrium experiments on them with a series of solutions. Data available for the previously recorded Kd values ${ }^{2}$ was compared with Kd's for solutions of the same composition. Resin from all four drums exhibited lower Kd's in 1993, though the decrease in performance was not uniform.

\subsection{Kd Studies on Stored Resin}

Resin grab samples were soaked in $2 \mathrm{M} \mathrm{NaOH}$ to convert the resin to the sodium form. The resin was then washed with deionized water and air-dried. Approximately $0.100 \mathrm{~g}$ samples of the air-dried resin were shaken overnight with $15 \mathrm{~mL}$ of a solution comprised of 4.5 moles per liter $\mathrm{NaNO}_{3}, 1.5$ moles per liter $\mathrm{NaOH}, 2.5 \mathrm{E}-4$ moles per liter $\mathrm{CsNO}_{3}$, and trace amounts of Cs-137. The untreated solution and the solution remaining at equilibrium with the resin after shaking were analyzed for Cs-137 content by gamma counting. Distribution constants, Kd's, were calculated from the following equation. 
S.D. FINK

February 1, 1994

WSRC-RP-94-146

Revision 0

Page 21 of 31

$$
\mathrm{Kd}=[(\mathrm{Co} / \mathrm{C})-1] \mathrm{V} / \mathrm{g}
$$

where: $\mathrm{Co}$ is the Cs-137 concentration in the untreated simulant

C is the Cs-137 concentration in the simulant at equilibrium

$\mathrm{V}$ is the volume of simulant used in the test $(15 \mathrm{~mL})$

$\mathrm{g}$ is the number of grams of air-dried resin used $(0.100 \mathrm{~g})$

Results of this study are shown in Figure 14.

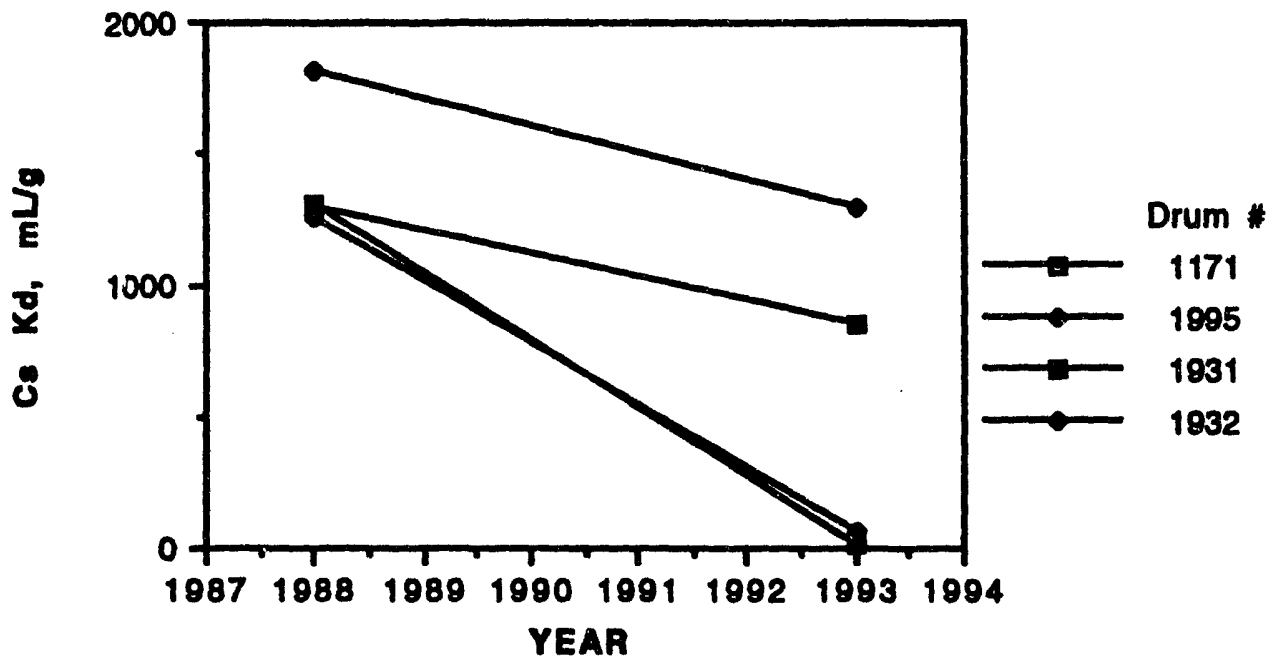

Figure 14. Loss in Cs Kd with Time in Drum

The resin had degraded since its purchase in 1988 but not at the same rate in each drum.

\subsection{Tests to Determine Possible Cause of Resin Degradation}

Two sets of tests were quickly performed to try to determine the cause of resin degradation on storage. They consisted of performing a series of successive freeze-thaw cycles on the resin and subjecting the resin to a steady air flow that might cause oxidation of the resin.

\subsubsection{Freezing the Resin}

Samples of resin taken from Drums 1171, 1995, 1931, and 1932 were converted to the $\mathrm{Na}$-form using $2 \mathrm{M} \mathrm{NaOH}$. The $\mathrm{Cs} \mathrm{Kd}$ was determined for each sample using the solution described in Section 5.0. The resin was then placed in a freezer for three days. After that time it was removed, allowed to warm to room temperature, and used for Kd determinations. The resin was frozen and thawed three times. It was suspected that freezing the resin, which had been stored outdoors for five years, might lead to its degradation. However, as Figure 15 shows, exposure to temperature extremes had little effect on the resin. 
S.D. FINK

February 1, 1994

WSRC-RP-94-146

Revision 0

Page 22 of 31

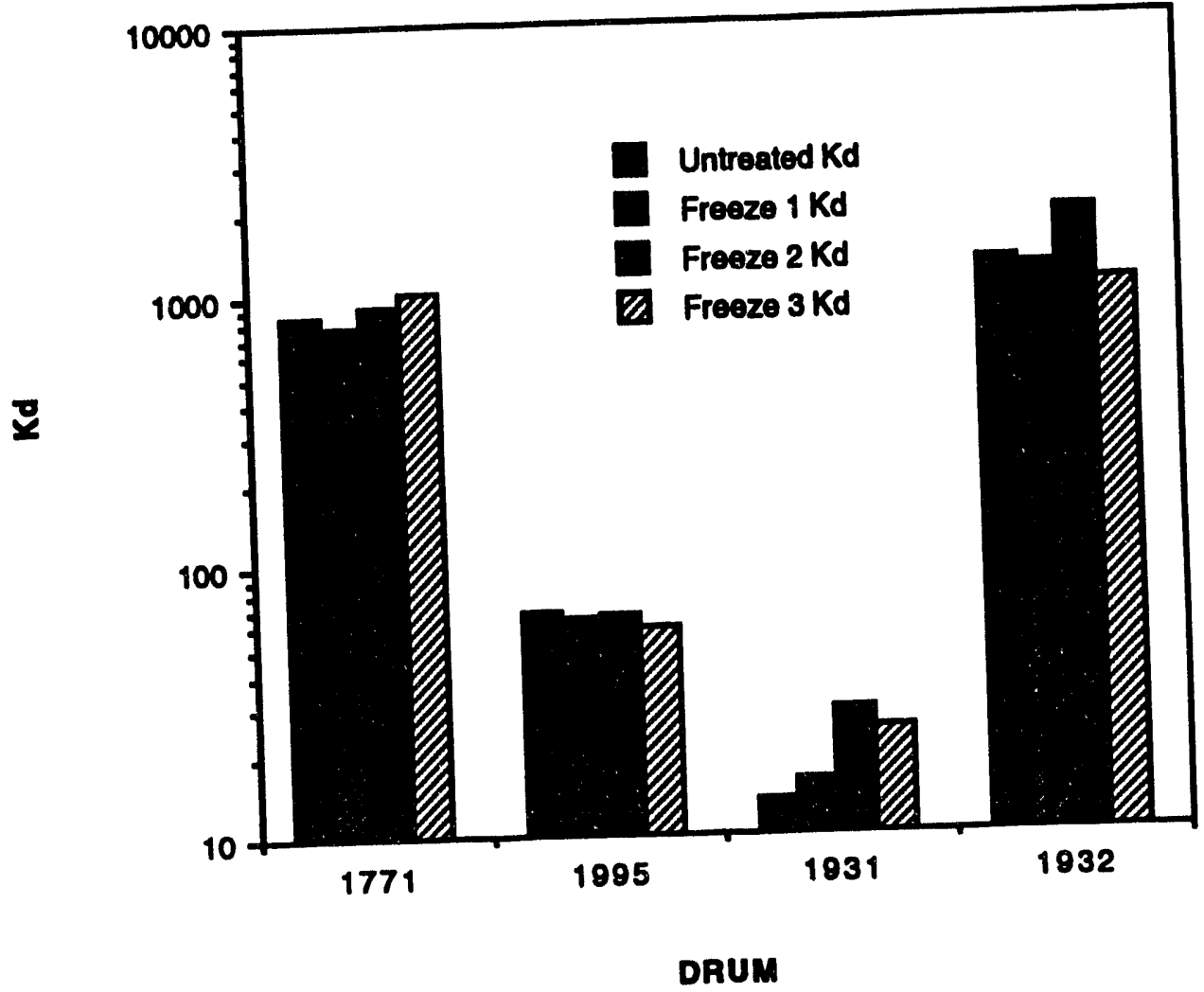

Figure 15. Effect of Freexing on Kd

\subsubsection{Exposure of Resin to Excess Air Flow}

A sample of the Na-form of the resin taken from Drum 1995 was placed in a Buchner funnel containing a coarse glass frit. Compressed air at 90 psig was forced upflow through the frit and resin for 7 days. At the end of that time, samples of the resin were used for $\mathrm{Kd}$ experiments with solutions of the following compositions.

1. $4.5 \mathrm{M} \mathrm{NaNO} 3$; $1.5 \mathrm{M} \mathrm{NaOH}$; trace Cs-137

2. $4.5 \mathrm{M} \mathrm{NaNO} 3$; $1.5 \mathrm{M} \mathrm{NaOH}$; $2.5 \mathrm{E}-4 \mathrm{M} \mathrm{CsNO}$; trace Cs-137

3. $4.5 \mathrm{M} \mathrm{NaNO} 3 ; 1.5 \mathrm{M} \mathrm{NaOH} ; 2.5 \mathrm{E}-3 \mathrm{M}$ CsNO3; trace Cs-137

4. SRS simulated supernate (2.5 E-3 $\mathrm{M} \mathrm{CsNO}$ ) 
S.D. FINK

February 1, 1994
WSRC-RP-94-146

Revision 0

Page 23 of 31

Figure 16 shows that the resin had lost some of its capacity or selectivity as a result of exposure to the air flow.

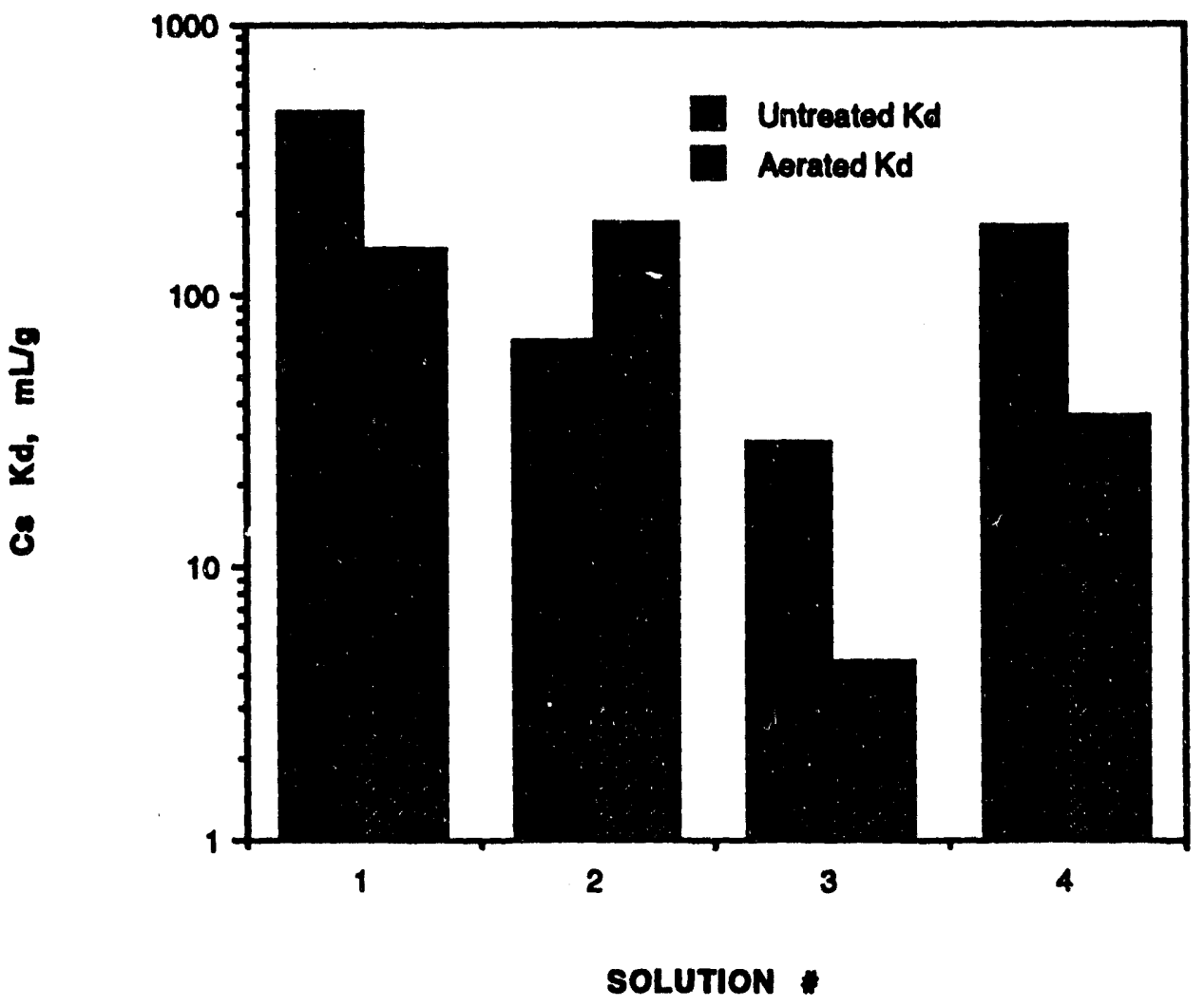

Figure 16. Cs Kd's Before and After One-Week Air Flush

This data was shared with researchers from Hanford, Battelle's Pacific Northwest Laboratory, and Oak Ridge National Laboratory. It was determined that a research effort should be mounted to determine the cause of the resin degradation and its prevention during storage. A contract was established with Clark Atlanta University of Atlanta, Georgia through the SRS Energy Research and Development Agreement (ERDA) consortium with Georgia universities. The scope of work for that contract is found in Attachment 2. In essence, Clark Atlanta University researchers will subject samples of the resorcinol-formaldehyde resin to air, ozone, nitrogen, and carbon dioxide atmospheres. They will characterize the resin before and after treatment using proton, C13, and Cs-133 NMR (nuclear magnetic resonance) spectrometry, FTIR (Fourier transfer infrared) spectrophotometry, and ESR (electron spin resonance) techniques. That effort is funded by the Office of Technology Development through SR1-02-20-01. 
S.D. FINK

February 1, 1994
WSRC-RP-94-146

Revision 0

Page 24 of 31

\subsubsection{Procurement of New Resin from Boulder Scientific Co.}

A new supply of resin was needed for use throughout the DOE Complex. Funding was supplied by the Office of Technology Development through SR1-02-20-01 for the purchase of 63 cubic feet of the K-form of the resin. The only company to bid on the contract was Boulder Scientific Co. Terms of the procurement required Boulder to provide resin of mesh size -20 to $+50(850 \mu \mathrm{m}-300 \mu \mathrm{m})$ with no more than 10 weight $\%$ of the particles less than $200 \mu \mathrm{m}$ in diameter. This resin particle size was selected for use in the full-scale SKid-mounted Ion exchange Demonstration (SKID) unit which has 250 $\mu \mathrm{m}$ screens. Also, the resin was to be tested by SRS researchers who would perform Kd experiments with grab samples of the resin. The resin was required to produce Cs Kd's of 2,000 or greater with simulated SRS supernate. Grab samples were taken from drums of the manufactured resin at the vendor's Meade, Colorado, site by a representative of the Savannah River Technology Center (SRTC). Those samples were subjected to the Kd tests and particle size analysis at SRTC. Particle size determination was performed using a Brinkman Model 1400 particle size analyzer and scanning electron microscopy (SEM). Resin samples were also sieved by hand using ASTM (American Society of Testing Materials) standard sieves. Particles smaller than the 50 mesh screen were collected and weighed. The SRS simulant used in the Kd studies contained 4.5 M NaNO3, 1.5 M $\mathrm{NaOH}, 2.5 \mathrm{E}-4 \mathrm{M}$ CsNO 3 , lesser amounts of $\mathrm{NaNO}_{2}, \mathrm{Na}_{2} \mathrm{CO}_{3}$, and $\mathrm{Na}_{2} \mathrm{SO}_{4}$, and trace amounts of Cs-137.

In all, eleven drums were sampled. Resin in all drums met the requirements of the contract except that in Drum 1. That resin was not accepted by SRS. The results of particle size and $\mathrm{Kd}$ tests are given in Table 11.

Table 11. Acceptance Tests on Boulder Scientific Co. Resin

Drum\#\# कof Particles $<2504 \mathrm{~m} \quad$ Cs Kd with SRS Simulated Supemate

$\begin{array}{lll}1 & 12 & 1.86 \mathrm{E}+4 \\ 2 & 5.8 & 2.02 \mathrm{E}+4 \\ 3 & 8.3 & 2.66 \mathrm{E}+3 \\ 4 & 5.6 & 3.95 \mathrm{E}+3 \\ 5 & 10 & 2.00 \mathrm{E}+4 \\ 6 & 8.1 & 2.06 \mathrm{E}+3 \\ 7 & 5.9 & 2.39 \mathrm{E}+3 \\ 8 & 6.3 & 1.01 \mathrm{E}+4 \\ 9 & 6.1 & 2.39 \mathrm{E}+3 \\ 10 & 8.3 & 2.00 \mathrm{E}+3 \\ 11 & 8.9 & 1.98 \mathrm{E}+4\end{array}$

\subsubsection{Thermal Analysis of Resorcinol-Formaldehyde Resin}

Thermogravimetric analysis (TGA) and differential scanning calorimetry (DSC) were performed on the $\mathrm{K}$ - and $\mathrm{H}$-form of the resorcinol-formaldehyde resin. Results are shown in Figures 17-22. The K-form represented the form of the resin in use during feed cycles; the H-form represented the form of the resin after elution with $\mathrm{HNO}_{3}$. 
S.D. FINK

February 1, 1994
WSRC-RP-94-146

Revision 0

Page 25 of 31

The TGA analyses showed a gradual weight loss by each form of the resin over the temperature range studied. The $\mathrm{K}$-form lost only $40 \%$ of its original weight at $700^{\circ} \mathrm{C}$. It was reduced to $\mathrm{K}_{2} \mathrm{O}$ on the TGA pan. The $\mathrm{H}$-form displayed complete weight loss at $650^{\circ} \mathrm{C}$ due to oxidation to $\mathrm{CO}_{2}$ and $\mathrm{H}_{2} \mathrm{O}$.

DSC analyses showed endotherms for both forms between $100^{\circ} \mathrm{C}$ and $110^{\circ} \mathrm{C}$, indicating a loss of water, followed by a slow exotherm as the resin burned. There was no evidence for any large exotherms or formation of potentially explosive (i.e., nitrated) products as a result of contact with the chemicals associated with an ion exchange process. It should be noted, however, that this thermal analysis data is for $10 \mathrm{mg}$ samples. Extrapolation to predict the behavior of large quantities of the resin should be made with care. Obviously, large masses of the resin will have different heat transfer characteristics that must be considered.

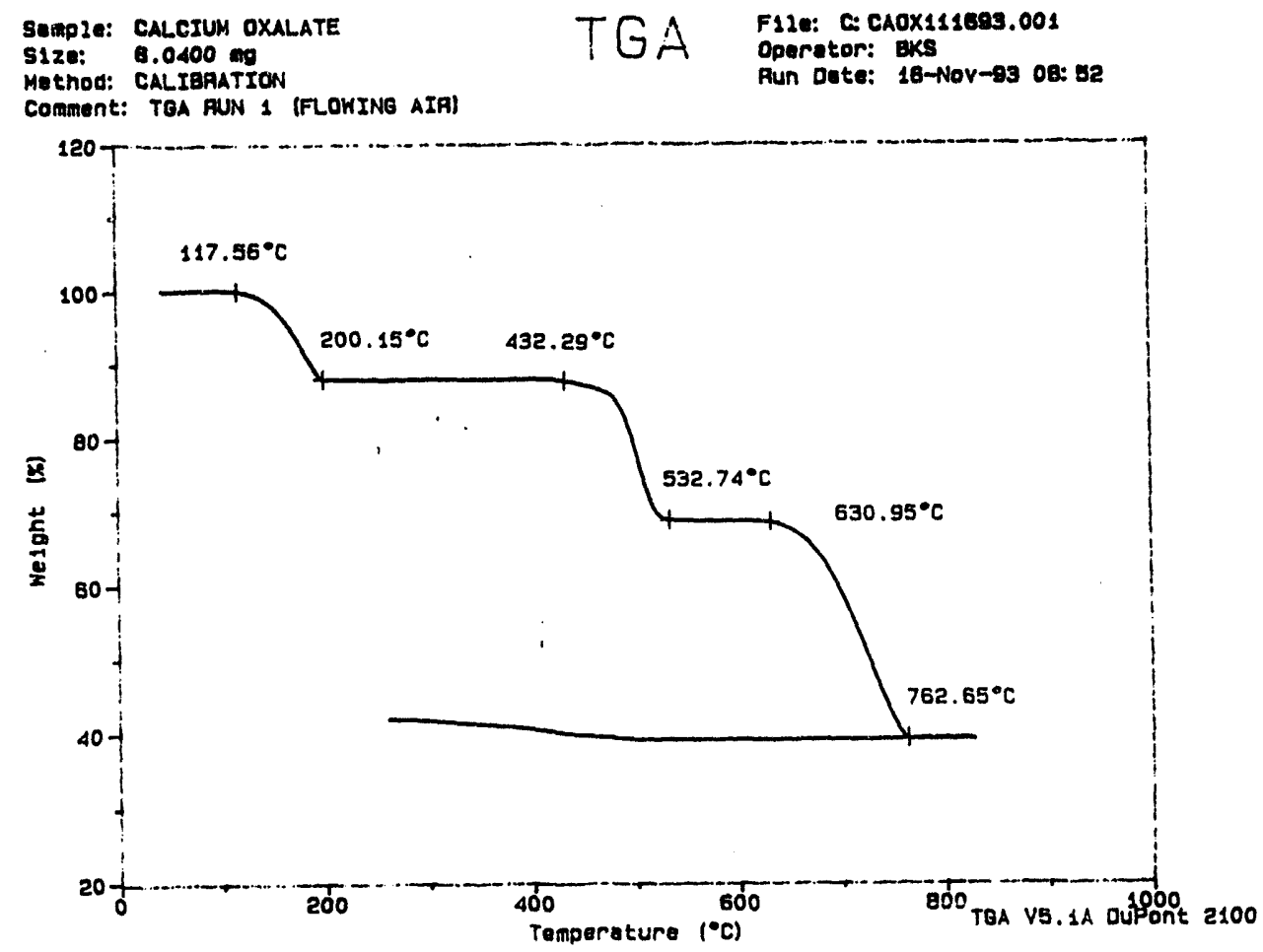

Figure 17. TGA Calibration Curve for Calcium Oxalate 
S.D. FINK

February 1, 1994
WSRC-RP-94-146

Revision 0

Page 26 of 31

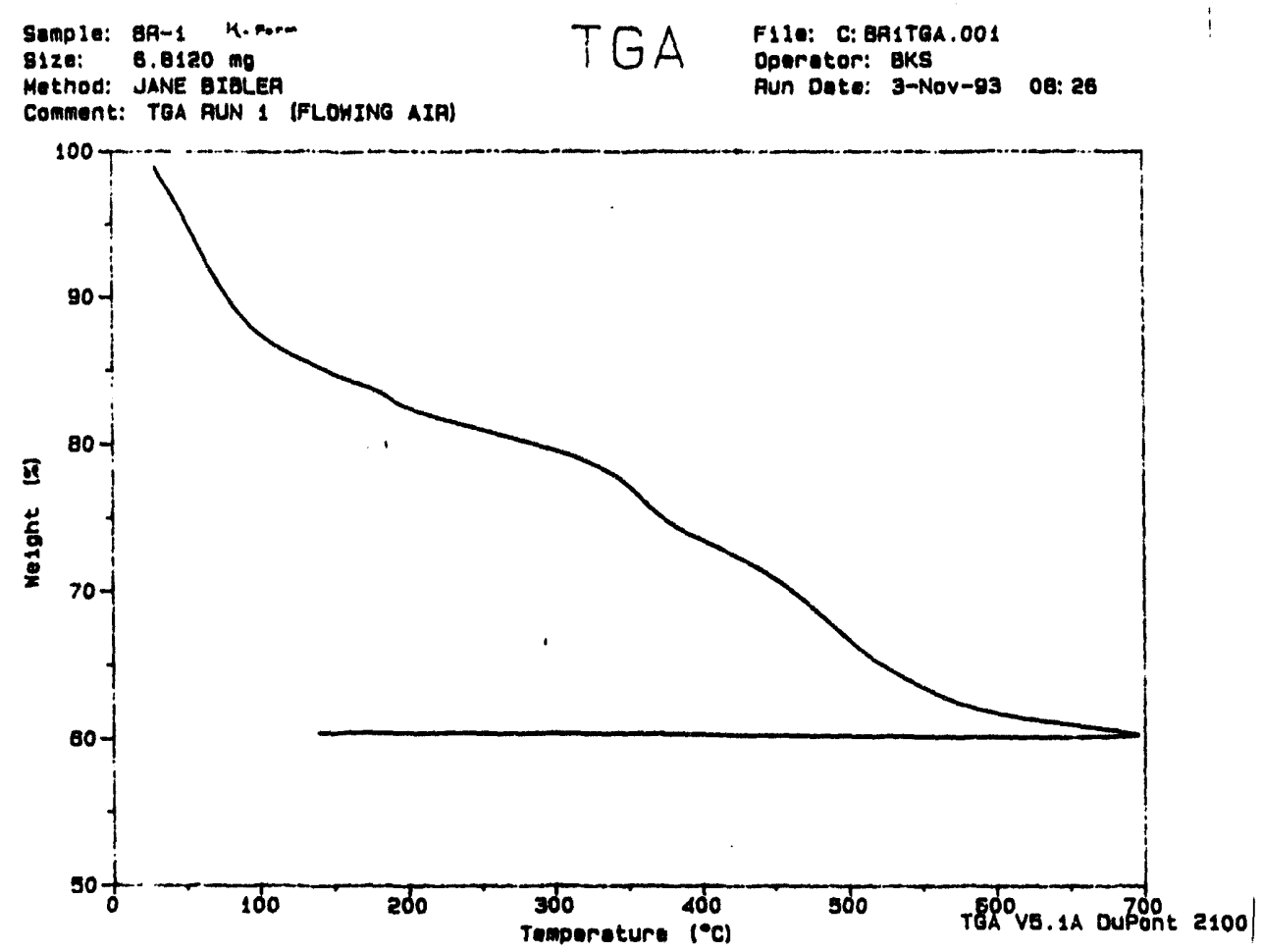

Figure 18. TGA for K-form of Resorcinol-Formaldehyde Resin

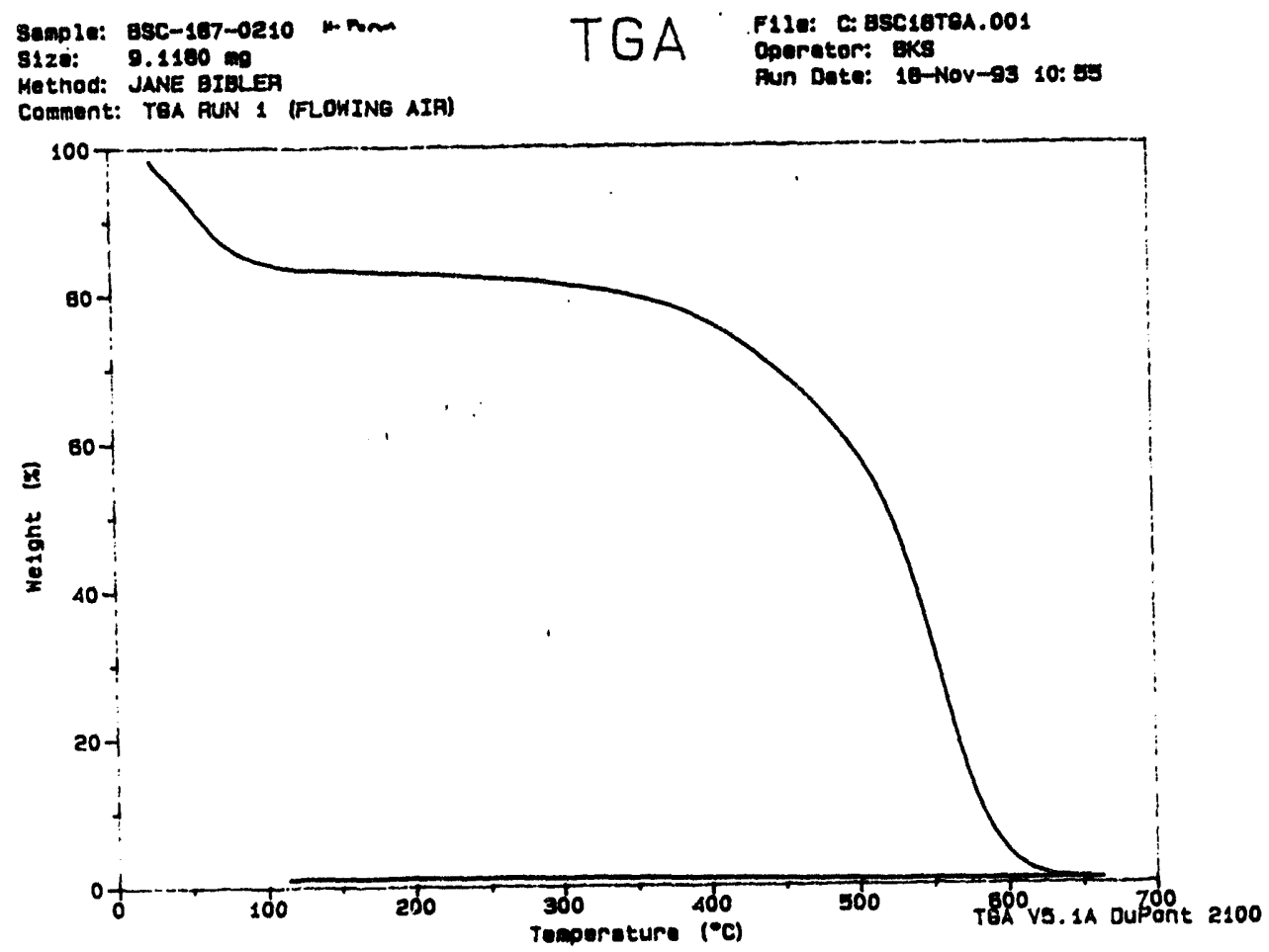

Figure 19. TGA for H-form of Resorcinol-Formaldehyde Resin 
S.D. FINK

February 1, 1994
WSRC-RP-94-146

Revision 0

Page 27 of 31

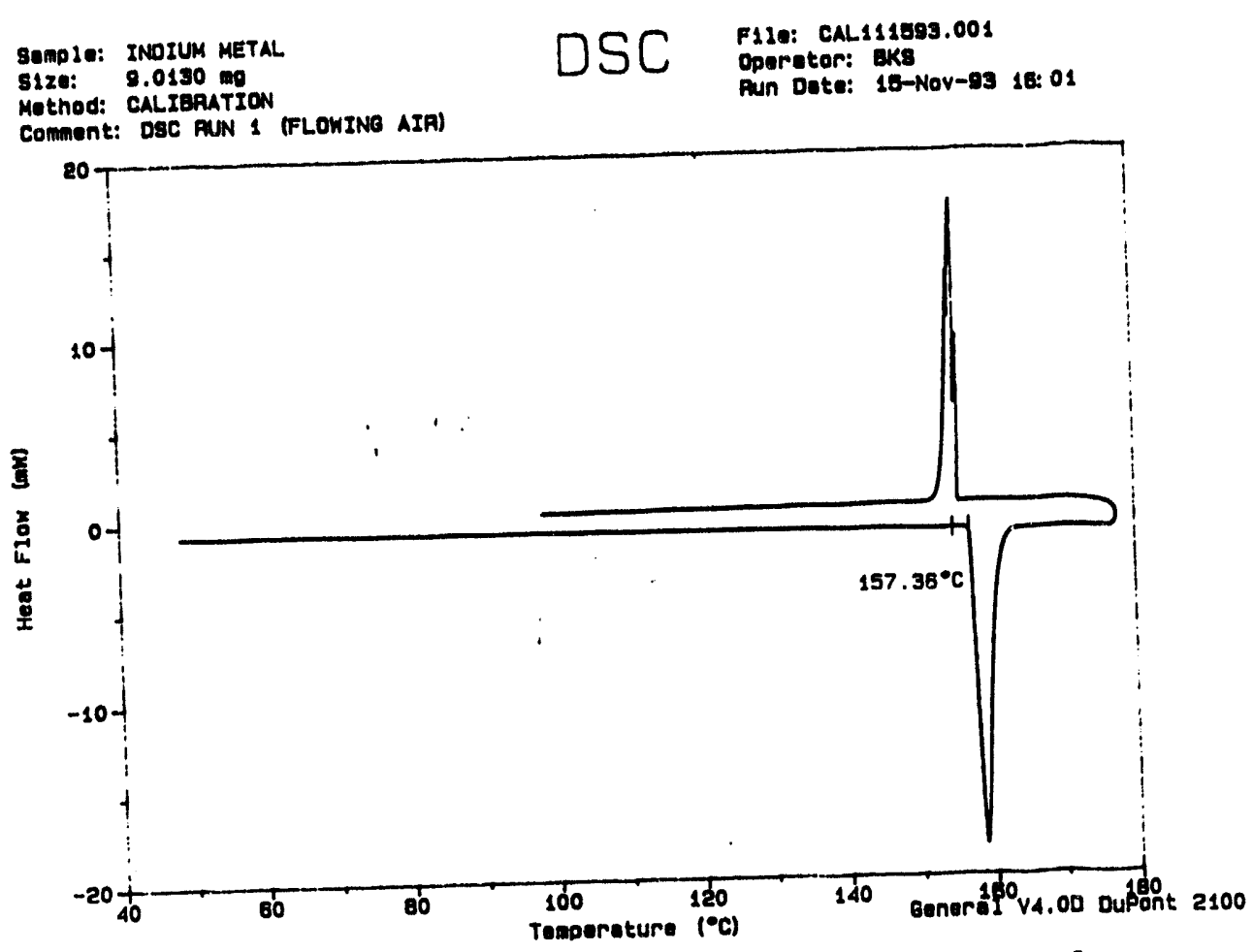

Figure 20. DSC Calibration Curve for Indium Metal

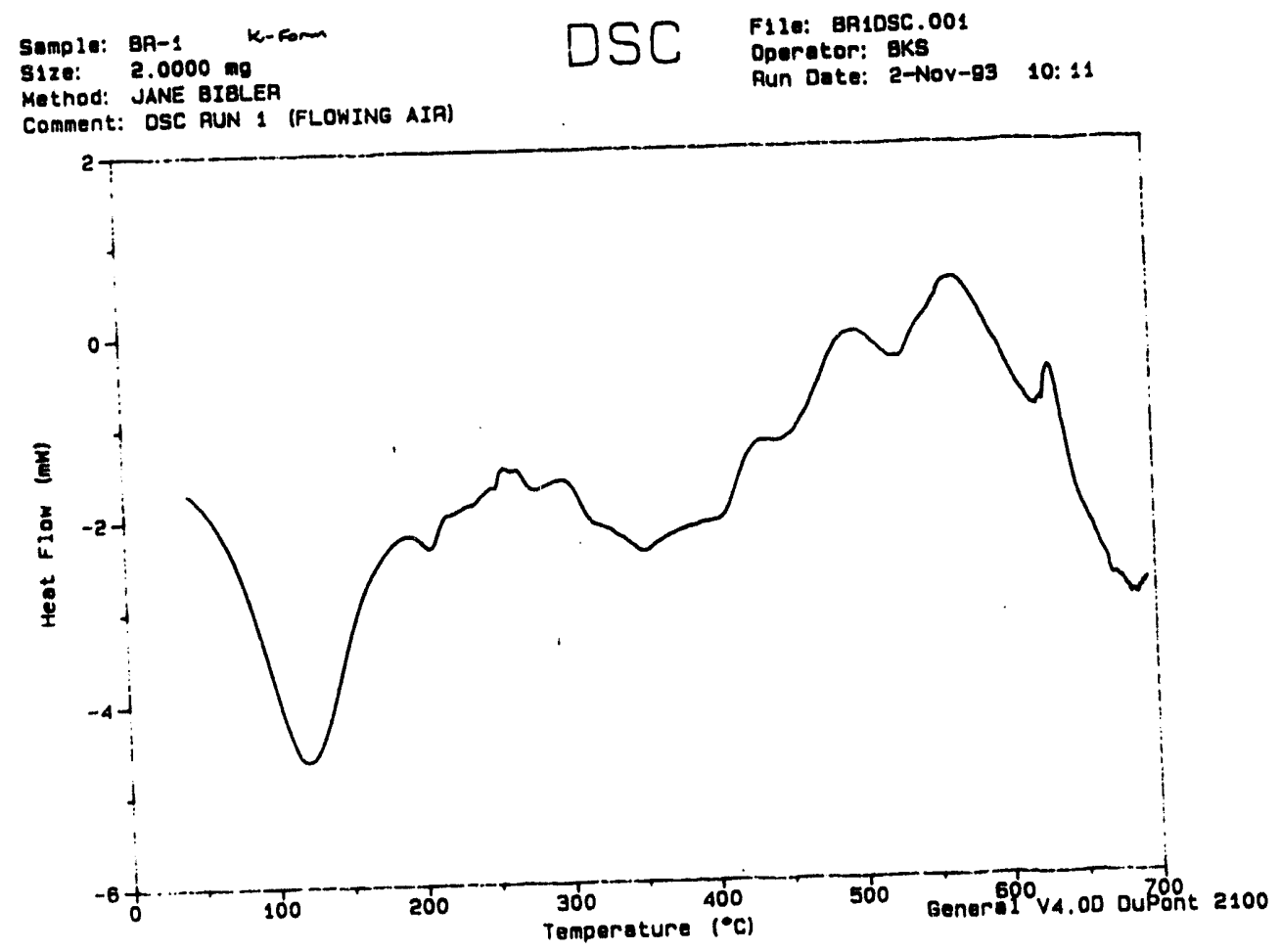

Figure 21. DSC for K-form of Resorcinol-Formaldehyde Resin 
S.D. FINK

February 1, 1994
WSRC-RP-94-146

Revision 0

Page 28 of 31

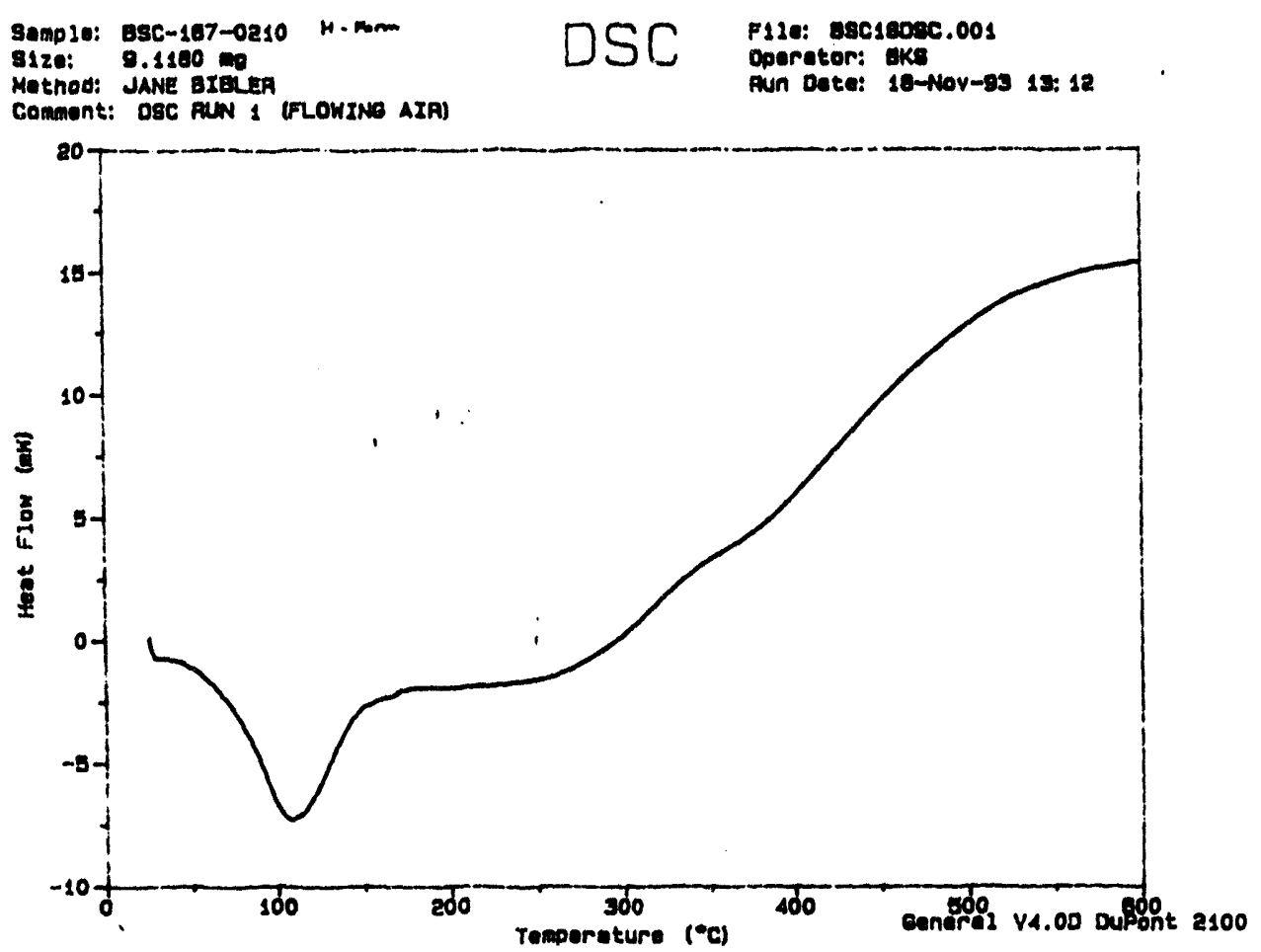

Figure 22. TGA for H-form of Resorcinol-Formaldehyde Resin

\subsection{RADIOLYSIS STUDIES}

The radiolytic stability of the resorcinol-formaldehyde resin has been studied by N.E. Bibler and C.L. Crawford up to doses of $1 \mathrm{E}+9$ rad. Their work has been reported separately and has been included in Attachment 3 .

\subsection{QUALITY ASSURANCE}

All solutions were prepared with reagent grade chemicals. Analyses were performed by the SRTC Analytical Development Section using blanks and standards that can be traced to NIST (National Institute of Standards Testing). Data for this work is recorded in laboratory notebooks WSRC-NB-90-188 and WSRC-NB-90-346. The performance of the particle size analyzer was checked periodically against NASA (National Aeronautics and Space Administration) standard $10 \mu \mathrm{m}$ polystyrene balls made in space on the space
shuttle.

\subsection{REFERENCES}

1. Kilpatrick, L.L. , Laboratory Notebook E37339, p 123.

2. Bibler, J.P., Laboratory Notebook DPSTN4268, p 155. 
S.D. FINK

January 31, 1994
WSRC-RP-94-146

Revision 0

Page 29 of 31

\section{ATTACHMENT 1}

\section{Procedure IWT-OP-067}

"Measuring the Viscosity of Transparent Liquids"

(9 pages) 


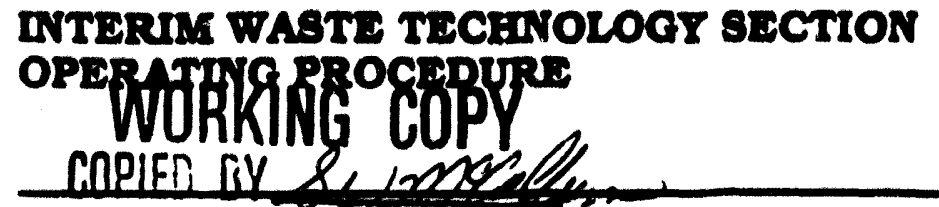

COPY DATE $4-1-93$

EXP. DATE $s^{\prime}-1-93$

Approved by:

\section{MEAsURANG TH: VIecosity OF TRANSPARENT LIQU⿴囗十⿱一口)}

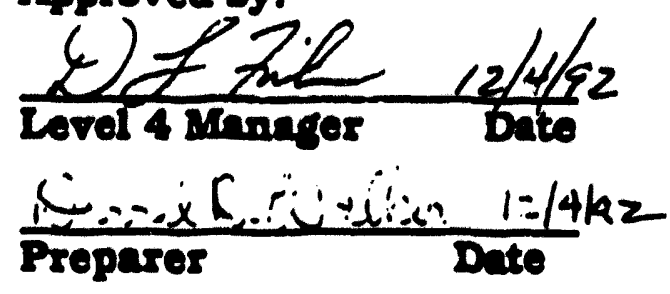

\subsection{PURPOEE}

The purpose of this procedure is to measure the linematle viscostty of transparent llquids using a Cannon-Fenske Routine Viscometer. In addition. this procedure includes a method to measure the density of the same solutions so that the dynamic viscosity can be calculated.

\subsection{SCOPE}

This procedure cain be used to determine the viscoalty of transparent Newtonian solutions with kinematic viscosities in the range 0.5 to 20.000 cSt. The equipment required is: (1) a Cannon-Fenske routine viscometer, (2) thermometer. (3) stopwatch. (4) constant temperature water bath, and (3) high purity water or other calibration standard. The viscosity can be measured at temperatures between room temperature and $70^{\circ} \mathrm{C}$ to an accuracy of $\pm 5 \%$. The procedure is based on ASTM Method D445 and D446. However, this procedure deviates from these methods with a consequent decrease in the accuracy and precision of the measurements.

\subsection{TERMS AND DEFUITTONS}

3.1 Kinematic viscosity - a measure of the resistive flow of a luid under gravity, the pressure head being proportional to the density of the fluld. The cgs unit of kdnematic viscosity is one centimeter squared per second and is called one stoke (St). One centistoke (cSt) is .01 stoke.

3.2 Density - the mass per unit volume of a fluld. The cgs unit of density is one gram per milliliter.

3.3 Dynamic viscosity (coefficient of) - the ratio between the applied shear stress and rate of shear. this coefflcient is a measure of the fluld's resistance to low and is commonly called the viscosity of the liquid. The cgs unit of dynamic viscosity is one gram per centimeter per second (or one dyne-second per centimeter squared) and is called one poise (P). One centipoise (CP) is .01 polse. 


\subsection{RESPONSIBILITEES}

It is the responsibility of the user to determine frequency for remeasuring the viscometer constant. The user may devtate from this procedure but these changes must be recorded in a laboratory notebook. If changes are made. the precision and accuracy stated above may not be valld.

\subsection{REgULRED EgUTPMENT}

The equipment required for this procedure is:

(1)

Cannon-Fenske routine viscometer

These are commercially avallable from scientinc equipment supply houses. They may be purchased with a certiled calibration or a callbration may be obtained by following this procedure. Viscometers are stzed for a particular viscosity range and a series of viscometers are needed to cover the range from 0.5 to $20.000 \mathrm{cst}$.

(2) Timing device

Any calibrated stopwatch with an accuracy of \pm 1 sec and precision of 0.1 sec in the range 2 minutes to 20 minutes can be used.

Temperature measuring device

Any callbrated temperature measurting device. such as a mercury thermometer, with an accuracy of $\pm 0.5^{\circ} \mathrm{C}$ and precision of $0.1^{\circ} \mathrm{C}$ can be used.

\section{Controlled temperature bath}

A transparent. controlled temperature bath is required that is large enough to immerse the sample (in the viscometer) such that no portion of the sample is less than $2 \mathrm{~cm}$ from the bottom, walls, or surface of the bath.

\subsection{PROCEDURE}

6.1 Select a viscometer having a range covering the estimated linematic viscosity. The flow time should not be less than 200 seconds. If the flow time is less than 200 seconds, a kinetic energy correction should be made (see Section 8.0). 
6.2 Clean and dry the viscometer between successtve determinations and before storing overnight.

(Note: An acceptable cleaning procedure for use with simulated salt solutions is to: (1) Aush the viscometer three times with $0.1 \mathrm{M}$ nitric acid. (2) Dush three times with distilled water. and (3) rinse with reagent grade acetone. Dry the viscometer for 2 minutes or longer (untu dry) with nitered alr or nitrogen gas. Soap should not be used to clean the viscometer uniess spectal care is taken to remove all soap residues.l

6.3 To charge the Cannon-Fenske routine viscometer, measure the sample into Tube $N$ (see Attachment 1). Use the same volume of sample as was used to calibrate the viscometer ( $1.1 \mathrm{~mL}$ ).

INote: 1. If the sample contains solid particles. fllter through a 200 mesh or finer fliter.

2. Measuring the sample is most easily done by welghing. To determine the weight required. the density of the solution must be measured irst. See Section 9.0 of this procedure.I

6.4 Mount the viscometer upright in the controlled-temperature bath keeping Tube $L$ vertical (see Attachment 1). Inmerse the viscometer to Point A (see Attachment 1).

6.5 Allow the sample to thermally equllibrate in the controlled temperature bath for 20 minutes.

6.6 Record the initial temperature of the water bath near the viscometer to the nearest $0.1^{\circ} \mathrm{C}$ just prior to starting the following steps.

6.7 Draw the solution into Bulb B (see Attachment 1) using a rubber bulb to apply pressure to Tube $L$ or suction to Tube $N$.

6.8 Remove the bulb and measure the time required for the meniscus to pass from Line $C$ to Line $E$. Record the time to the nearest 0.1 sec.

6.9 Record the final temperature of the water bath at the end of the timing period in Step 6.8. If the initial and anal temperature differ by more than $0.2^{\circ} \mathrm{C}$. repeat the measurement.

6.10 Repeat Steps 6.6 through 6.9 untul three acceptable measurements are made within a temperature range of $0.2^{\circ} \mathrm{C}$. Acceptable measurements of the time must agree within $0.4 \%$. Determine the average of the three emux times and use the average to calculate the kinematic viscosity.

NOTE: If the three measurements do not agree within $0.4 \%$, it is recommended that the viscometer be emptied and cleaned before repeating the measurement. 
6.11 Remove the viscometer from the bath and visually examine the capllary tube. If any dust particles or other solids are vistble, clear and refil the viscometer and repeat the ineasurement.

6.12 To calculate the kinematic viscosity (ln cSt). multiply the average eqlux time (seconds) by the viscoineter constant (see Section 7.0). The viscometer constant for the same temperature as the viscosity measurement must be used.

6.13 To calculate dynamic visicosity (in CP), multiply the kinematic viscostty (cSt) by the density of the sample $(\mathrm{g} / \mathrm{mL})$ at the same temperature as the viscosity measurement.

\subsection{MEASUREMENT OF VISCOMETER CONSTANT}

7.1 The viscometer constant should be remeasured at a frequency determined by the user.

7.2 The viscometer constant is determined by measuring the emux time for distilled water or other suitable standard at the temperature of interest using the procedure given above.

7.3 Calculate the viscometer constant from the following formula:

$k=n / t$

where $k=$ viscometer constant at the temperature of the measurement.

$t=$ efllux time (seconds)

$n=$ viscosity of standard (cSt) at the temperature of the measurement (see Attachment 2 for the linematic viscosity of water). Values for the viscosity at temperatures intermediate between table entries can be obtained by linear interpolation.

\subsection{KINETIC ENERGT CORRECTION TO VISCOMTETER CONSTANT OR VISCOSITY MEASUREMENT}

8.1 For viscometers whose callbration constants are $0.05 \mathrm{cSt} / \mathrm{s}$ or less, a lanetic energy correction must be made when the efllux time is less than 200 seconds. This correction is made to the viscometer constant if the enflux time with the callbrating fluld is less than 200 seconds. This correction is made to the kinematic viscosity of an unknown when the efllux time is less than 200 seconds. 
8.2 The equation for correcting the viscometer constant or kinematic viscosity is:

$$
\begin{aligned}
& n=\alpha \cdot \frac{1.6 \sigma y^{3 / 2}}{u \operatorname{col} 1 / 2 t^{2}} \\
& \text { where } \mathbf{n}=\text { kinematic viscosity (cSt). } \\
& V=\text { volume of the timing bulb }\left(\mathrm{cm}^{3}\right), r \\
& L=\text { capllary workding length }(\mathrm{cm}) . \\
& d=\text { caplllary workdng diameter }(\mathrm{cm}), v \\
& t=\text { eflux time (sec). } \\
& C=\text { viscometer constant. }
\end{aligned}
$$

8.3. If during callbration the efflux time is less than 200 seconds, the corrected callbration constant is calculated from Equation 8.1 using the measured efflux time (t). linematic viscosity of the standard (n), and measurements on the viscometer (V, L, and d).

8.4 If during a viscostty measurement on a sample the efllux time is less than 200 seconds, the corrected. kinematic viscosity is calculated from Equation 8.1 using the measured efilux time (t). callbration constant (C), and measurements on the viscometer (V. L, and d).

\subsection{DENSITY MEASUREMENT}

9.1 Obtain a clean, dry volumetric lask (10 mL or larger).

9.2 Weigh the empty volumetric flask (with stopper) to the nearest $0.1 \mathrm{mg}$. Record the weight (weight "A").

9.3 Fill the volumetric flask to slightly below the line with the sample.

9.4 Place the flask into the controlled temperature bath at the same temperature as that used for the viscosity measurement. Allow the flask to reach thermal equllibrium (20 minutes).

9.5 Finish flling the flask to the line with the sample at the temperature of the measurement. Stopper the lask.

9.6 Dry the outside of the flask and allow it to cool to room temperature.

9.7 Weigh the flled lask at room temperature and record the weight (weight "B"). 
9.8 Calculate the density of the sample solution from the following equation:

$$
D=\frac{(B-A)}{V}
$$

where: $A$ and $B$ are the weights described above measured in grams, and $v=$ volume of the volumetric lask (mL) at the temperature of the measurement.

\subsection{RECORDS}

A record of each measurement of viscosity and viscometer constant will be kept in an ofnctal laboratory notebook.

\subsection{REETRENCES}

11.1 ASTM Method D445-88, "Standard Test Method for Kinematic Viscostty of Transparent and Opaque Liquids (and the Calculation of Dynamic Viscosityl."

11.2 ASTM Standard D446-89a, "Standard Spectications and Operating Instructions for Glass Capillary KInematic Viscometers."

\subsection{ATtachments}

12.1 Attachment 1 - Dlagram of Cannon-Fenske Routine Viscometer

12.2 Attachment 2 - Kinematic Viscosity of Water at Vartous Temperatures

12.3 Attachment 3 - Density of Water at Various Temperatures 

SAVANTAF RTVER TECENOLOGT CENTER Mnnul No:

Revision:

INTERIM WASTE TECENOLOGT SECTION OPERATING PROCEDURE
Caterory: Isoue Date:
Page:
L12.1

IWT-OP-067

0

3

12-09-92

7 of 9

Attachment 1 - Diagram of Cannon-Fenske Routine Viscometer

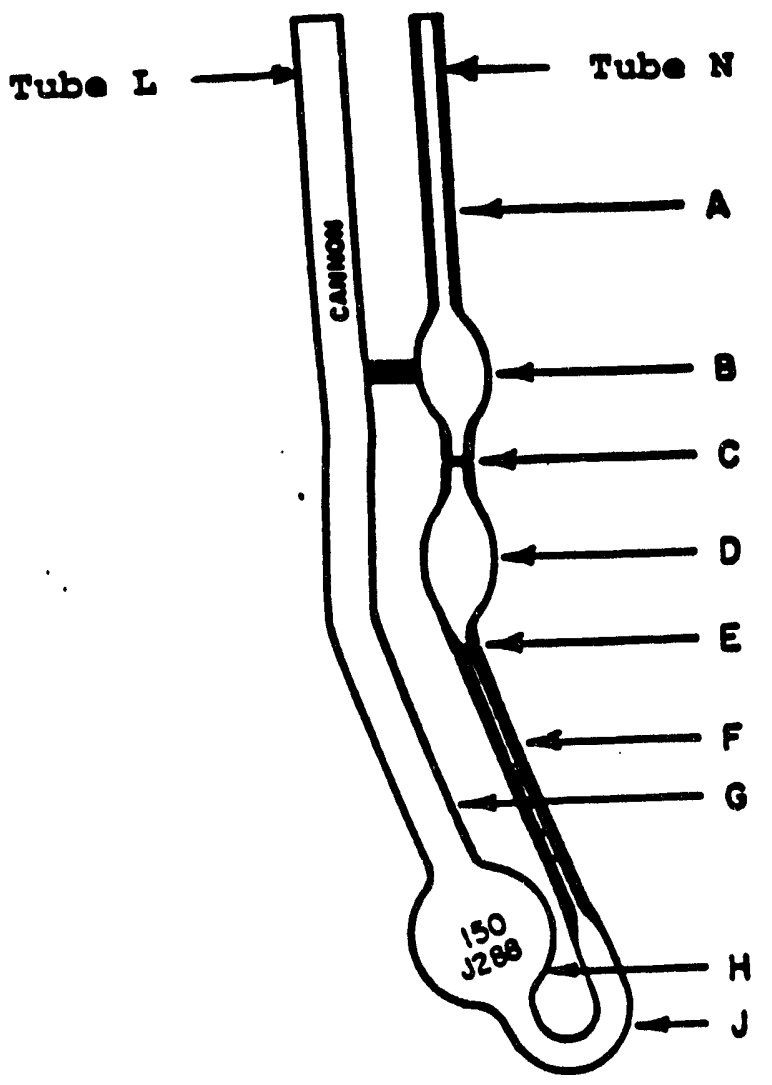




\begin{tabular}{|c|c|c|c|}
\hline $\begin{array}{l}\text { Temp. } \\
\left(^{\circ} \mathrm{C}\right)\end{array}$ & $\begin{array}{l}\text { Viscosity } \\
\text { (cSt) }\end{array}$ & $\begin{array}{l}\text { Temp. } \\
\text { ('C) }\end{array}$ & $\begin{array}{l}\text { Viscoalty } \\
\text { (cSt) }\end{array}$ \\
\hline $\begin{array}{l}20 \\
21 \\
22 \\
23 \\
24 \\
25 \\
26 \\
27 \\
28 \\
29 \\
30 \\
31 \\
32 \\
33 \\
34 \\
35 \\
36 \\
37 \\
38 \\
39 \\
40 \\
41 \\
42 \\
43 \\
44 \\
45 \\
46 \\
47 \\
48 \\
49 \\
50 \\
51 \\
52 \\
53 \\
54\end{array}$ & $\begin{array}{c}1.004 \\
.9799 \\
.9569 \\
.9348 \\
.9136 \\
.8930 \\
.8733 \\
.8543 \\
.8359 \\
.8181 \\
.8010 \\
.7844 \\
.7685 \\
.7531 \\
.7381 \\
.7237 \\
.7097 \\
.6961 \\
.6831 \\
.6704 \\
.6580 \\
.6461 \\
.6345 \\
.6234 \\
.6124 \\
.6019 \\
.5916 \\
.5817 \\
.5719 \\
.5626 \\
.5534 \\
.5446 \\
.5359 \\
.5274 \\
.5193\end{array}$ & $\begin{array}{l}55 \\
56 \\
57 \\
58 \\
59 \\
60 \\
61 \\
60 \\
63 \\
64 \\
65 \\
66 \\
67 \\
68 \\
69 \\
70 \\
71 \\
72 \\
73 \\
74 \\
75 \\
76 \\
77 \\
78 \\
79 \\
80 \\
81 \\
82 \\
83 \\
84 \\
85 \\
86 \\
87 \\
88 \\
89 \\
90\end{array}$ & $\begin{array}{l}.5113 \\
.5035 \\
.4960 \\
.4886 \\
.4814 \\
.4745 \\
.4677 \\
.4610 \\
.4545 \\
.4483 \\
.4421 \\
.4360 \\
.4301 \\
.4244 \\
.4186 \\
.4134 \\
.4080 \\
.4028 \\
.3977 \\
.3927 \\
.3878 \\
.3831 \\
.3784 \\
.3739 \\
.3694 \\
.3650 \\
.3607 \\
.3565 \\
.3524 \\
.3484 \\
.3445 \\
.3406 \\
.3369 \\
.3332 \\
.3296 \\
.3260\end{array}$ \\
\hline
\end{tabular}

"Reference: These values were calculated from the density of water fisted in Attachment 3) and the dynamic viscosities listed in: Chemical Rubber Company, Handbook of Chemistry and Physics. 61st Edition. 1980-81, Robert C. Weast. Editor. CRC Press, Boca Raton, p. F-51. 
SAVANNAF RTVER TECFNOLOGT CENTER MnUUal No:

Procedure:

L12.1

Revilion:

DNTERIM WASTE TECENOLOGT SECTION

Category:

Isoue Date:

Page:

IWT-0P-067

9 of 9

$\longrightarrow$

Attachment 3 - Density of Water at Varlous Temperatures*

\begin{tabular}{|c|c|c|c|}
\hline $\begin{array}{l}\text { Temp. } \\
\left({ }^{\circ} \mathrm{C}\right)\end{array}$ & $\begin{array}{l}\text { Dendity } \\
(8 / \mathrm{mL})\end{array}$ & $\begin{array}{l}\text { Temp. } \\
\left({ }^{\circ} \mathrm{C}\right)\end{array}$ & $\begin{array}{l}\text { Dendt } \\
(\mathrm{s} / \mathrm{mI}\end{array}$ \\
\hline $\begin{array}{l}20 \\
21 \\
22 \\
23 \\
24 \\
25 \\
26 \\
27 \\
28 \\
29 \\
30 \\
31 \\
32 \\
33 \\
34 \\
35 \\
36 \\
37 \\
38 \\
39 \\
40 \\
41 \\
42 \\
43 \\
44 \\
45 \\
46 \\
47 \\
48 \\
49 \\
50 \\
51 \\
52 \\
53 \\
54\end{array}$ & $\begin{array}{l}.99823 \\
.99800 \\
.99777 \\
.99753 \\
.99730 \\
.99707 \\
.99679 \\
.99651 \\
.99623 \\
.99595 \\
.99567 \\
.99535 \\
.99503 \\
.99470 \\
.99438 \\
.99406 \\
.99370 \\
.99333 \\
.99297 \\
.99260 \\
.99224 \\
.99184 \\
.99144 \\
.99105 \\
.99065 \\
.99025 \\
.98981 \\
.98938 \\
.98894 \\
.98851 \\
.98807 \\
.98760 \\
.98713 \\
.98667 \\
.98620\end{array}$ & $\begin{array}{l}55 \\
56 \\
57 \\
58 \\
59 \\
60 \\
61 \\
62 \\
63 \\
64 \\
65 \\
66 \\
67 \\
68 \\
69 \\
70 \\
71 \\
72 \\
73 \\
74 \\
75 \\
76 \\
77 \\
78 \\
79 \\
80 \\
81 \\
82 \\
83 \\
84 \\
85 \\
86 \\
87 \\
88 \\
89 \\
90\end{array}$ & $\begin{array}{l}.98573 \\
.98523 \\
.98473 \\
.98424 \\
.98374 \\
.98324 \\
.98271 \\
.98218 \\
.98165 \\
.98112 \\
.98059 \\
.98003 \\
.97948 \\
.97892 \\
.97837 \\
.97781 \\
.97723 \\
.97664 \\
.97606 \\
.97547 \\
.97489 \\
.97428 \\
.97367 \\
.97305 \\
.97244 \\
.97183 \\
.97119 \\
.97056 \\
.96992 \\
.96929 \\
.96865 \\
.96799 \\
.96733 \\
.96666 \\
.96600 \\
.96534\end{array}$ \\
\hline
\end{tabular}

-Reference: Chemical Rubber Company, Handbook of Chemistry and Physics, 61st Edition, 1980-81, Robert C. Weast, Editor. CRC Press, Boca Raton. p. F-11. 
S.D. FINK

January 31, 1994
WSRC-RP-94-146

Revision 0

Page 30 of 31

\section{ATTACHMENT 2}

Scope of Work for Resin Degradation Studies

at Clark Atlanta University

(17 pages) 
PREPARATION AND AGNG OF RESORCINOL/FORMALDEHYDE RESARS

\author{
submitted to
}

Westinghouse Savannah River Technology Center

by

Professor Ishrat $M$ Khan

Department of Chemistry

Clark Atlanta University

Atlanta, GA 30314

Tel. (404) $880-8583$

in response to

ERDA RFP \# 93035 


\section{TABLE OF CONTENTS}

$\begin{array}{ll}\text { Abstract } & 1 \\ \text { Introduction } & 1 \\ \text { Projected Studies } & 1 \\ \text { Task 1 } & 2 \\ \text { Task 2 } & 3 \\ \text { Conclusion } & 5 \\ \text { References } & 6 \\ \text { Budget } & 7 \\ \text { Budget Explanation } & 9 \\ \text { Vita of P.I. } & 10 \\ \text { Background \& Experience of P.I. } & 14 \\ \text { Facilities and Resources } & 14 \\ \text { Quality Requirements } & 15\end{array}$


Abstract: The mechanism of degradation of resorcinolformaldehyde ion exchange resins will be studied by variable temperature ${ }^{1} \mathrm{H},{ }^{13} \mathrm{C}$ CP-MAS, FT-IR and ESR. Degradation studies by spectroscopic methods will be carried out on samples (dry and in water) aged under controlled conditions. Spectroscopic studies will be complemented by MNDO and molecular mechanies calculations. Variable temperature ${ }^{133}$ Cs CP-MAS will be used to obtain information about the ion exchange sites present in the resins. The effect of varying hydroxide concentration on the different ion exchange sites will be determined. Thernodynamics of the ion exchange process will be studied by ${ }^{133} \mathrm{Cs}$ NMR on resins swollen in $\mathrm{D}_{2} \mathrm{O}$.

\section{INTRODUCTION}

Resorcinolformaldehyde resins, developed by Wallace and Bibler at the Savannah River Technology Center, has been shown to be superior for separating cesium ions from waste compared to commercially prepared phenolformaldehyde resins.' However, resorcinolformaldehyde resins suffer from a serious drawback in that it is degraded on storage, most likely by an oxidative mechanism. On degradation the selectivity and capacity of the resins for cesium ions are lost. Before these resorcinolformaldehyde resins may be used in any reproducible manner in process applications, the mechanism of degradation of the resin must be determined. Such mechanistic understanding will allow for proper storage procedures, procurement schedules and concievably design methods to slow down the degradation during storage.

In our proposed work both the aging process of the resins will be studied and the nature of the ion exchange sites present in the resins will be determined by variable temperature CP-MAS methods.

\section{PROJECTED STUDIES}

The projected studies may be divided into two parts - Task I and Task 2. It should be noted that experimental work under these twe parts will complement each other.

A) Task 1: May be divided into three sections.

1. Creation of baseline spectroscopy data with freshly prepared and undegraded resins.

2. Aging studies on resorcinal/formaldehyde resins.

3. Mechanism of degradation.

B) Task 2: Ion exhange sites in the Resins. 


\section{TASK 1}

Freshly prepared and undegraded resorcinolformaldehye resins will be obtained from the Savannah River Technology Center.

1. Creation of brseline spectroscopic data on freshly prepared and undegraded resins: The baseline spectroscopic data will be of use in all studies carried out on the resins. In order to definitively assign the microstructure of the resin, ${ }^{1} \mathrm{H}$ and ${ }^{13} \mathrm{C} N \mathrm{NM}$ studies .op the resins swelled with $\mathrm{D}_{2} \mathrm{O}$ will be underiaken. By using DEPT sequence, it should be definitively possible to assign all different carbon nuclei. DEPT NMR spectra obtained on swelled resins should give narrower linewidths and better coupling constant information. This information will be powerful in assigning CP-MAS spectra. Information available from solution and solid state ${ }^{1} \mathrm{H}$ and ${ }^{13} \mathrm{C}$ NMR will be used to determine a general microstructure of the resins. Also, FT-IR spectra on undegraded samples will be obtained. In order to obtain direct information regarding the thermal and oxidative stabilities of the resins, thermal gravimetric analysis (TGA) on the undegraded resins in air and nitrogen atmospheres will be determined.

Once the baseline information is available, degraded samples currently held by SRTC will be studied and in as much as possible the structure determined by solid state NMR and FT. $\mathbb{R}$.

2. Aging studies on ResorcinolFormaldehyde resins: The best fashion to obtain the degradation mechanism of the resorcinol/formaldehyde resins is by studying saamples that have been aged under controlled conditions. Dry resins will be aged by exposing to nitrogen, oxygen and ozone, samples will be removed at specific intervals and analyzed by

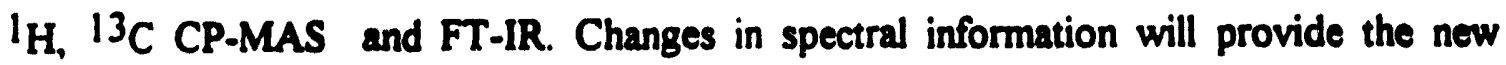
microstructure of the resins. If in the degraded resins certain carbon nuclei cannot be definitively assigned by CP-MAS, DEPT pulse sequence on samples swelled by $\mathrm{D}_{\mathbf{2}} \mathrm{O}$ will be used to help in assignment. It is important to follow how each nuclei in the resin is affected in the aging process under these controlled conditions. Thermal and oxidative stability of aged samples will be studied by TGA.

It is probable that the degradation mechanism is most likely oxidative. The observed presence of free-radicals in the degraded samples is quite expected. The degraded resins should contain quinone like structures and these are known to be radical scavengers. ${ }^{2}$ Before undertaking any ESR studies, the possibility that the resins may be partially degraded through a radical mechanism will be studied. The resins, containing $-$ 
different concentrations of p-benzoquinone (a radical scavenger) ${ }^{3}$, will be subjected to aging under nitrogen and oxygen. A slow down in the degradation will indicate that radicals may be involved in this process. The aging, process will be studied by ${ }^{13} \mathrm{C} \mathrm{CP}$. MAS. If indeed radicals play a role in the degradation process, ESR will be also used to follow the aging process.

Resins stored under distilled water and regular tap water will also be exposed to nitogen, oxygen and ozone and the degradation process studied by spectroscopy.

3. Mechanism of Dernedation: From the microstructural information of the freahly prepared resins and that of the changing microstructure of the resins on aging, a mechanism for the degradation process will be postulated. If two or three different mechanisms or pathways are possible, the energetics of the most probable mechanism will be determined by semi-emprical quantum mechanical (MNDO) calculation. In recent studies, MNDO has been successfully used to study the hydrolytic degradation of absorbable biomaterials consisting of homopolymers. and copolymers of glycolic acid. 4 However, due to certain limitations inherent in semi-empirical methods, the calculations will be supplemented with force field methods. The BIOSYM programs have been parameterized to model static and time dependent behavior of solvated systems. We expect these calculations coupled with spectral information will allow us to postulate the most reasonable degradation mechanism.

\section{TASK 2}

Variable temperature ${ }^{133}$ Cs CP-MAS studies will be carried out on resorcinol/formaldehyde resins. ${ }^{133} \mathrm{Cs}$ nuclei has a low quadropole moment $\left(Q=-3 \times 10^{-31}\right.$ $\mathrm{m}^{2}$ ) and high receptivities as compared to the ${ }^{13} \mathrm{C}$ nuclei. ${ }^{5}$ Also, the cesium- 133 nuclei chemical shift is very suscepitble to small changes in the solvation shell or the binding site or the ion exchange site. While, very little information is available regarding ${ }^{133} \mathrm{Cs} \mathrm{CP}$ MAS, we have successfully obtained high resolution ${ }^{133} \mathrm{Cs}$ CP-MAS spectra in our laboratories (See tigure 1 for a $133 \mathrm{Cs} \mathrm{CP}$-MAS of a poly(2-vinylpyridine)/CsClO complex). The spectra indicates that at least at the lower cesium concentrations local quadropolar interaction is not a problem. Furthermore, large differences in chemical shift between cesium nuclei in slightly different environment is observed. Because of the large chemical shift range over which the cesium-133 nuclei resonates, small changes in the $\cdots$ 


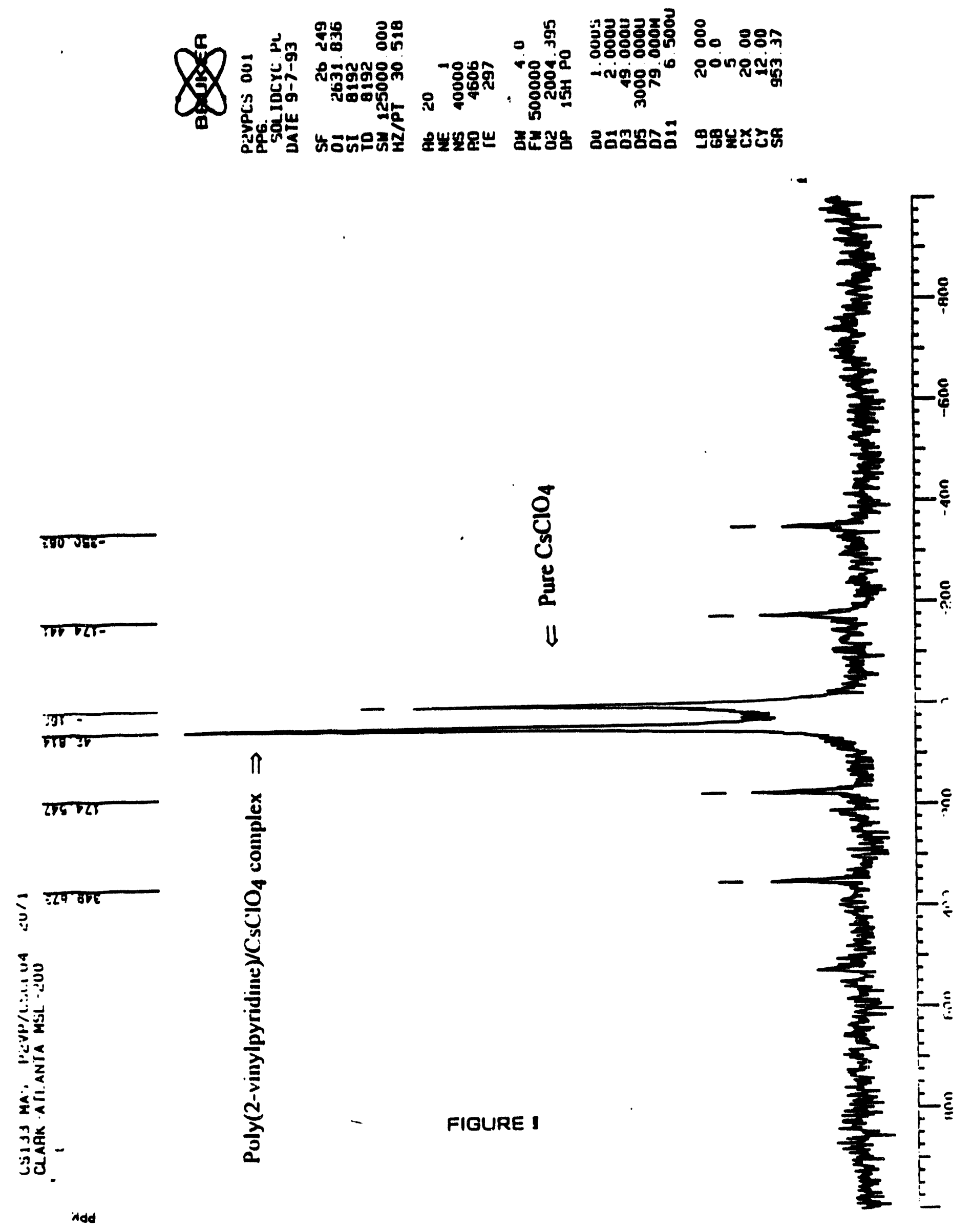


environment (complex structure, binding sites, ion exchange sites) will result in the nuclei resonating at different frequencies. The differences in the chemical shift will be used to identify ${ }^{133} \mathrm{Cs}$ muclei present in different (structural) ion exchange sites in the resins.

Two specific sets of experiments will be carried out in this regard.

a) Variable temperature ${ }^{133} \mathrm{Cs}$ CP-MAS spectra will be obtained as a function of the cesium ion concentration in the resins. Initially, it is expected that at the lower cesium ion concentration, the ion will be preferentially located at the energetically favored site. As the concentration is increased and the energetically favored site is occupied, the other site will start to be occupied - each site will be associated with different chemical shifts. If both sites are energetically equal, two resonances will be observed to start with. The second scenario is highly unlikely. Most studies will be undertaken at the temperature where exchange between the two sites are slow on the NMR time scale. From the coalesence temperature, the thermodynamic parameters of the system will be determined. ${ }^{7}$ FT-IR studies will be undertaken to complement CP-MAS data, slight changes in the aromatic $C=C$ - stretching $\left(1600 \mathrm{~cm}^{-1}\right)$ may be observed if cesium ions are present in the ion exhange sites. Cesium ions occupying ion exchange sites may slightly alter the delocalization of the resorcinol ring.

b) The second experment will determine the effect of the hydroxide concenration on the resin. ${ }^{133}$ Cs CP-MAS study will be carried out as a function of different hydroxide concentrations. Since we will have already determined. see previous section, the chemical shifts of the two original ion exchange sites, this study should give us information regarding the generation of newer sites and relative distribution among the sites.

\section{CONCLUSION}

The proposed study will lead to the evaluation of the mechanism of degradation of resorcinol/formaldehyde ion exchange resins. Additionally, the nature and energetics of the ion exchange sites will be determined. The results of this study will be useful in determining storage conditions of the resins, activity and selectivity of the resins towards different types of waste and the overall performance of the resins in process conditions. Such information is critical for the successful commercialization of the resorcinol/formaldehyde ion exchange resins. 


\section{REFERENCES}

1. Personal communication with Dr. Jane Bibler at SRTC and ERDA Task order No. 93035.

2. F. A. Carey and R.J. Sundberg, Advanced Organic Chemistry, Part A, Plenum Press, N.Y. , 1977, p. 501.

3. George Odian, Principles of Polymerization, Second Edition, Wiley, N.Y., 198.4. p.246.

4. a) L. Pratt, C. Chu, J. Auer, A. Chu, J. Kim, J.A. Zollweg, C.C. Chu, J. Polym. Sci. Part A: Polym. Chem. Ed. 31,1759 (1993). b) L. Pratt, C.C. Chu, J. Comp. Chem. in press (1993).

5. C.C. Detellier in "NMR of Newly Accessible Nuclei", P. Laszlo (Editor), Academic, N.Y., Vol. 2, p. 105.

6. I.M. Khan and J. Li, unpublished results from our laboratory.

7. E.D. Becker, High Resolution NMR: Theory and Chemical Appllications, Second Edition, Academic Press, N.Y. 1980, p. 240.

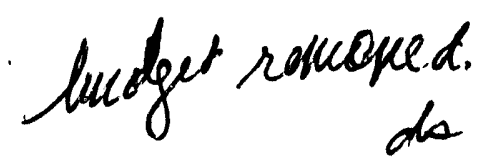




\section{BUDGET EXPLANATION}

Personnel: One month summer salary is requested for the PI. A postdoctoral fellow will participate in the project and will be paid for 10 months during the period. The person will be selected from between the two postdoctoral fellow/research technician currently in the group. The postdoctoral fellow will be invoived in all aspects of the project - solid and solution NMR, aging of samples and theoritical studies. Also working on the project will be a graduate student, the research goal of the graduate student will be to determine the mechanism of degradation of the resins and this work will tum into the student's M.S. Thesis. An undergraduate (B.S.M.S.) student will assist the postdoctoral fellow in determining the thermodynamics of the ion exchange process. The secretary/admin. asstt. (150 hours) will carry out record keeping and typing of monthly reports. The PI will directly supervise and evaluate performance of all personnel supported by this contract.

Equipment: One vacuum oven for drying samples and two vacuum pumps will be purchased.

Travel: The PI will travel to one ACS National meeting for exchange of ideas. The budget also inchudes travel by students or then postdoctoral fellow to an ESR or high resolution FT- $\mathbb{R}$ facility.

Materials and Supplies: This includes NMR supplies, solvents, glassware and tubing, gases (nitrogen, oxygen and ozone), gas cylinder holders and regulators.

Consultant Services: Dr. Jan Lovy of Kingston Technologies, Inc. Dayton, NJ 08810, has agreed to serve as an consultant to aid in solid state NMR studies. Dr. Lovy is the NMR spectroscopist of Kingston Technologies. Dr. Lovy will help us with specialized solid-state experiments. It is expected that Dr. Lovy will make two trips to Clark Atlanta, per trip expenses of $\$ 700$ ( $\$ 300$ for airfare and $\$ 200 /$ per diem).

Other Expenses: Instrument time for solid and solution NMR spectroscopy, tuition charges for graduate students, photocopy expenses. 


\section{ISHRAT M. KGHAN \\ Department of Chemistry \\ Clark Atlanta University \\ Atlanta, GA 30314 \\ Tel. (404) 880-85.83}

\section{PROFESSIONAL POSITIONS}

1988 - present

$1985-1988$
Assistant Professor of Chemistry

Clark Atlanta University

Atlante, GA 30314

Postdoctoral Fellow

SUNY - College of Environmental Sciences and Forestry

Syracuse, NY 13210

\section{EDUCATION}

Ph.D.

Organic Chemistry, Dec. 1984

University of Florida

Gainesville, FL 32611

B.A.

Chemistry with Honors, 1979

Susquehanna University

Selinsgrove, PA 17870

\section{PUBLICATIONS}

1. Oligomerization of Vinyl Monomers, 15. $1 \mathrm{H}$ and ${ }^{13} \mathrm{C}$ NMR of Carbanion Intermediates in the Polymerization of 2-Vinylpyridines in THF - Dimeric and Trimeric Models. I.M. Khan and T E. Hogen-Esch, Makromol. Chem.. Rapid Ciommun 4, 569 (1983).

2. Studies on the Active Centers in the Anionic Polymerization of 2-Vinylpyridine in THF. I.M. Khan, C.C. Meverden and T.E. Hogen-Esch, Polymer Preprints, 24,(2), 273 (1983).

3. Stereoregular Oligomerization and Polymerization of 3-Methyl-2-Vinylpyridine. I.M. Khan and T.E. Hogen-Esch, Polymer Preprints, 26(2), 273 (1985).

4. Thermal and Conducting Properties of Solid Complexes of Lithium Perchlorate with Poly (w- Methoxyhepta(oxyethylene)ethoxy) methylsiloxane. D. Fish. I.M. Khan and J. Smid, Makromol. Chem., Rapid Commun., I IIS (1986).

5. Ion Containing Styrene- Methoxypolyethyleneglycolmethacrylate ABA Triblock Polymers. I.M. Khan, D. Fish and J. Smid. Polymer Preprints, 27,(1), 200 (1986).

6. Role of $E$ and $Z$ Carbanions in the Stereochemistry of Anionic Vinyl Polymerization. I.M. Khan and T E. Hogen-Esch, Polymer Preprints, 27(1), 159 (1986). 
7. Poly(methoxyheptaethyleneoxide)methylsiloxane/Lithium Perchlorate Complexes as Solvent Free Electrolytes for High Density Energy Storage Devices. D. Fish, I.M. Khan and J. Smid, Polymer Preprints, 27(1), 325 (1986).

8. Role of $E$ and $Z$ Carbanions in the Stereochemistry of Anionic Vinyl Polymerization. I.M. Khan and T.E. Hogen-Esch in "Recent Advances in Anionic Polymerization", Elsevier Science Publishing, NY (1987) p. 261.

9. Ion Containing Styrene- Methoxypolyethyleneglycolmethacrylate ABA Triblök Polymers. I.M. Khan D. Fish and J. Smid in "Recent Advances in Anionic Polymerization". Elsevier Science Publishing, NY (1987), p. 451.

10. Synthesis and Stereochemical Characterization of Isotactic Poly(3-Methyl-2Vinylpyridine). I.M. Khan and T.E. Hogen-Esch, Macromolecules, 20, 2335 (1987).

11. Polymer Electrolyte Complexes of $\mathrm{LiClO}_{4}$ and Comb Polymers of Siloxane with Oligo-Oxyathylene side Chains. D. Fish, I.M. Khan, E. Wu and J. Smid, Brit. Poly. J. 20, 281 (1988).

12. Oligomerization of Vinyl Monomers, 21. Characterization of Model Carbanions of Living Poly(2-Vinylpyridine) in THF by $T_{\mathrm{Li}} \mathrm{NMR}$ and Conductance. Evidence for the Occurence and Nature of Triple Ion Formation. I.M. Khan and T.E. Hogen-Esch, J. Polym. Sci. Part A. Polym. Chem., 26 2553 (1988).

13. Anionic Ring-Opening Polymerization of Cyclotetrasiloxanes with Oligo-Oxyethylene Substituents. D. Fish I.M. Khan and J. Smid, Polymer Preprints, 29(2), 8 (1988).

14. Effects of Chain Length and Stereochemistry on the Kinetics of Addition of 1,1'Diphenylethylene of Oligomeric Models of Living Poly(2-Vinylpyridine)-Lithium. G. Helary, M. Fontanille, I.M. Khan and T. E. Hogen-Esch. Polymer Preprints. 22(2), 31 (1988).

15. Comb-like Polysiloxanes with Oligo-Oxyethylene Side Chains. Synthesis and Properties. I.M. Khan, Y. Yuan, D. Fish, E. Wu and J. Smid. Macromolecules, 21, 2684 (1988).

16. Comb Polysiloxanes with w-Hydroxyoligo(Oxyethylene) Side Chains.

E. Wu. I.M. Khan and J. Smid, Polym. Bull 20, 455 (1988)

17. Cation-Conducting Comb Polysiloxanes with Oligo-Oxyethylene Side Chains. G.B. Zhou, I.M. Khan and J. Smid, Polymer Preprints, 30(1), 416 (1989).

18. Cation Transport Polymer Electrolytes. Siloxane Comb Polymer with Pendant OligoOxyethylene Chains and Sulfonate Groups. G.B. Zhou, I.M. Khan and J. Smid. Polymer Commun. 30, 53 (1989).

19. ABA Triblock Comb-Copolymers with Oligo-Oxyethylene Side Chains as Matrix for Ion Transpor. I.M. Khan, D. Fish, Y. Delaviz and J. Smid, Makromol. Chem.. 190, 1069(1989).

20. Stereochemistry of Anionic Oligomerization. 22. Effects of Chain Length and Stereochemistry on the Kinetics of Addition of 1,1 -Diphenylethylene Oligomeric Models 
of Living Poly(2-Vinylpyridine)-Lithium. G.Helary, M. Fontanille, I.M. Khan and T.E. Hogea-Esch, Makromol. Chem., 190, 341 (1989).

21. Neutral Comb-Like Polysiloxanes with Hydrophilic Pendant Groups. D. Fish, E. Wu, I.M. Khan, J. Smid, Polymer Preprints, 30(2), 187 (1989).

22. Vinylpyridine Polymers. I.M. Khan in "Encyclopedia of Polymer Science and Engineering", 2nd Edition, Wiley, NY, 17, 567 (1989).

23. Polysiloxane-Based Polymer Electrolyte Complexes. J. Smid, D. Fish, I.M. Khan, E. Wu and G.B. Zhou, in "Advances in Silicon Based Polymer Science", G. Fearon and J. Ziegler (Eds). Aduances in Chemistry Series No. 224. Am. Chem. Soc.,Pages 113-123 Washingtor, DC, (1990).

24. Synthesis of Block Copolymers for Mixed (Electronic and Ionic) Conducting Polymer Matrix, J. Li, L.M. Khan, Polymer Preprints, 31(1), 388 (1990).

25. Anionic Ring Opening Polymerization of Cyclotetrasiloxanes with Large Substituents, D. Fish, I.M. Khan, J. Smid, Maloromol. Chem., Makromol. Symp., 20, 241 (1990).

26. An Absolute Measure for Stereoblock and Heterotactic Polymers, I. M. Khan, Polym. Bull. 24, 305 (1990).

27. Mixed (electronic and ionic) conductive solid polymer matrix, 1. Synthesis and properties of poly $(2,5,8,11,14,17,20,23$ - octaoxapentacosyl methacrylate) - block - 4 poly (4vinylpyridine), J. Li. I.M. Khan Makromol Chem. 192, 3043 (1991).

28. Synthesis of Three Arm Poly(styrene-arm-styrene-arm-2-vinylpyridine) Star Copolymers. I.M. Khan, Z: Gao, K. Khougaz, A. Eisenberg, Macromolecules, 25.3002 (1992).

29. New Concepts in Electroactive Polymers. Microphase Separated Mixed (Electronic and Ionic) Conductive Solid Polymer Matrix, J. Li, I. M. Khan, Polymer Preprints 33(2), 250 (1992).

30. Poly(ethyleneoxide)/Poly(2-vinylpridine)/Lithium Perchlorate Blends. New Materials for Solid Polymer Electrolytes, Li, Jean; Mintz, Eric A.; Khan, [shrat M., Chemistry of Materials. \& 1131,1992.

31. Solid : slymer Electrolytes by Blending High Molecular Weight Commercial Polymers and Alkali Metal Salts, Preparation and Characterization of Poly(ethyleneoxide)/Poly(2vinylpyridine)/or Poly(4-vinylpyridine)/Lithium Perchlorate Blends, Jean Li, Eric A. Mintz and Istrat .M. Khan, Polymer Preprints, 34(1), 612 (1993).

32. Microphase Separated Mixed (Electronic and Ionic) Conductive Solid Polymer Matrix. Synthesis and Characterization of Poly[3-methylthiophene-block-wmethoxyocta(oxyethylene)methacrylate], Jean Li, E.A. Mintz, I. M. Khan. Polymer Preprinis. 3+(1), 485 (1993). 
33. Solvent Free Cation Conducting Polysiloxane Electrolytes with Pendant OligoOxyethylene and Sulfonate Groups, G. B. Zhou, I. M. Khan, J. Smid, Macromolecules. 26, 2202, (1993).

34. Highly Conductive Solid Polymer Electrolytes Prepared By Blending High Molecular Weight Poly(ethylene oxide), Poly(2 or 4-vinylpyridine) and Lithium Perchlorate, Jeani Li, Istrat M. Khan, Macromolecules, 26, Aug. 16 issue, in press (1993).

35. Surface Micelle Formation at the Air/Water Interface from Nonionic Diblock Copolymers, S. Li, S. Hanley, I. M. Khan, S. Varshney, A. Eisenberg, R. B. Lennox, Longmuir. submitted (1993).

36. Electroactive Block Copolymers, J. Li, I.M. Khan, Polymer Preprints, 34(2), in press (1993).

37. Electroactive Block Copolymers, J. Li, I.M. Khan, Makromol. Chem. Macromol. Symp., submitted (1993). 


\section{BACKGROUND AND EXPERIENCE OF THE P.L. - Ishrat M Khan}

The principal investigator has a career total 37 publications, from 1988 to present the P.I.'s publications total 27. All the publications of the P.I. are in the area of synthesis and characterization of polymeric materials. Several of the P.I.'s publications are in the area of NMR characterization of polymers and elucidation of microstructural information. At Clark Atlanta, the P.I. has developed a polymer research group with funding from the National Science Foundation and the U.S. Army Research Office. The research group has recently grown to five graduate students and two postdoc./research technicians. Current active research areas are in electroactive polymers, stereoregular polymers and star copolymers. In addition to development of new preparative methodologies, the research group is also involved in careful characterization. Current routine characterization techniques include NMR spectroscopy, FT-IR, differential scanning calorimetry (DSC) and thermal gravimetric analysis (TGA), Gel Permeation chromatography (GPC), vapor phase osmometry (VPO), electronic measurments, UV-visible and polarimetry.

\section{FACIIITIES AND RESOURCES}

The individual research group of the PI is adequately equipped for polymer/material synthesis and characterization. The PI's group has adequate space for six to eight students/postdoctoral fellows. The PI has two research laboratories and two instrument rooms dedicated to his group. Any space limitations will be removed by the opening of the Research Center in January 1994. Current group instrumentations include: a HP 4192A Impedance Analyzer, a Perkin-Elmer LC 95 GPC/HPLC system, a Perkin Elmer DSC 4 equipped with a thermal data station, a Vapor Pressure Osmometer and a Rudolph Polarimeter. The department of chemistry has a TGA and an FT-IR for routine studies. The NMR facilities of the chemistry department include a $200 \mathrm{MHz}$ Bruker MSL200 spectrometer dedicated to solid state NMR and a Bruker $250 \mathrm{MHz}$ NMR. The PI has recently received funding from the Department of Energy - University Research Instrumentation program to add a $400 \mathrm{MHz}$ NMR spectrometer to the departmental NMR center. This spectrometer may be operational by January of 1994, making a new high resolution instrument available for this proposed study. The university does not have an ESR facility, it is hoped that arrangements for use of an ESR will be worked out with the Oak Ridge Laboratory of DOE. 


\section{QUALITY REQUTREMINTS}

The work to be carried out will meet all the quality requirements of good R\&D practices and be consistent with the ERDA QA checklist dated August 31, 1992. The principal investigator will have first-line responsibility in following the guidelines of the ERDA QA checklist and any additional requirements imposed by WRSC on this Task Order (ERDA RFP \#93035).

$$
\begin{aligned}
& \text { Hackucut } 3 \text { romoned as } \\
& \text { seperate report, } \\
& \text { W S RC- RP- } 94-148
\end{aligned}
$$




\section{DISTRIBUTION:}

Tamosaitis, W.L., 773-A

Wright, G.T., 703-H

Jump. M.R., 703-H

Schwenker, M.G., 703-H

Morin, 719-4A

Brooke, J.N., 241-120H

Davis,. N.D., 719-4A

Marra, J.E., 703-H

Marra, J.C., 773-A

Van Pelt, W.B., 241-120H

Coleman, J.T., 773-41A

Brown, D.F., 703-H

Jacobs, R.A., 704T

Hyder, M.L., CCC1

Walker, D.D., 773-A

McCabe, D.J., 773-A

Barnes, M.J., 773-A

Meyer, M.L., 676-T

Kilpatrick, 676-T

SRTC-LWG, 773-A

TIM, 703-43A 

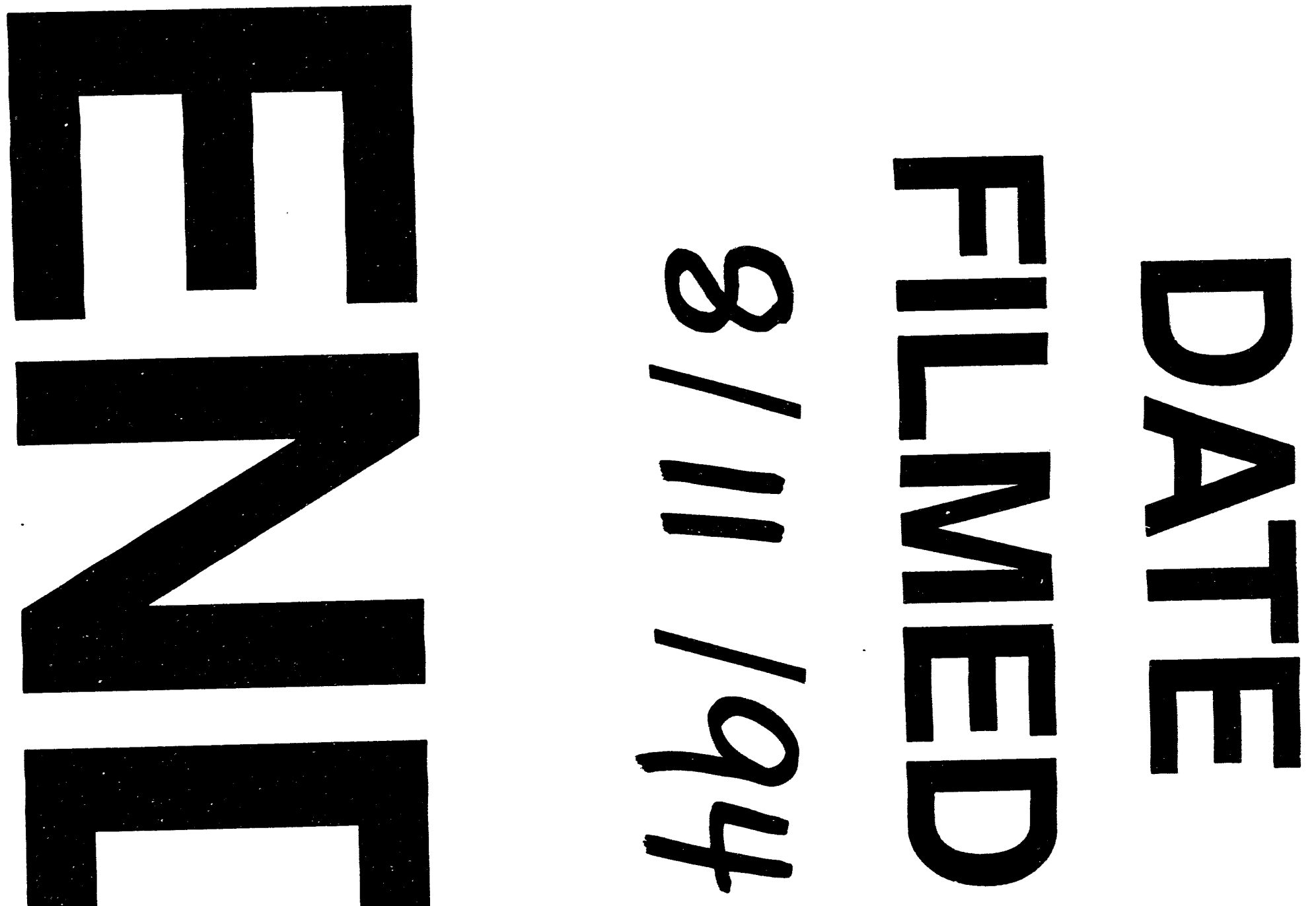
